
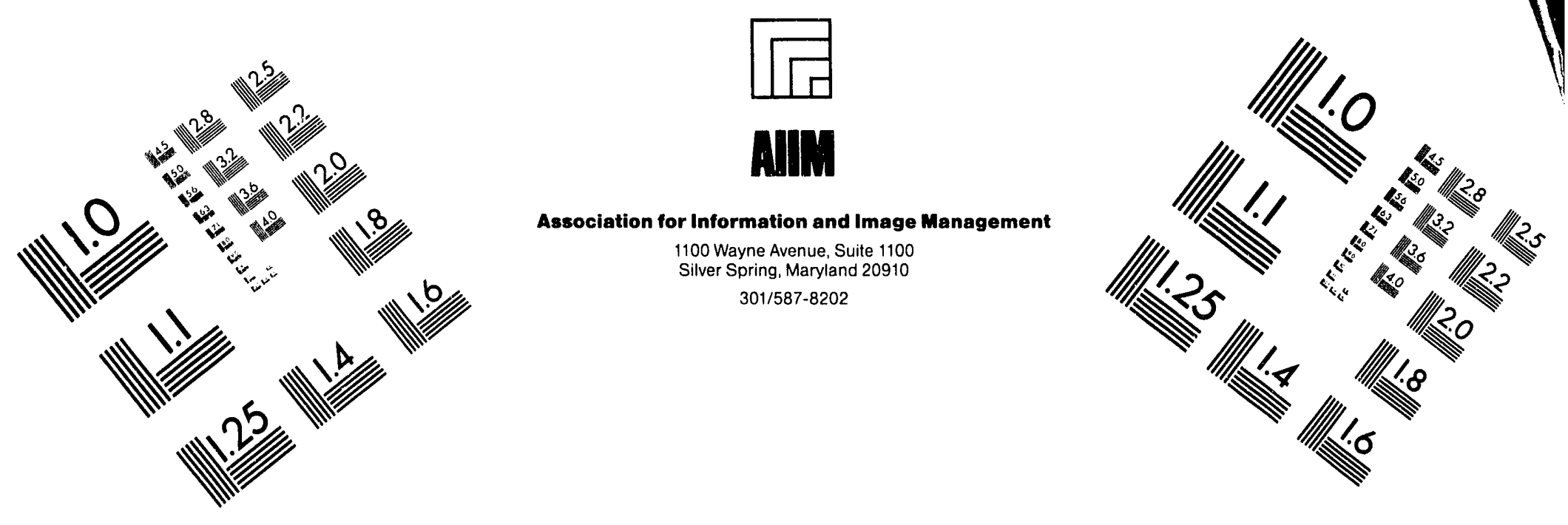

\title{
Centimeter
}

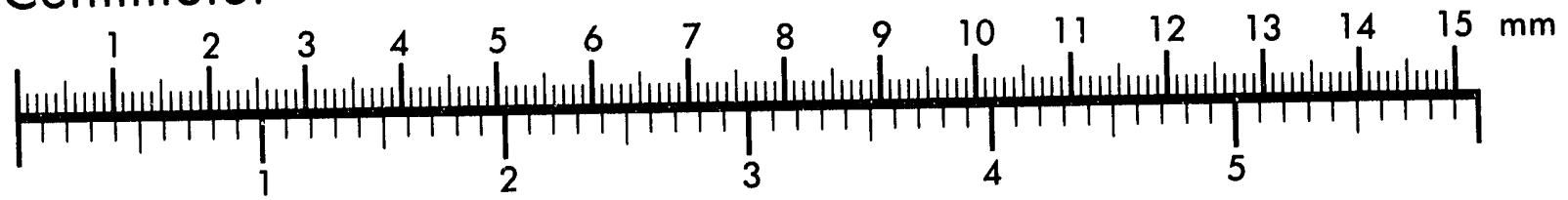

Inches
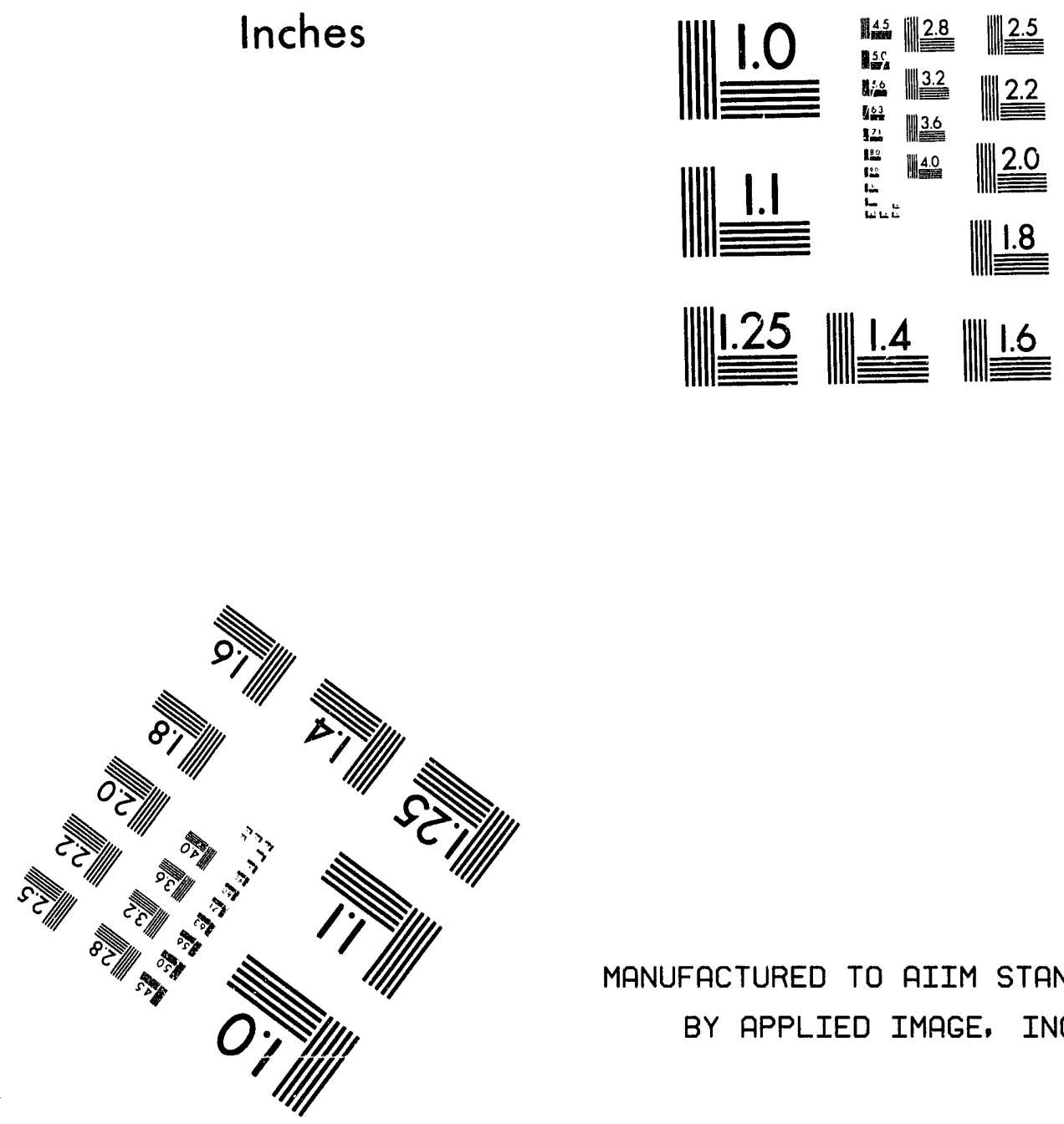

MANUFACTURED TO AIIM STANDARDS

BY APPLIED IMAGE, INC.

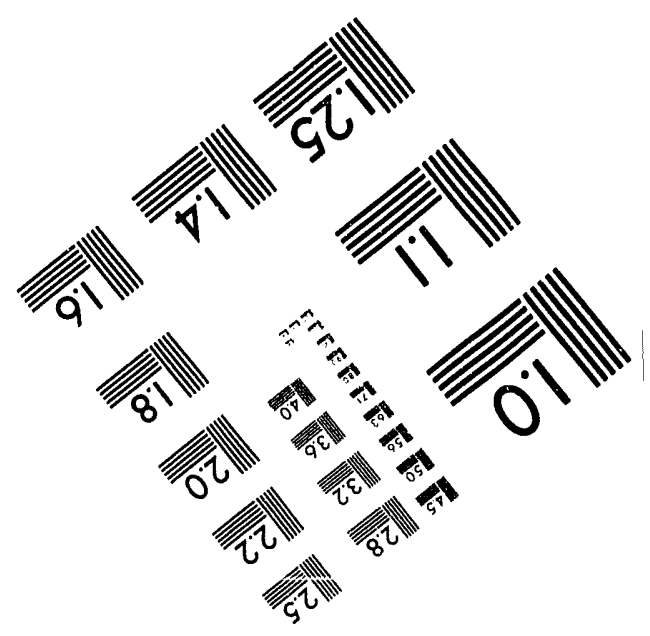



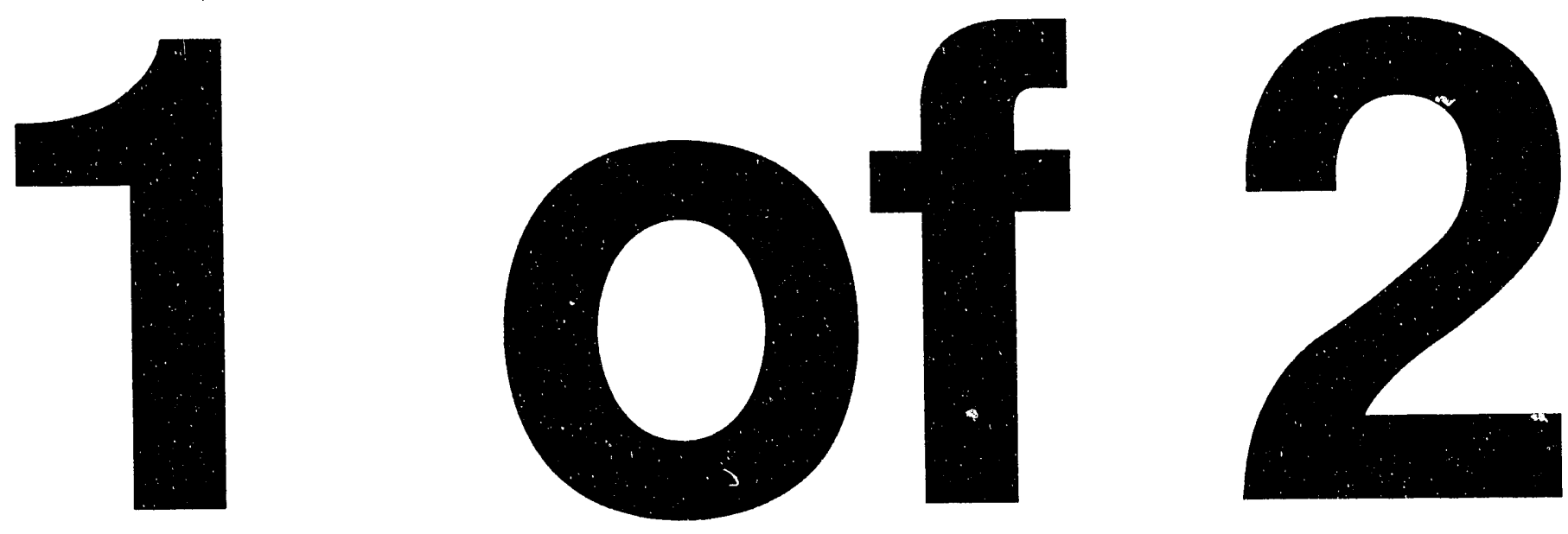


\section{Implementation Plan for the Waste Experimental Reduction Facility Restart Operational Readiness Review}

Published March 1993

Idaho National Engineering Laboratory

EG\&G Idaho, Inc. Idaho Falls, Idaho 83415

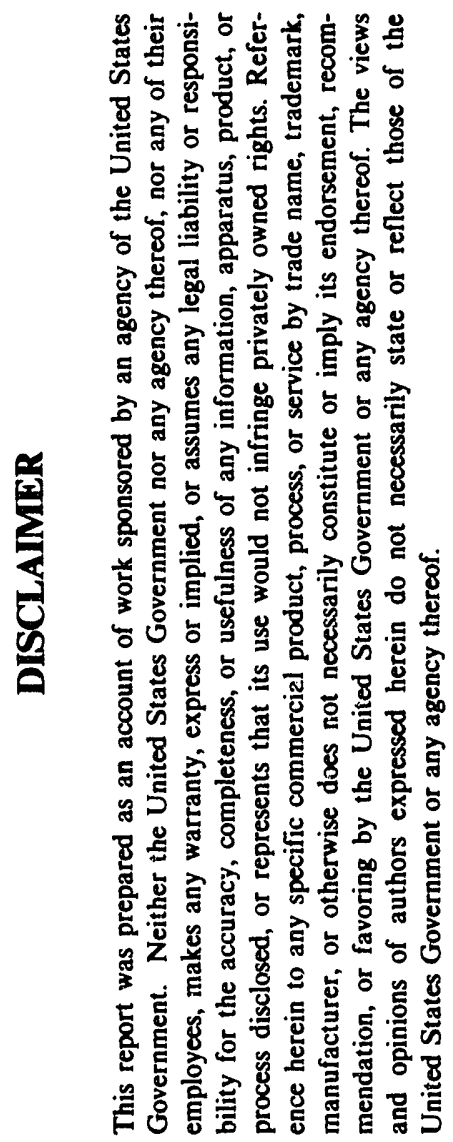

Prepared for the

U.S. Department of Energy

Office of Environmental Restoration and Waste Management Under DOE Idaho Fleld Office

Contract DE-AC07-76ID01570

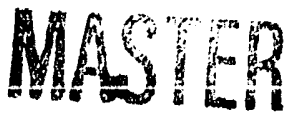




\section{Implementation Plan for the Waste Experimental Reduction Facility Restart Operational Readiness Review}

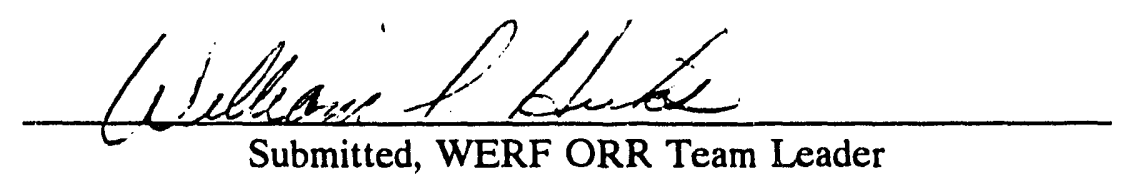

Approval contained in J. L. McAnally letter to W. N. Sato,

JLM-04-93, dated January 7, 1993

Forwarded for Approval,

Chairman, WERF ORR Board

Approval contained in W. N. Sato letter to J. L. McAnally,

AM/ERWM/WMOB 93-036, dated February 18, 1993

Approved, DOE-ID

Released by: $\frac{\text { Ahaven K Kathaway }}{\text { WERF DCC. Date }} 3 / 9 / 93$ 


\section{CONTENTS}

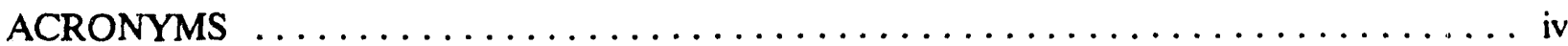

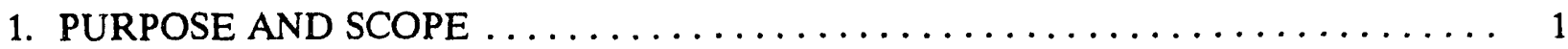

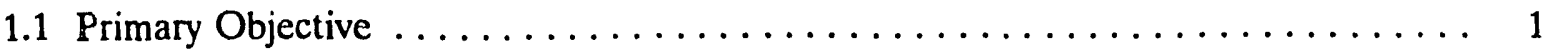

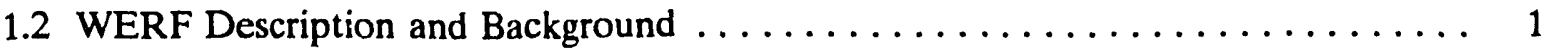

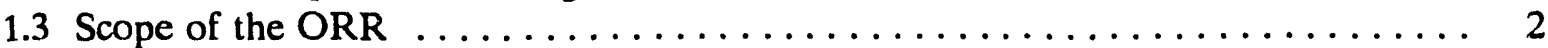

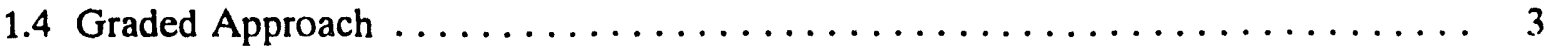

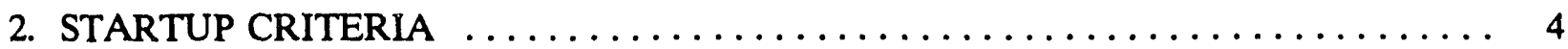

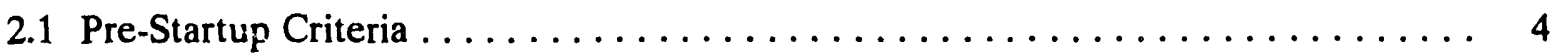

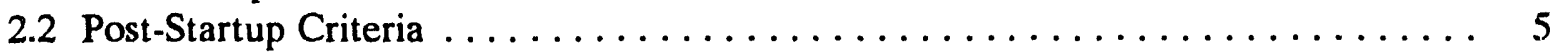

3. SUMMARY OF SUB-OBJECTIVES $\ldots \ldots \ldots \ldots \ldots \ldots \ldots \ldots \ldots \ldots \ldots \ldots \ldots$

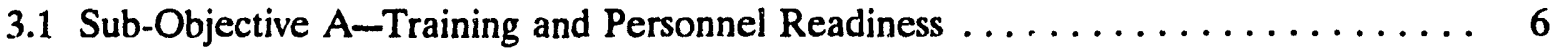

A.1 Management and Organization .................... 6

A.2 Personnel Training and Qualification $\ldots \ldots \ldots \ldots \ldots \ldots \ldots \ldots$

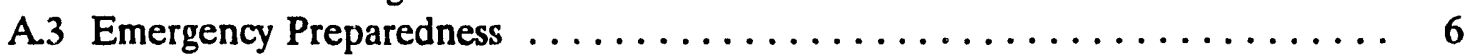

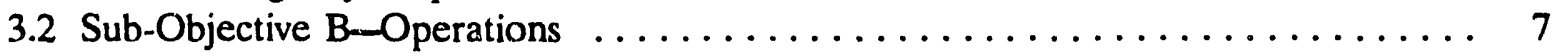

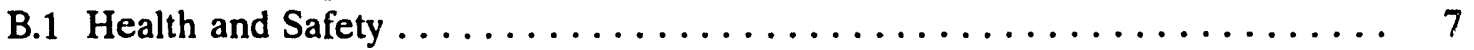

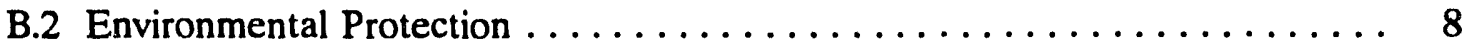

B.3 Safety Analysis Report/Technical Safety Requirements ............. 8

B.4 Operations and Maintenance Performance ................ 9

3.3 Sub-Objective $\mathrm{C}-$ Facilities and Hardware $\ldots \ldots \ldots \ldots \ldots \ldots \ldots \ldots \ldots$

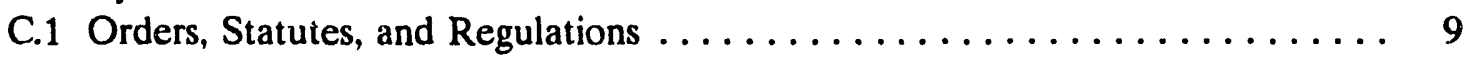

C.2 Safety Analysis Report and Technical Safety Requirements . . . . . . . 10

C.3 Facilities ............................... 10

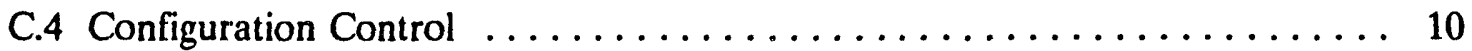

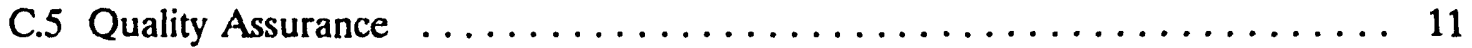

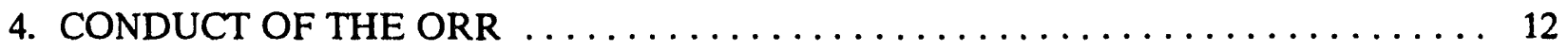

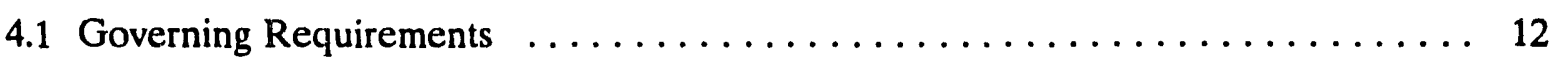

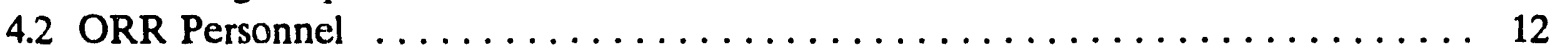

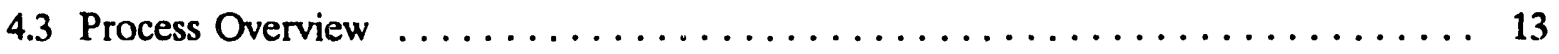

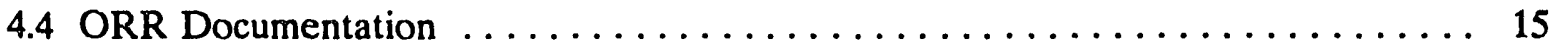

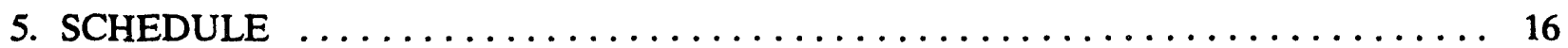

6. REFERENCES $\ldots \ldots \ldots \ldots \ldots \ldots \ldots \ldots \ldots \ldots \ldots \ldots \ldots \ldots \ldots \ldots \ldots$

Appendix A

Operational Readiness Review $\ldots \ldots \ldots \ldots \ldots \ldots \ldots \ldots \ldots \ldots \ldots \ldots \ldots \ldots \ldots \ldots \ldots \ldots$ 


\section{Appendix B}

Criteria and Review Approaches $\ldots \ldots \ldots \ldots \ldots \ldots \ldots \ldots \ldots \ldots \ldots \ldots \ldots \ldots \ldots \ldots$

Appendix C

Referenced Regulations, DOE Orders and EG\&G Idaho Implementing Documents $\ldots . .$. C-1 Appendix D

Operational Readiness Review Team Resumes $\ldots \ldots \ldots \ldots \ldots \ldots \ldots \ldots \ldots \ldots \ldots$ 


\section{ACRONYMS}

ALARA As Low As Reasonably Achievable

ANSI American National Standards Institute

CFR Code of Federal Regulations

CRA Criteria and Review Approach

DOE U.S. Department of Energy

DOE-ID U.S. Department of Energy, Idaho Field Office

DOT U.S. Department of Transportation

EA Environmental Assessment

EG\&G Idaho EG\&G Idaho, Inc.

EP Emergency Preparedness

EPM Emergency Preparedness Manual

EM DOE's Office of Environmental Restoration and Waste Management

ERDA Energy Research and Development Administration

ERO Emergency Response Organization

ES\&Q Environment, Safety, and Quality

GOCO Government-Owned Contractor-Operated

HEPA High Efficiency Particulate Air (Filter)

IDAPA Idaho Air Pollution Act

IDM DOE-ID Manual

LLW Low-Level Radioactive Waste

MLLW $\quad$ Mixed Low-Level Waste

M\&TE Measuring and Testing Equipment

NEPA National Environmental Policy Act 


\begin{tabular}{|c|c|}
\hline NESHAP & National Emission Standards for Hazardous Air Pollutants \\
\hline NFPA & National Fire Protection Association \\
\hline ORE & Operation Readiness Evaluation \\
\hline ORR & Operational Readiness Review \\
\hline PM & Preventive Maintenance \\
\hline PSO & Program Secretarial Officer \\
\hline PTC & Permit To Construct \\
\hline PSD & Prevention of Significant Deterioration \\
\hline QPP & Quality Program Plan \\
\hline $\mathrm{RCRA}$ & Resource Conservation and Recovery Act \\
\hline RRD & Regulatory Requirements Document \\
\hline RWMC & Radioactive Waste Management Complex \\
\hline SAR & Safety Analysis Report \\
\hline TSD & Treatment, Storage, and Disposal \\
\hline TSR & Technical Safety Requirement \\
\hline USC & United States Code \\
\hline USQ & Unreviewed Safety Question \\
\hline WAC & Waste Acceptance Criteria \\
\hline WERF & Waste Experimental Reduction Facility \\
\hline WIPP & Waste Isolation Pilot Plant \\
\hline WMO & Waste Management Operations \\
\hline WWSB & WERF Waste Storage Building \\
\hline
\end{tabular}




\section{Implementation Plan for the Waste Experimental Reduction Facility Restart Operational Readiness Review}

\section{PURPOSE AND SCOPE}

\subsection{Primary Objective}

The primary objective of this Operational Readiness Review (ORR) is to ensure that the Waste Experimental Reduction Facility (WERF) is ready for Restart and Safe Operations and is in compliance with applicable regulations following modifications to the facility and its Operating Documentation.

\subsection{WERF Description and Background}

The mission of WERF is to treat Low-Level Radioactive Waste (LLW) and Mixed Low-Level Waste (MLLW) for disposal through volume reduction as much as 200:1 and through destruction of the hazardous component of mixed wastes by Incineration. Specific processes include Incineration, Stabilization, Sizing, and Compaction. Temporary storage of LLW and MLLW is also provided.

The WERF Complex includes (1) the main WERF Building, which houses the Waste Incineration, Waste Solidification, and Facility Support Operations and offices; (2) the new Sizing Building, which houses Size Reduction Operations, including the waste compactor; (3) the auxiliary building, which is used for storage; and (4) the new WERF Waste Storage Building (WWSB), which will store MLLW, hazardous waste, and contaminated lead. WERF is classified as a Category 3 hazard operation.

The present WERF Incinerator is a controlled-air incinerator and consists of two combustion chambers (primary and secondary) and three burners. Two burners (one each in the primary and secondary combustion chambers) burn fuel oil or propane, and are used to preheat the incinerator and provide auxiliary heat as necessary. The third burner (in the primary chamber) is a liquid waste burner connected to the WERF Drum Feed/Blending Unit; it is used to blend various liquid wastes or to consolidate small volumes to obtain waste with characteristics suitable for incineration.

Solid LLW size reduction capabilities include size reduction by cutting (plasma arc) of large metal shapes and compaction of solid LLW not authorized for incineration.

Typical secondary wastes that can be treated in the WERF Waste Stabilization Unit are Incinerator Fly Ash and Bottom Ash. The ash is collected in drums and transported to the WERF Solidification Room where it is stabilized with portland cement. The unit can effectively treat a wide variety of wastes by stabilization. (A further detailed description of WERF is available in the WERF Safety Analysis Report (SAR), Sections 1 and 3.) 
WERF was shut down by EG\&G Idaho, Inc. (EG\&G Idaho) in February 1991, due to deficiencies in safety documentation, operational procedures, and structural and operational components of the facility. Because of the duration of the shutdown and the scope of the modifications implemented, it was determined that a Type 3 restart was required.

\subsection{Scope of the ORR}

The WERF Restart Project Management Plan, EGG-WM-10165 defines the technical objective of the Restart Project as follows:

"The primary technical objective for the WERF Restart Project is to assess, upgrade where necessary, and implement management, documentation, safety, and operation control systems that enable the resumption and continued operation of waste treatment and storage operations in a manner that is compliant with all environment, safety, and quality (ES\&Q) requirements of the U.S. Department of Energy (DOE) and Federal and State regulatory agencies. Specific processes that will be resumed at WERF include compaction of low-level compactible waste; size reduction of LLW, metallic and wood waste; incineration of combustible LLW and MLLW; and solidification of low-level and mixed low-level incinerator bottom ash, baghouse fly ash. and $c$ mpatible sludges and debris. WERF will also provide for the operation of the WW $;$ which includes storage of MLLW in accordance with Resource Conservation and Recovery Act (RCRA) requirements."

The scope of the ORR will include those facilities, processes, and procedures under the control of the WERF Manager and necessary to restart WERF Operations as described above. For those activities or personnel outside the control of the WERF Manager, the ORR Scope will include evaluation of the controls exercised at the interface to WERF and the procedures in effect within WERF, including facility-specific requirements. For example, the ORR will review procedures to ensure that calibrated instrumentation is in use but will not evaluate the central calibration laboratory procedures. The facilities and processes to be evaluated are as described in the WERF SAR. The procedures are those applicable to WERF. For example, for those DOE Orders or regulations for which EG\&G Idaho requirements applicable to WERF have been defined, the ORR will evaluate WERF to the applicable Company procedure. Processes or operations that continued through the shutdown period will not be within the scope of the ORR to the degree that they will not change under operational conditions. If any issues are identified by the ORR Team to be outside the scope of the ORR, they will be identified to line management for resolution. 


\subsection{Graded Approach}

The WERF ORR will take a graded approach as defined in DOE's Environmental Restoration and Waste Management Policy and Guidance for Readiness Determinations, approved and issued on September 17, 1992, which states: "Graded Approach is the process by which the rigor and formality of a systematic approach to readiness determinations is adjusted to correspond to the hazard potential, complexity, and present and future mission of the facility or activity. Graded Approach is a concept, not a precise process." By this concept, the selection of appraisal areas, and the depth and detail to which they will be appraised, is based on the facility itself. Areas critical to WERF Operations and to protection of the health and safety of workers, the public, and the environment will receive the most detailed review, based on the ORR Team's qualitative assessment of risk, the WERF Hazard Analysis, and the WERF SAR.

The graded approach is evident in the ORR Plan through the criteria for pre-startup findings and the specific criteria and review approaches (CRAs). Criteria for pre-startup findings are discussed in the next section of this plan. The CRAs comprise the details of review and, therefore, finally establish the planned "graded" level of review. The review team will "pull the string" and probe more deeply in areas that appear weak during the evaluation of the CRAs. The CRAs represent the minimum level of review within the scope of the ORR. A more detailed discussion of the evaluations is included in Appendix A.

The CRAs detail the special requirements, review methodology, and acceptance criteria. Appendix $C$ lists each referenced DOE Order, the implementing EG\&G Idaho document (where one exists), and the element of the sub-objective checklist that addresses the Order. Each element is further broken down into sub-elements, which are summarized in Section 3 of this plan. For each sub-element, CRAs are included in Appendix B.

The detail to which each CRA element is evaluated will be based on the significance of the element to the safety envelope defined by the SAR, meeting the environmental requirements for WERF Operations, and assurance of health and safety of the workers and the public. Any decisions concerning the depth to which each element is evaluated will be made by the evaluator (who is an expert in the area), under the direcion of the subteam leader and the review of the WERF ORR Team Leader. As described in Appendix A, the record will clearly describe what was actually evaluated and how it was evaluated.

There is some overlap in the CRAs from the three sub-objectives. This is intended to gain a broad viewpoint of the various aspects of personnel, systems, documentation, and hardware. Unnecessary overlap has been "scrubbed." 


\section{STARTUP CRITERIA}

An important part of the graded approach to WERF Restart is to establish criteria by which findings will be divided into two categories: those that must be closed prior to restart (pre-startup) and those that may be completed on a priority basis at the discretion of WERF Management (post-startup). In addition, the ORR will identify concerns that, if corrected, will lead to excellence of operations.

\subsection{Pre-Startup Criteria}

An ORR Finding will be categorized as pre-startup if it meets any of the following criteria:

Degraded protection of health and safety of workers or the public. Any deficiency that identifies a situation that could significantly endanger the safety or health of the public or workers must be corrected prior to restart.

Pctential for spill or other environmental release. Deficiencies that could result in a reportable spill, airborne release, or other environmental damage must be corrected prior to restart. Again, the risk must be graded, based on the magnitude of hazard and the likeihood of a problem. For example, solid hazardous waste in storage would be of less concern than an airborne release of radioactivity.

Potential for violation of any permit or statute or Technical Safety Requirement. As stated in the WERF Restart Project Management Plan, it is the intent of WERF Management to fully comply with all Federal, State, DOE, and EG\&G Idaho requirements. For purposes of this ORR, however, it is impractical to meet this objective literally, and the process of compliance improvement is an ongoing one. Therefore, this plan defines specific regulatory requirements that must be fully met prior to restart. These are detailed in the sub-objectives and are summarized here. The facility must comply with all aspects of its permits under RCRA and the Clean Air Act. All Federal and State laws must be obeyed. The Technical Safety Requirements (TSR), which implement the safety requirements of the SAR, and the Regulatory Requirements Document (RRD), which implements regulatory limitations, are vital. Any deficiency in TSR or $\mathrm{RRD}$ implementation will be categorized as pre-startup.

Substantial effect on the ability of WERF to carry out its mission. Deficiencies that prevent WERF from operating normally to complete its programmatic mission must be corrected prior to restart. In addition to deficiencies under the first three categories, which would clearly fall under this category also, problems in the physical plant, maintenance backlogs, or transportation must be judged on a risk basis. Likewise, training, staffing, and management deficiencies must be considered. As with the other criteria, the probability and consequences of the deficiency in this regard must be judged by the ORR Team. 


\subsection{Post-Startup Criteria}

4) URR Finding will be categorized as post-startup if it fails to meet the criteria of a pr. $\quad$ finding and it is demoristrated that the protection of worker and public health and safe: : the environment are not compromised. In general, findings that would be categorized as Category I or II under the criteria of EG\&G Idaho Company Procedure 1.8 will be pre-stat tup findings. while those findings that would be category III will be post-startup findings. 


\section{SUMMARY OF SUB-OBJECTIVES}

\subsection{Sub-Objective A-Training and Personnel Readiness}

WERF Management and staff are trained and qualified, properly organized, and fully understand their facility, the requirements under which it operates, and their own function in its operation, including the relationship to safety documentation and environmental permits.

\section{A.1 Management and Organization}

A.1.1. The organization under which WERF is operated is clearly defined and documented, including both lines of authority and lines of communication. Interfaces to support organizations are clear.

A.1.2. Turnover from the restart project management structure to the permanent operating management structure is clearly defined and can be accomplished with minimal impact on facility operation.

A.1.3. Security issues, including security interface activities, are adequately addressed by the WERF Organization.

A.1.4. The facility has defined an order compliance program to identify and determine applicability, status of compliance, and established compensatory measures and have action plans for meeting compliance.

\section{A.2 Personnel Training and Qualification}

A.2.1. A properly implemented EG\&G Idaho training organization and program is in place. A training program for all organizations that support WERF Operations is in place. Policies, procedures, and records that ensure and document compliance with program requirements are in place and are maintained current.

A.2.2. Training program requirements are performance based and developed on the basis of a thorough analysis of the job requirements. Training program elements include aspects such as classroom training, specialized training, and operational and emergency response training. Facility functions are included in the training program; maintenance, operations, emergency response and all associated supporting elements satisfy the objectives identified by the job analysis. Personnel knowledge is evaluated by means of interviews and performance observation to verify training program results. 'Training requirements for support organizations are clearly defined, implemented and recorded.

\section{A.3 Emergency Preparedness}

A.3.1. An Emergency Preparedness Program, consisting of plans and procedures for responding to operational emergencies, has been established and is maintained. 
A.3.2. The facility's emergency preparedness program includes provisions for simulated emergency drills and exercises that develop and maintain the knowledge and skills necessary for emergency personnel to effectively respond to and control an emergency. The drills and exercises shall demonstrate the capability to ensure adequate emergency response in all applicable areas.

A.3.3. The facility's Emergency Preparedness Program must provide an emergency drill that demonstrates the knowledge and skills of emergency response organization personnel to respond to and control an emergency effectively, and that demonstrates the capability to plan, conduct, control, evaluate, and critique an emergency drill. The drill shall demonstrate the capability to ensure adequate emergency response in all applicable areas, or the ability of the drill control team to identify and correct inadequate performance.

\subsection{Sub-Objective B-Operations}

The personnel, facilities, and documentation of WERF and supporting organizations and facilities are ready to conduct each of the six processes and operations safely and in compliance with all appropriate statutes, orders, and permits, and within the safety envelope defined by the SAR, both in a normal mode and in case of emergency.

\section{B.1 Health and Safety}

B.1.1. WERF has implemented a fire protection program and an emergency plan that ensure the protection of personnel and property against loss. The :rogram includes hardware, procedures, design features, training, and staffing in compliance with appropriate regulations. Fire hazard has been adequately evaluated, particularly for the incinerator and plasma arc cutting operations. Reliance on administrative controls is minimized. Regular inspections are conducted.

B.1.2. A program to maintain and improve industrial safety is active. Information is readily available to employees on the hazards of the workplace. The workplace is free from avoidable hazards and complies with appropriate standards. Hazards that cannot be eliminated are clearly marked. Personnel understand safe work practices and employ them in all circumstances. Personal protective equipment is available and used properly. Professional support and equipment are available as required to support the safety program. Regular inspections of facilities and work practices are conducted.

B.1.3. A radiation protection program conforming to applicable regulations and employing the as low as reasonably achievable (ALARA) principle has been implemented. Contaminated areas are minimized and regular surveys are conducted. Dosimetry devices are used properly. Proper work practices are employed in radiation areas. Anti-contamination equipment is used properly, and radioactive waste is minimized by work practices. All staff have a basic understanding of radiation protection. The program meets the criteria specified in the WERF SAR.

B.1.4. Records are kept as required, including injury and accident logs, facility survey results, radiation exposure records, lock and tag logs, and other records maintained by WERF. Performance indicators are maintained on important items as a means to measure and improve health and safety performance. 
B.1.5. Literfaces that support health and safety organizations are clear and understood. Staffing and scheduiing is adequate. Authority and responsibility of support staff is clear.

WERF has a list of all interface agreements in force; the agreements are sufficient in number and scope to support WERF Operations.

\section{B.2 Environmental Protection}

B.2.1. WERF meets the RCRA requirements for hazardous waste generators and for treatment, storage, and disposal facilities; it also meets transportation and training requirements. WERF has in place procedures to ensure timely and accurate reporting of environmental parameters to appropriate agencies.

B.2.2. WERF has obtained the State of Idaho air pollution conirol permits for a stationary source; the facility also complies with the National Emissions Standards for Hazardous Air Pollutants (NESHAP) requirements. The proper training programs are in place to ensure continued compliance with statutes related to air quality.

B.2.3. The requirements associated with the Superfund Amendment and Reauthorization Act (SARA) are met at the WERF Facility. All procedures and reporting requirements for toxic chemical releases and recordkeeping relating to hazardous chemicals located in the facility are in place.

B.2.4. The requirements associated with the National Environmental Policy Act (NEPA) have been met for WERF.

B.2.5. The WERF Facility has the procedures in place to ensure compliance with the requirements associated with the Clean Water Act.

B.2.6. WERF has implemented the Regulatory Requirements Document.

\section{B.3 Safety Analysis Report/Technical Safety Requirements}

B.3.1. WERF has an SAR approved in accordance with DOE Order 5480.23. WERF has a mechanism by which the SAR is reviewed annually; updates are submitted to the Program Secretarial Officer (PSO). All copies of the SAR are current.

B.3.2. WERF has an approved TSR that fully implements the requirements of the SAR. Procedures, facility design features, equipment, and staff are prepared to meet every aspect of these documents. The implementing features of the SAR/TSR can be traced from the SAR/TSR to the implementing procedure or facility feature. Limiting conditions of operation that require action in advance of a TSR limit are clearly established and implemented. A mechanism is in place to provide for changing the TSR upon changes in source documents. Training is documented for all TSR changes. 


\section{B.4 Operations and Maintenance Performance}

B.4.1. Conduct of Operations has been implemented in accordance with the EG\&G Corporate Conduct of Operations Manual and as described in the SAR for the six processes and operations at WERF. Conduct of Operations is consistent with the philosophy of DOE Order 5480.19.

B.4.2. Maintenance activities comply fully with DOE Order 4330.4A, Maintenance Management Program, as defined by the WERF Maintenance Implementation Plan.

B.4.3. Procedures for development of existing WERF routine, abnormal, and casualty procedures include technical review by systems engineering experts and validation of the procedures by actual facility walkdown.

B.4.4. Waste accepted for treatment or storage at WERF meets written requirements of a formal WAC. Implementing procedures, facilities and equipment, and personnel are available to ensure that all receipts are documented as meeting the WAC or to take corrective action when they do not. The WAC, and supporting documentation, is audited annually, and appropriate corrective action for discrepancies is taken.

B.4.5. Shipping, receiving, and pad storage facilities, procedures, operations, training, and personnel ensure compliance with all applicable waste and hazardous materials packaging and transportation requirements.

B.4.6. WERF has in place procedures to ensure the timely and accurate notification of appropriate authorities and tracking, recording, and investigation of reportable events. WERF incorporates any lessons learned from reportable events into its operations training program.

B.4.7. WERF has fully implemented a lockout and tagout program meeting the requirements of DOE Order 5480.19, Conduct of Operations, and the Occupational Safety and Health Administration's lockout and tagout requirements.

\subsection{Sub-Objective C-Facilities and Hardware}

The facility and related hardware is ready to perform its programmatic mission in compliance with the SAR/TSR and its permits. All required upgrades and maintenance items have been completed to approved designs and have been fully tested.

\section{C.1 Orders, Statutes, and Regulations}

C.1.1. Facilities, systems, and hardware comply with the requirements defined in the NEPA documentation, Federal Permits (RCRA Part A/B), and State of Idaho Permits (Air Pollution Permit/PDS Permit/NESHAP). 
C.1.2. Compliance with DOE Orders 6430.1A and 5480.5, as described in the SAR, can be demonstrated in the facility and related hardware, as appropriate. This includes the documentation and design bases for the facility, particularly recent modifications and upgrades. Graded compliance with DOE Order 6430.1A, General Design Criteria, is specifically demonstrated.

\section{C.2 Safety Analysis Report and Technical Safety Requirements}

C.2.1. The facility is as described in the SAR for those aspects critical to the analysis and to hazard mitigation. General descriptive sections of the SAR are accurate for the purposes intended.

C.2.2. Facility features required by the TSR are complete, ope:able, and fully tested. They are documented by accurate drawings readily available in the facility. Design bases for features or hardware required for TSR implementation are traceable to the source document.

\section{C.3 Facilities}

C.3.1. All corrective actions and upgrades described in the WERF Restart Project Management Plan are complete and formally accepted by facility management. Satisfaction of design basis is demonstrated and verified through testing, inspection, or some other independent means. Outstanding items are formally managed in the commitment tracking system.

C.3.2. The facility, supporting all six processes and operations, is in a general state of readiness. Housekeeping is excellent. Preventive maintenance is up-to-date, and corrective maintenance has been completed as required. Any outstanding maintenance items that affect safety have been specifically justified for deferral. Except in specific special cases, no temporary construction or equipment is in use or located within the facility. Where such items are used, justification is documented.

C.3.3. An Integrated Systems Test and associated Component Checklist and Systems Operation Tests have demonstrated the operability of the entire facility, including interfaces between cooperating systems. Reaction of the system to expected upset and off-normal conditions has been tested or simulated. Safe shutdown under emergency conditions has been demonstrated.

\section{C.4 Configuration Control}

C.4.1. Approved processes are defined and implemented to ensure that facility modification activities maintain a controlled technical baseline.

C.4.2. Key drawings are those drawings identified by WERF Management as critical to normal and emergency operation of the facility. They are maintained up-to-date and readily available to operators and the emergency response organization, and are controlled through approved WERF procedures. 


\section{C.5 Quality Assurance}

C.5.1. A Quality Program Plan (QPP) that identifies the facility quality assurance and control requirements and implementation procedures applicable to the facility has been established. The QPP has been approved as required by the EG\&G Idaho Quality Manual and is maintained current.

C.5.2. The facility has approved procedures in place that implement the requirements for each QPP element; the requirements of the EG\&G Idaho Quality Manual are fully implemented.

C.5.3. The facility has identified training requirements and personnel (management, operations, technical support, administrative, and others) who are to be indoctrinated and trained on primary QPP requirements and QA principles; training records are maintained. 


\section{CONDUCT OF THE ORR}

\subsection{Governing Requirements}

The requirement to conduct an ORR is noted in DOE Orders 5480.5, Safety of Nuclear Facilities and 4700.1, Project Management System. Formal guidance as to the conduct of an ORR is not currently detailed in DOE Orders. EG\&G Idaho Company Procedure 2.2 contains requirements for readiness reviews; however, consensus on the requirements for an ORR is evolving. DOE's Environmental Restoration and Waste Management Policy and Guidance for Readiness Determinations, approved and issued on September 17, 1992, establishes requirements that will be adhered to for the WERF ORR. The DOE Procedure for Restart of Reactors and Nonreactor Nuclear Facilities, issued by DOE's Office of Nuclear Engineering (NE-1) on February 26, 1992, is also applicable. This procedure is consistent with the EM Policy and Guidance. An important feature of the procedure is its definition of the types of restart, which depends on the reason for shutdown and the level of approval required for restart. WERF was shut down by EG\&G Idaho because of deficiencies in safety documentation, operational procedures, and structural and operational components of the facility, and has since undergone substantial upgrades in material and documentation. DOE has agreed that this is a Type 3 restart under the procedure, and therefore requires the approval of the PSO, EM-1 in this case.

\subsection{ORR Personnel}

EG\&G Idaho has established a WERF ORR Organization with a team leader and three subteam leaders. Each subteam leader has responsibility for one sub-objective and will organize a subteam of qualified technical personnel to conduct the appraisal. The team leader is a senior EG\&G Idaho employee who has been approved by the WERF ORR Board (senior EG\&G Idaho Managers). The team leader and all subteam leaders and subteam members are independent of the line rnanagement of WERF. The team leaders and members are:

- Team Leader: W. L. Hicks

- Training and Personnel: Subteam Leader, H. M. Jones; Member A. A. Kovach

- Operations: Subteam Leader, W. L. Powell; Members, H. D. Oak, G. A. Leuzinger, W. L. Nees, D. J. Allred, J. Alvarez, M. M. Garland.

- Facilities and Hardware: Subteam Leader, T. L. Rasmussen; Members, D. E. Wilkins, R. C. Hill, J. D. Mullin.

This ORR Team was chosen based on the qualifications and prior experience of each member. In particular, prior experience in ORRs or similar operational appraisals was a key qualification. A summary of each team members' qualifications is included in Appendix D. 
Additional review staff may be selected by the subteam leaders. Subteams will be comprised of individuals with relevant expertise. Subteams will be small. Additional subteam members may be called upon to provide specific areas of expertise. These members and their qualifications will be documented in the WERF ORR Report. An individual with specific technical qualification in the area of incinerator operations will be added to the team.

The WERF ORR Team Members will receive indoctrination that includes Conduct of Operations, radiation worker, quality assurance, and WERF-Specific Safety and Orientation Training. Previously completed indoctrination will be recognized after review and approval by the WERF ORR Team Leader. All ORR Team Members will complete a Required Reading Checklist of key documents prior to participation in the ORR. The checklists will be maintained by the ORR Team Leader and will become part of the permanent ORR Records. Training and required reading will be focused on ensuring expertise to evaluate the CRAs contained in Appendix B.

\subsection{Process Overview}

The EG\&G Idaho ORR Process can be described in sequence as follows: (1) to establish requirements, (2) to conduct appraisals, (3) to report findings, (4) to verify closure of pre-startup findings, and (5) to issue a Declaration of Readiness to Operate to DOE. DOE will then conduct an independent overview of the EG\&G Idaho ORR, known as an Operation Readiness Evaluation (ORE). Upon completion of the ORE and closeout of any findings, the DOE team will recommend restart to the PSO, who must ultimately approve the WERF Restart.

The requirements for the EG\&G Idaho ORR are established by this implementation plan. These requirements are tiered into a primary objective, sub-objectives, and specific CRAs. When approved by DOE, these elements form the complete basis upon which appraisals will be conducted. This implementation plan also establishes criteria by which appraisal findings will be sorted into pre- and post-startup actions. This plan also details the participants, methodology, and reporting format for the ORR.

The review teams will review records and other documents; interview staff and management; observe dry runs, exercises, drills, and other activities; and inspect the facility itself. The scope of their review, as well as the criteria and methodology, are defined by the CRAs. Each team member will record observations for each criteria, identifying findings (deficiencies), concerns (items which, if corrected, would lead to excellence in operations), and areas without deficiencies. It may not be possible to observe all evolutions and operations specified in the CRAs because of plant conditions or other unforeseen circumstances. If an evolution cannot be conducted, the ORR Team Leader will be consulted, and every effort will be made to assess the requirement using other methods. 
In every case, observations will be documented on an appraisal form (Apper $\ldots$ ix A). At a minimum, the record will include the specific requirement evaluated, the methodology, facilities or procedures observed, people contacted, summary of observations, and any findings or concerns. The basis for any finding of deficiency must also be documented. The draft appraisal forms will be collected daily by each subteam leader, who will attend .: daily closeout meeting with facility management. This closeout will provide an opportunity for a factual review, ensuring that the data and bases for findings are accurate. The daily closeout is not intended to be a forum to debate findings, only to consider questions of fact. Each subteam leader is responsible for judging the observations in his sub-objective and for determining what is deficient. The facility manager will acknowledge each finding, signifying his understanding, but not necessarily his agreement. The appraisal forms will be considered to be in draft form until the end of the ORR; at that time the appraisal forms will be signed and will become final.

Frequently during the appraisal process the subteam leafers will meet with the team leader to consider the observations to date. They will consider any common threads that are appearing in the observations and decide whether special attention needs to be focused in a certain area.

At the conclusion of the appraisal, subteam leaders will meet again to determine which findings are pre-startup and whether or not they will recommend approval of facility operation. The team leader will approve all pre-startup findings. Following this meeting, the team leader will brief facility management, EG\&G Idaho Senior Management, and DOE. A complete report of the ORR will be written at this point. The report will contain the following:

- A brief summary of review activities.

- A description of the conclusions reached and a summary of the basis for reaching each conclusion.

- A section identifying deficiencies as pre-startup findings (those situations that could si : icantly endanger the environment or the safety or health of the public or workers), as post-startup findings (those situations that would not preclude $r$ tart but require correction), and concerns (items which, if corrected, would lead to exuellence in operations). This section shall confirm that pre-startup deficiencies have been resolved, along with explanations of deviations from DOE Orders or other requirements.

- A schedule for resolution of the post-startup findings and a justification of why the post-startup finding conditions do not compromise the adequate protection of the environment, or the safety or health of the public or workers.

- A description of lessons learned from the ORR that may be applied to future ORRs.

- A section that provides ORR Team Members with an opportunity to offer professional opinions that differ with ORR Conclusions, non-judgmental general comments, and observations. 
Unless the ORR Team finds nothing required prior to restart or finds that the facility as a whole is unqualified for restart (neither conclusion is expected), EG\&G Idaho's recommendation for WERF Restart will depend on closure of pre-startup findings only. The WERF Organization will be responsible for closure of all findings. Verification of closure of pre-startup findings will be the responsibility of the ORR Team Leader, who will issue an addendum to the ORR Report documenting the closure. Post-startup findings will be entered into the commitment tracking system for tracking and documentation of closure by the WERF Organization. The tracking, management, and closure of post-startup findings is the responsibility of WERF Management. WERF will develop a schedule for the closure of the post-startup findings. This schedule will become part of the ORR Team's Report.

The WERF ORR Team shall issue to DOE a final report that includes a "Declaration of Readiness to Operate" from EG\&G Idaho Senior Management. This declaration will be recommended to EG\&G Idaho Senior Management by the ORR Team after all ORR Pre-Startup Findings have been satisfactorily resolved. The final report shall contain a schedule for resolving post-startup findings. The report shall also provide adequate justification for startup with post-startup findings outstanding. DOE will conduct its ORE and grant approval to commence operations only after the "Declaration of Readiness to Operate" has been submitted with the final ORR Report by EG\&G Idaho's Senior Management.

\subsection{ORR Documentation}

An auditable record of the ORR will be maintained. The primary record will consist of a chronological file of specified ORR Records and an accompanying document log. At a minimum, the following ORR Records will be included:

- All internal and external correspondence related to conduct of the ORR.

- $\quad$ Resumes and Required Reading Checklists for team leaders and members.

- All Appraisal and Deficiency Forms. In the case of pre-startup deficiencies, both the initial form and the approved closure form will be included.

- This ORR Implementation Plan.

- The ORR Final Report.

- The Declaration of Readiness to Operate.

All documents will be assigned a unique number and entered in a log as they are filed. The log will be part of the record.

At the completion of the ORR, all records and documents collected and prepared for the conduct of the review will be validated for completeness and auditability, after which they wil! become part of the WERF Facility Records. 


\section{SCHEDULE}

The draft implementation plan was issued on November 20,1992. Comments were requested by December 11, 1992. The final plan was submitted for approval of the CRR Committee and subsequent transmission to DOE-ID on December 22, 1992. The scheduled start date for the WERF ORR is February 22, 1993.

Conduct of the ORR Appraisal and issue of the ORR Report depend on WERF Facility readiness. The following durations are projected:

- Conduct field appraisal-2 weeks

- Draft ORR Report-1 week

- Review and issue initial ORR Report-1 week.

If the appraisal begins on February 22, 1993, the draft ORR Report will be issued on or before March 22, 1993.

Closure of pre-startup findings depends on the nature and scope of those findings, if any, and cannot be projected prior to the field appraisal.

EG\&G Idaho intends that the majority of the ORR will be conducted prior to the integrated test of the WERF Incinerator. The ORR Evaluation will be the basis for EG\&G Idaho's certification of readiness to conduct the test and justification for the request for approval from DOE-ID to start the integrated test. The final report and the Declaration of Readiness to Operate will be issued after closure of all pre-startup findings is documented. 


\section{REFERENCES}

DOE, "Project Management System," Order 4700.1, U.S. Department of Energy, Washington, D.C., June 1992.

DOE, "Safety of Nuclear Facilities," Order 5480.5, U.S. Department of Energy, Washington, D.C., September 1986.

Duffy, L. P., DOE, 1992, to Distribution, Subject: "EM Policy and Guidance for Readiness Determinations," September 17, 1992.

EG\&G Idaho, Inc., 1992, Waste Experimental Reduction Facility Program Management Plan, EGG-WM-10165, June 1992.

EG\&G Idaho, Inc., Company Procedures Manual, currenı issue. 


\section{Appendix A}

\section{Operational Readiness Review In-Process Documentation}




\section{Appendix A}

\section{Operational Readiness Review In-Process Documentation}

The validity of, and the ability to defend, the results of the WERF ORR will depend in large part on the thoroughness with which the process and the observations are documented. The process will utilize the individual sub-element checklists in a graded approach. The record must be clear as to what was evaluated and the methodology of the evaluation. Specifics such as sample size, numbers of individuals interviewed or observed, and specific records reviewed must be recorded as part of the official record of the ORR. For every sub-element checklist (CRA) the record will contain at least one appraisal form with a marked-up copy of the CRA attached. If any changes are deemed necessary to the CRA, that will be indicated and approved by the ORR Team Leader. The marked-up CRA may contain the bulk of the record of the methodology for the evaluation. If so, the information need not be recopied onto the appraisal form.

The identification of findings (deficiencies) must be precise and complete. Each individual finding must be recorded on a separate deficiency form. The description must permit correction. An individual finding may be generic with several examples to describe or clarify the issue. Every finding is a deficiency to a requirement placed upon WERF by DOE, EG\&G Idaho, or a WERF procedure. The reference against which the finding is deficient must be recorded on the individual deficiency record. The reference must be specific as to subpart of an order, manual, or procedure. The designation of the finding as to pre-startup or post-startup will be accomplished as discussed in Section 4.3. Each finding will have a unique identifier assigned for accounting and tracking of corrective action status.

Concerns are better ways of doing business with the assumption that current practices or procedures are not deficient but may not be most efficient or effective. The concerns will be described in sufficient detail that managers will readily understand the issue and the proposed Best Management Practice which applies. For efficiency, ORR Team Members should reserve identification of concerns to those items for which a large payoff is possible from a change in practice or procedure. Opinions and ideas which are individual preferences or choices should be identified to individual counterparts for consideration. In many instances, these "good ideas" may also be discussed with WERF Management. Every documented concern will be included on a deficiency form with the concern block marked. Each concern will have a unique identifier assigned for accounting purposes.

ORR Team Members will ensure that the designated counterpart WERF staff member understands the issues behind each item reported on a deficiency form, whether it is a finding or a concern. The counterpart should also be fully cognizant as to how the individual CRA was evaluated and be familiar with the contents of the appraisal form accompanying the completed CRA. 
The example appraisal, issue identification, and finding response/disposition forms on the following pages are samples of the type of forms to be used. The actual forms used during the ORR may have minimal changes in form to enhance efficiency of use. 


\section{ISSUE IDENTIFICATION}

Waste Experimental Reduction Facility Operational Readiness Review EG\&G Idaho Appraisal Form
Identified by:

Date:

Log \#:

CRA Number:

CRA Title:

Requirement:

Reference (specific as to section):

Issue:

Finding $(\mathrm{Y} / \mathrm{N})$

Concern $(\mathrm{Y} / \mathrm{N})$

Finding Designation and Approval: Pre-Startup Sub-Team Leader:

Post-Startup Date:

ORR Team Leader:

Date: 


\section{FINDING RESPONSE/DISPOSITION}

Waste Experimental Reduction Facility

Operational Readiness Review

Date:

EG\&G Idaho Appraisal Form

Pre-Startup Finding:

Post-Startup Finding:

Acknowledged:

WERF Restart Project Manager

Date:

Actionee:

Date:

WERF CTS \#:

Action/Disposition:

Date Completed (Pre-Startup Only):

Certified By:

Date:

Verified By

(pre-startup on 1y):

Date:

ORR Team Leader 
CORRECTED COPY - 3/15/93

\section{ORR APPRAISAL FORM}

Waste Experimental Reduction Facility

Inspected by:

Operational Readiness Review

Date:

EG\&G Idaho Appraisal Form

Log \#:

CRA Number:

CRA Title:

Method of Appraisal (short description):

- Personnel intacted/position:

- Records \& other documents reviewed:

- Evolutions/operations witnessed:

- Spaces visited

Deficiency or Concern Identification Numbers (If none, so state):

Approved By:

ORR Team Leader

Date: 


\section{Appendix B}

\section{Criteria and Review Approaches}




\section{WERF OPERATIONAL READINESS REVIEW ORR CHECKLIST}

Reviewer

Date

Checklist Designator A.1.1

\section{Requirements Identification}

1. Element - Management and Organization

2. Sub-element - Organization

3. Basic References:

DOE Order 5480.19, "Conduct of Operations"

EG\&G Idaho Policies and Procedures

DOE Order 5480.5, "Safety of Nuclear Facilities"

WERF Safety Analysis Report, Section 12

4. Description of Requirement - The organization under which WERF is operated is clearly defined and documented, including both lines of authority and lines of communication. Interfaces to support organizations are clear.

\section{Review Criteria}

a. The WERF Organization is documented and approved.

a.1 Review a current organization chart and confirm its accuracy.

a.2 Review high-level facility documents (e.g., project directives) for enabling statements and descriptions of responsibilities and authorities of management positions.

b. Lines of authority and communication are clear.

b.1 Interview managers and at least three staff to ensure that they understand their own authority, when they must seek higher level approval and how that is done, and where they can find answers to questions.

b.2 Confirm a clear and effective line of communication to the responsible manager within DOE-ID.

b.3 Ask several staff, chosen at random, specifically how they report a safety concern and if they understand stop work authority. 
b.4 Observe posting of notices for the EG\&G Idaho ombudsman and the DOE ES\&Q "hotline."

c. Levels of review and approval of documents is clearly defined.

c.1 Review the chartering document for the line management independent review committee, or equivalent.

c.2 Have a manager walk through the review and approval process for a high-level (e.g., a project directive) and a low-level (e.g., a site work release) document.

d. Incumbents in key positions (managers, key operating staff, key support positions) are fully qualified by experience, skills, and training. Ensure that alternates to key positions are available.

d.1 Ask each manager who his alternate is; interview the alternate to ensure that he/she understands his/her responsibilities and is prepared to accomplish them if required.

d.2 Review position questionnaires (PQs) and/or job assignment outlines (JAOs) for selected key personnel and compare them with resumes or personal interviews.

e. The responsibilities and requirements for each position are clearly specified, and each person understands the position description for the job.

e.1 Spot check PQs/JAOs to ensure that they are complete and concise.

e.2 Interview two or more selected people to determine whether their understanding of their job matches that described in the PQ/JAO. 


\section{WERF OPERATIONAL READINESS REVIEW ORR CHECKLIST}

Reviewer

Date

\section{Checklist Designator A.1.2}

\section{Requirements Identification}

1. Element - Management and Organization

2. Sub-element - System Turnover

3. Basic References: DOE Order 4700.1, "Project Management System"

4. Description of Requirement - Turnover from the restart project management structure to the permanent operating management structure is clearly defined and can be accomplished with minimal impact on facility operation.

5. Review Criteria

a. Ensure the plan for turnover addresses the following:

- Schedule

- New organization

- Training and qualifications of new personnel

- Acceptance criteria

- Turnover of maintenance and upgrade backlog

- $\quad$ Funding

a.1 Review the turnover plan.

a.2 Interview the new group manager to ensure that he/she understands the turnover process and is comfortable with it.

b. Turnover will not be an excessive burden to the new or existing staff:

b.1 For selected key positions, review the additional responsibilities to be placed on them, if there are any.

b.2 If there are significant new responsibilities, interview the incumbents to determine their ability to meet them. 


\section{WERF OPERATIONAL READINESS REVIEW ORR CHECKLIST}

\section{Reviewer}

Date

\section{Checklist Designator A.1.3}

\section{Requirements Identification}

1. Element - Management and Organization

2. Sub-element - Security

3. Basic References:

EG\&G Idaho Safeguards and Security Manual

WERF Physical Security Plan

Memorandum of Understanding with Protection Technology of Idaho, Inc.

4. Description of Requirement - Security issues, including security interface activities, are adequately addressed by the WERF Organization.

\section{Review Criteria}

a. WERF has implemented a security plan in accordance with EG\&G Idaho requirements.

a.1 Review the WERF Plan for currency and adequacy.

a.2 Spot check several implementing actions or procedures to confirm that they are in fact implemented.

a.3 Check recent (last 12 months) audits by others for security findings.

b. Physical security is adequate for an unclassified area and can be temporarily upgraded for occasional receipt of classified waste.

b.1 Inspect access controls for personnel and vehicles. Are they operable and in accordance with the security plan?

b.2 Interview one manager and one person responsible for waste receipt. Do they know how to deal with classified material in case WERF is asked to process such material? 


\section{WERF OPERATIONAL READINESS REVIEW ORR CHECKLIST}

Reviewer

Date

\section{Checklist Designator A.1.4}

Requirements Identification

1. Element - Management and Organization

2. Sub-element - DOE Order Compliance

3. Basic References:

EG\&G Idaho DOE Order Compliance Plan

4. Description of Requirement - The facility has defined an order compliance program to identify and determine applicability, status of compliance, and established compensatory measures and have action plans for meeting compliance.

5. Review Criteria - The facility's program to identify, evaluate, and correct nonconformances with DOE Orders will be evaluated. The program should provide for the identification of DOE Order requirements applicable to the facility operation, the degree of compliance to those requirements, and the establishment and implementation of appropriate compensatory measures when noncompliances exist. Appropriate corrective actions shall be identified and planned to bring about compliance with requirements.

a. A formal program exists that ensures that the requirements of DOE Orders are identified and evaluated for applicability. Applicable requirements are implemented in plant programs and procedures and are periodically reviewed.

b. WERF Management conducts self-assessment evaluations of compliance with DOE and Company requirements.

c. Issues of noncompliance with DOE Orders have been fully corrected; or adequate compensatory actions, as appropriated, have been approved and are in place.

d. Facility management has verified that approved compensatory measures and compliance schedules are effectively implemented.

e. All noncompliance issues have been addressed by facility management and compliance schedule approvals are approved for operation. The compliance schedule approvals include adequate technical basis and the schedule supports attainment of compliance.

f. All noncompliance issued are identified and tracked in the commitment tracking system. 


\section{WERF OPERATIONAL READINESS REVIEW ORR CHECKLIST}

Reviewer

Date

\section{Checklist Designator A.2.1}

\section{Requirements Identification}

1. Element - Personnel Training and Qualifications

2. Sub-element - Training policies, procedures, and records

3. Basic References:

DOE Order 5480.5, "Safety of Nuclear Facilities"

DOE Order 5480.20, "Personnel Selection Qualification and Staffing Requirements at

DOE Reactor and Non-Reactor Nuclear Facilities"

EG\&G Idaho Company Procedure 1.11

WERF Safety Analysis Report, Section 13

4. Description of Requirement - A properly implemented EG\&G Idaho training organization and program is in place. A training program for all organizations that support WERF Operations is in place. Policies, procedures, and records that ensure and document compliance with program requirements are in place and are maintained current.

\section{Review Criteria}

a. Training policies are formally established at all organizational levels and define a program that complies with higher tier (e.g., DOE Order) requirements. A review of these policies indicates that they are clear, current, and in compliance.

a.1 Review and assess the written training policies regarding initial and continuing training, paying specific attention to established prerequisites for specific training, systematic job task analysis, evidence of performance-based training, and evaluation of students.

a.2 Interview the training manager or equivalent to discuss training policies and how they were derived. (Combine with $d$. below.) 
b. Training procedures clearly define specific facility requirements for training and are maintained accessible and current. A review of training procedures confirms that implemented training program requirements comply with training policies and requirements. Training procedure maintenance requirements are clearly specified. Training procedures clearly define requirements for all support personnel, subcontract or short-term workers, and other non-organizational personnel that may work at WERF.

b.1 Review established qualification procedures and standards.

b.2 Review an operator qualification standard.

b.2.1 Evaluate methods of assessing initial technical knowledge.

b.2.2 Are prerequisite job tasks clearly defined?

b.2.3 Does it provide a logical process for achieving indicated levels of knowledge and performance?

\section{b.2.4 Is the final certification process clearly defined?}

b.3 Review the General Employee Training Program to ensure compliance with EG\&G Idaho Company Procedure 1.11, Section A.

b.4 Review any current provisional qualification programs and procedures for final certification.

b.5 Review training plan for accuracy.

b.6 Evaluate the requalification/recertification program.

c. Instructor guides, examinations, lesson material, and reference documents are available and adequate to support an effective training program. Lesson materials and instructor guides adequately support the achievement of learning objectives and are used to provide an effective and consistent plan.

c.1 Review one course that is used to train operators and support personnel.

c.1.1 Evaluate lesson materials and instructor guides for accuracy and effectiveness in supporting course objectives.

c.1.2 Monitor course in progress, if possible, for adherence to the instructor guide.

c.1.3 Interview instructor if course is not monitored to determined instructor guide effectiveness. 
c.2 Evaluate examination from the course and/or a qualification examination from a. above.

c.2.1 Determine if examinations adequately measure student knowledge.

c.2.2 Verify administrative procedures and security to prevent examination compromise.

d. Training organization and responsibilities are clearly defined. Training positions are formally identified and an interview of key personnel in these positions indicates that program requirements are clearly understood. Training is being managed in a formal manner which supports the maintenance of a formal work environment.

d.1 Interview Training Manager, or equivalent, to assess level of adherence to training requirements and guidance (combine with a. above).

\section{d.1.1 Determine level of understanding of position responsibilities using DOE 5480.20 .}

d.2 Interview five operators and five support personnel in regards to their understanding of the training organization and their responsibilities to support the facilities training mission.

e. Ensure specific training is conducted and documented for workers exposed to hazardous materials and subject to radiation exposure.

e.1 Evaluate adherence to EG\&G procedure 1.11 sections $B$. and C.

e.1.1 Determine process for determining worker applicability.

e.1.2 Evaluate plan for ensuring long term commitments are met.

e.1.3 Interview applicable workers to evaluate their understanding of their responsibilities. 


\section{WERF OPERATIONAL READINESS REVIEW ORR CHECKLIST}

Reviewer

Date

\section{Checklist Designator A.2.2}

\section{Requirements Identification}

1. Element - Personnel Training and Qualifications

2. Sub-element - Conduct of Performance of Training

\section{Basic References:}

DOE Order 4330.4A, "Maintenance Management Program"

DOE Order 5480.5, "Safety of Nuclear Facilities"

DOE Order 5480.19, "Conduct of Operations"

DOE Order 5480.20, "Personnel Selection Qualification and Staffing Requirements at DOE Reactor and Non-Reactor Facilities"

40 CFR 265.16

WERF Safety Analysis Report, Section 13

4. Description of Requirement - Training program requirements are performance based and developed on the basis of a thorough analysis of the job requirements. Training program elements include aspects such as classroom training, specialized training, and operational and emergency response training. Facility functions are included in the training program; maintenance, operations, emergency response and all associated supporting elements satisfy the objectives identified by the job analysis. Personnel knowledge is evaluated by means of interviews and performance observation to verify training program results. Training requirements for support organizations are clearly defined, implemented and recorded.

\section{Review Criteria}

a. Training program requirements are developed using a performance-based approach and considerations of a job or task analysis are defined in each training requirement. A review of at least four major training requirements and interviews with training personnel will verify that the requirement has been met.

a.1 Review four major training requirements to verify they were evaluated using the performance-based approach and have had considerations of job or task analysis defined.

a.2 Interview two training personnel to verify that facility elements were evaluated in detail. 
a.3 Verify that the facility elements were incorporated into the training program by formal procedure.

b. Verify the training program is being conducted in a formal, disciplined, and objective manner. Training feedback and problem identification are ensuring that training program and personnel problems and deficiencies are being promptly identified and resolved.

b.1 Assess the knowledge of WERF Personnel.

b.1.1 Verify that formal training programs adequately control initial and continuing training of the WO, ICO, and SS.

b.1.2 Compare the training requirements against job responsibilities and facility safety requirements (specifically the SAR/TSR and DOE Orders 5480.19 and $4330.4 \mathrm{~A})$.

b.1.3 Review the training program content against system and facility operational requirements to ensure that an adequate scope and level of training are provided.

b.1.4 Review six training records of support personnel to ensure that the personnel have completed the required reading.

b.1.5 Interview two WOs and two ICOs and evaluate the adequacy of the retained knowledge of the operators to perform their duties (specifically the SAR/TSR and DOE Orders 5480.19 and 4430.4A).

b.1.6 Interview two trained personnel to evaluate the adequacy of the retained knowledge of the personnel to perform their duties.

b.1.7 Is a single, comprehensive written and oral examination required prior to final qualification? Is the scope, frequency, and depth of examination sufficient to verify long-term retention of knowledge?

b.1.8 Interview six support personnel and evaluate the adequac, of the retained knowledge, as appropriate, $i_{1}$ the areas of environmental protection and wastc management, radiation and industrial safety, industrial hygiene, maintenance and testing, fire protection, and emergency preparedness and quality assurance.

\section{b.2 Observe training of WERF Personnel.}

b.2.1 Observe one classroom training session to assess quality, formality, and detail performances of the training as it relates to personnel performance, problem resolution, and operational safety. 
b.2.2 Observe one operational or on-the-job training evolution to assess quality, formality, and detail performances of the training as it relates to personnel performance, problem resolution, and operational safety.

c. Verify compliance with procedures.

c.1 Review training program documentation for emphasis on procedural compliance and understanding of safety requirements (specifically the SAR/TSR, primary DOE Orders, and the EG\&G Idaho documents implementing these Orders).

c.2 Verify that the training program examinations include questions that elicit student understanding of the importance of compliance with approved procedures, posted safety limits, and operational safety requirements (specifically the SAR/TSR, primary DOE Orders, and the EG\&G Idaho documents implementing these Orders).

c.3 Select key steps from three different procedures that have significant safety implications. Interview two WOs, two ICOs, and two SSs to verify their awareness of the safety consequences of noncompliance.

d. Verify safety and environmen:al protection training.

d.1 Verify that directives and guidance have been provided to personnel at all levels and disciplines regarding the need to comply with safety and environmental protection requirements, specifically the general requirements of RCRA and the Clean Air Act and of the specific requirements of the facility's permits under RCRA (Part A or B) and the Clean Air Act (PTC/PSD).

d.2 Examine training program materials to establish that personnel are receiving formal training on the need to comply with safety and environmental protection requirements.

d.3 During the course of all observations and interviews, identify examples of an individual's awareness or lack of awareness of safety and environmental protection requirements.

e. Verify formal qualification and staffing requirements for the safe operations of the facility have been established for WOs, ICOs, SSs, and support personnel.

f. Verify that training and qualification have been completed and documented for all procedures performed by WOs, ICOs, SSs, and support personnel.

g. Review the training records for two WOs, two ICOs, and two SSs to verify that their training and qualification are based on the most recent procedure revisions. 
h. Verify the qualification process for WOs, ICOs, SSs, and support personnel includes hands-on demonstration of proficiency for each procedure to be performed.

i. Verify the formality and adequacy of procedures to ensure that instructors and individuals designated to certify qualification knowledge are adequately knowledgeable of training and qualification procedures and information associated with the subjects for which they are certified. 


\section{WERF OPERATIONAL READINESS REVIEW ORR CHECKLIST}

Reviewer

Date

\section{Checklist Designator A.3.1}

\section{Requirements Identification}

1. Element - Emergency Preparedness

2. Sub-element - Emergency Plans and Implementing Procedures

3. Basic References:

DOE Order 5500.2B, "Emergency Categories, Classes, and Notification and Reporting Requirements"

DOE Order 5500.3A, "Planning and Preparedness for Operational Emergencies"

DOE Order 5480.11, "Radiation Protection for Occupational Workers"

DOE-ID Emergency Plan

EG\&G Idaho Emergency Preparedness Manual

WERF Safety Analysis Report, Sections 5, 11, and 19

4. Description of Requirement - An Emergency Preparedness Program, consisting of plans and procedures for responding to operational emergencies, has been established and is maintained.

\section{Review Criteria}

The emergency plan, the emergency plan implementing procedures, and their supporting documentation should provide for effective response to operational emergencies. To verify that an effective facility-wide emergency preparedness program has been established and that implementing procedures, organization, resources, training, communications, facilities and equipment are in place, the following items, as applicable to each of the six processes and operations, must be evaluated:

a. Conduct a review of the facility's emergency plan and implementing procedures to ascertain that:

a.1 Emergency plans and implementing procedures are compatible with and based on existing SAR.

a.2 Plans/procedures provide protective measures for the entire range of credible emergencies.

a.3 Emergency plans are based on the hazards from specific credible events. 
a.4 Review, approval, and periodic updating of the emergency plans and implementing procedures are in accordance with requirements.

b. Verify the Emergency plans and implementing procedures contain the following elements:

b.1 Classification of emergency events and response levels are clearly defined;

b.2 Notification and activation of emergency response organizations;

b.3 Authorities and responsibilities of the emergency organizations and individual emergency team member positions are clearly defined;

b.4 Technical capability exists for assessment of emergency events and consequence mitigation;

b.5 Facility specific, site-wide and on-site personnel protective actions are defined and implementing procedures are in place;

b.6 Adequate communications systems exist to provide timely and accurate information to plant personnel, to the public media, and to outside organizations (DOE, State, and local officials);

b.7 Agreements with external organizations supporting the emergency response action plans are in place;

b.8 Coordinated re-entry and recovery plans are in place;

b.9 Operational procedures to promptly and safely shutdown the facility in the event of an emergency are in place;

b.10 Annual and periodic exercises/drills are conducted

b.11 Feedback from evaluations, simulated exercises and drills, and actual emergencies in other facilities, is evaluated and effectively used in improving the emergency plan.

b.12 Procedures address emergency release reporting under EPCRA and SARA 313, as appropriate.

c. Verify procedures contain detailed information with specific instructions, responsibilities, and steps identified. Prerequisites and cautions identified.

d. Verify an effective Emergency Response Organization (ERO) personnel training program is in place, including:

d.1 Lesson plans for training emergency response personnel; 
d.2 Specialized training requirements for facility personnel including management personnel, training is specific to job tasks;

d.3 Records and documentation of classroom and practical training for emergency response personnel;

d.4 Periodic retraining is conducted;

d.5 General training provided to all employees regarding operational emergencies (evacuation, assembly, accountability, alarm recognition);

d.6 Facility-specific orientation training is provided annually for outside response agencies;

d.7 Provisions for public information and media training on the facility hazards must also be provided as appropriate;

d.8 Training requirements for emergency responders stipulated in OSHA 1910.120 are implemented as required.

e. An appropriate and sufficient number of facilities and equipment are in place.

e.1 Emergency facilities for operations, Health Physics, and medical support are designated, staffed, equipped, and maintained ready to support an emergency.

e.2 Primary and backup communication systems and equipment are in place.

e.3 Emergency equipment is inventoried, tested, and serviced on a periodic basis.

e.4 Sufficient monitoring equipment is available for facility use.

e.5 Up-to-date emergency preparedness procedures are readily available to emergency response personnel.

e.6 Adequate emergency command center (ECC) equipment and supplies are available and operable.

e.7 An ECC and alternate are established.

e.8 The staffing, operation, and response activities of the ECC should be documented in procedures.

f. ERO and assignment of responsibility.

f.1 Specific individuals' (and their alternates') responsibilities and authorities are defined. 
f.2 Assurance that the individuals assigned to emergency response functions are capable of performing those assigned functions under emergency stress conditions.

f.3 Identification and specification of on-site and off-site emergency support personnel in the plan.

f.4 Identification of sufficient staff to permit 24-hour staffing of emergency response and control facilities.

f.5 Positions filled by personnel with day-to-day responsibility similar to ERO duties.

g. Emergency action levels.

g.1 Emergency action levels have been provided to State and local authorities.

g.2 Identification of initiating conditions for each level are provided in the emergency plan.

g.3 Formal arrangements with DOE, State, and local organizations for expected response actions.

h. Emergency notifications.

h.1 Primary and backup notification systems are in place.

h.2 Facility alarm and notification systems are in place.

h.3 These systems are tested periodically.

i. Incident assessment.

i.1 Resources and expertise are available for rapid assessment of radiological hazards and non-hazards.

i.2 Potential release of radioactive materials or hazardous materials are identified and determined in relation to the emergency response level.

j. Protective response.

j.1 On-site evacuation routes and transportation to predetermined locations have been established and are coordinated with the Central Facilities Emergency Plan.

j.2 Guidelines are in place for protection of emergency workers, plant personnel, and the general public. 
j.3 Access control procedures are in place to control the access to on-site evacuated areas.

j.4 Personnel accountability procedures are specified.

k. Radiological and hazardous material exposure control.

k.1 Emergency worker standards are in place and in compliance with DOE Order 5480.11, and with OSHA and EPA Standards.

k.2 Specific procedures are in place for emergency worker exposure protection and control.

k.3 Sufficient respiratory equipment, protective clothing, and supplies are available.

k.5 Effective decontamination equipment, procedures including decontamination limits, and facilities are provided for personnel and equipment.

1. Medical and health support.

1.1 On-site medical support facilities and personnel are available.

1.2 Memoranda of Understanding are in place with local hospitals and backup hospitals for emergency medical services.

1.3 Appropriate transportation arrangements are in place for transporting on-site victims to medical support facilities.

1.4 Capabilities of local hospitals and medical support facilities are tested periodically.

m. Recovery and re-entry plans and post-incident operations.

m.1 Site and facility re-entry authorities and responsibilities are established and identified.

m.2 Essential information for emergency operation is provided.

m.3 Personal protective equipment and clothing, and other essential emergency equipment are in storage and readily available.

m.4 A procedure is in place for obtaining information about the emergency and for developing the re-entry and recovery plan.

n. Effective fire fighting support is available, including prearranged plans with the DOE-ID Fire Department and local fire services, as appropriate. 
o. A program for annual internal appraisal of all aspects of emergency management by independent organizations is in place.

p. Provisions are made for the coordination of plans and procedures with DOE-Headquarters and with State and local officials.

q. The emergency plan is properly reviewed and approved by DOE.

r. The Emergency Readiness Assurance Plan has been developed and is being used to manage the emergency program. 


\section{WERF OPERATIONAL READINESS REVIEW ORR CHECKLIST}

Reviewer

Date

Checklist Designator A.3.2

Requirements Identification

1. Element - Emergency Preparedness

2. Sub-element - Drill and Exercise Program

3. Basic References:

DOE Order 5500.2B, "Emergency Categories, Classes, and Notification and Reporting Requirements"

DOE Order 5500.3A, "Planning and Preparedness for Operational Emergencies"

DOE Order 5480.10, "Contractor Industrial Hygiene Program"

DOE-ID Emergency Plan

EG\&G Idaho Emergency Preparedness Manual

4. Description of Requirement - The facility's emergency preparedness program includes provisions for simulated emergency drills and exercises that develop and maintain the knowledge and skills necessary for emergency personnel to effectively respond to and control an emergency. The drills and exercises shall demonstrate the capability to ensure adequate emergency response in all applicable areas.

\section{Review Criteria}

A coordinated program of drills and exercises must be an integral part of the emergency management program. The facility's Emergency Preparedness Plan must be evaluated to ensure that requirements for drills and exercises are included, along with a Five-Year Emergency Readiness Assurance Plan (ERAP). The ERAP identifies the schedule for drills/exercises and resources required and ensures that all elements of the emergency plan are exercised. The drill and exercise program should provide for events conducted under realistically simulated conditions for the identified credible emergencies. To assess the adequacy of the drill/exercise portion of the facility's emergency plan, the following must be evaluated:

a. Review the drill and exercise schedule for the facility.

a.1 An annual exercise must be conducted to assess the adequacy of the Emergency Preparedness Program.

a.2 Sufficient drills should be conducted to ensure that ERO members are familiar with their responsibilities, facilities, and equipment. 
a.3 Review drill and exercise participation records for a minimum of three ERO positions. Each ERO member must participate in a drill or exercise annually. Verify that each member of the selected positions has participated in a drill or exercise as required. Verify that an administrative control system has been established to ensure participation by all members of the ERO.

b. Review the drill and exercise program to ensure that the major elements of the drill and/or exercise objectives include the following:

b.1 Emergency event detection and classification;

b.2 Notification of on-site and off-site response organizations;

b.3 Communications;

b.4 Command and control;

b.5 Radiological or hazardous material exposure assessment and control;

b.6 Protective action recommendations;

b.7 Performance of the emergency response personnel in their assigned role:

b.8 Emergency response support facilities;

b.9 Recovery and reentry plans;

b.10 Interface with off-facility plans, procedures, and formal agreements.

c. The assessment of the adequacy of the drill and exercise program should verify that the scenarios provide a framework for testing and assessing the following aspects of the emergency preparedness program:

c.1 Integrated capabilities for timely response to an emergency condition;

c.2 Contents of selected implementing procedures and methods are adequate;

c.3 Operability of emergency equipment;

c.4 Performance assessment of the emergency response organizations and response personnel;

c.5 Training for the emergency response organizations personnel;

c.6 The development of a credible and logical drill scenario and sequence of events;

c.7 Coordination with outside facilities, agencies, and organizations. 
c.8 Effectiveness of employee and public communications.

d. Verify that the following specific steps are part of the drill and exercises development and conduct program:

d.1 The Facility Emergency Planning Coordinator and scenario development team have prepared a scenario that satisfies the objectives.

d.2 The scenarios reviewed include:

- Identified objectives

- Time and location dependent data

- Narrative Summary, Time Sequence of Events, and Expected Actions

- Controller telephone and/or radio net directory

- Controller assignments

- Evaluator and observer assignments

- $\quad$ Exercise evaluation guide

- Safety considerations.

d.3 The exercise/drill scenarios are reviewed and approved by facility management.

d.4 Briefings have been conducted with the following:

- Controllers

- Evaluators

- $\quad$ Players

- Observers.

e. Documentation of post-drill/exercise critiques should be reviewed. The critiques shall be conducted at the facility with all available ERO participants in attendance.

e.1 Post-drill/exercise critiques are conducted

e.2 Critiques shall include objective discussions of the concerns identified during the drill/exercise and the proposed corrective actions. 
e.3 Strengths, deficiencies, weaknesses, and improvement items identified during the critique(s) are entered into a commitment tracking system.

e.4 A procedure is in place for tracking corrective actions entered into the commitment tracking system.

e.5 A written report is prepared within 20 days. The report summarizes the exercise/drill and outlines deficiencies and corrective actions. 


\section{WERF OPERATIONAL READINESS REVIEW ORR CHECKLIST}

Reviewer

Date

Checklist Designator A. 3.3

\section{Requirements Identification}

1. Element - Emergency Preparedness

2. Sub-element - Emergency Drill

3. Basic References:

DOE Order 5500.3A, "Planning and Preparedness for Operational Emergencies"

DOE Order 5500.4, "Public Affairs Policy and Planning Requirements for Emergencies"

DOE-ID Emergency Plan

EG\&G Idaho Emergency Preparedness Manual

4. Description of Requirement - The facility's Emergency Preparedness Program must provide an emergency drill that demonstrates the knowledge and skills of emergency response organization personnel to respond to and control an emergency effectively, and that demonstrates the capability to plan, conduct, control, evaluate, and critique an emergency drill. The drill shall demonstrate the capability to ensure adequate emergency response in all applicable areas, or the ability of the drill control team to identify and correct inadequate performance.

\section{Review Criteria}

An emergency drill, involving a simulated fire with radioactive materials and/or hazardous materials must be prepared, scheduled, and performed during the ORR. The facility's implementation of the emergency plan and implementing procedures must be evaluated to ensure that response capabilities are adequate to support resumption of operations. The drill selected for demonstration shall be conducted under realistically simulated conditions for the identified credible emergency. To assess the adequacy of performance, the inspector shall:

a. Ensure that the facility's proposed drill objectives and scenario are reviewed by the ORR team prior to conduct of the drill.

b. Determine whether the proposed drill objectives and scenario provide an adequate framework for assessing the acceptability of the emergency preparedness program and its implementation. The major elements of the objectives of the proposed drill should include the following:

b.1 Emergency event detection and classification; 
b.2 Initial notification of on-site and off-site rusponse organizations;

b.3 Communications;

b.4 Command and control;

b.5 Radiological or hazardous material exposure assessment and control;

h.6 Protective action recommendations of on-site and off-site personnel;

b.7 Performance of the emergency response personnel in their assigned roles;

b.8 Emergency resnonse support facilities;

b.9 Recovery and reentry plans;

b.10 On-scene medical support.

c. The assessment of $t$ : adequacy of the proposed $d$ ill scenario should verify that the scenario provides a framework for testing and assessing the following aspects of the WERF Emergency Preparedness Program:

c.1 Integrated capabilities for timely response to an emergency condition;

c.2 Contents of selected implementing procedures and methods are adequate;

c.3 Operability of emergency equipment;

c.4 Performance asses sment of the emergency response organizations and response personnel;

c.5 Training for the emergency response organizations' personnel;

c.6 Development of a credible and logical drill scenario and sequence of events;

c.7 Coordination of outside facility and agency invcivement;

c.8 Effectiveness of employee and public communications.

d. Verify that the following specific steps of the drill development process are documented:

d.1 The facility emergency planning coordinator and scenario development team have prepared a scenario that satisfies the requested objectives;

u.2 The scenario includes all elements required.

d.3 The exercise/drill scenario is appropriately reviewed and approved. 
d.4 Briefings have been conducted as required.

e. Verify the following drill activities are demonstrated by the facility's ERO:

e.1 Proper detection and classification of the emergency events.

e.2 To ensure that a continual emergency assessment capability exists and is effective, the following are evaluated:

e.2.1 The Facility's ERO implements established emergency plans and procedures.

e.2.2 On-scene command personnel assess the following:

- Building and area status

- Prognosis of the emergency event

- Expected duration of the emergency condition.

e.3 Notification procedures and communications equipment are in place.

e.3.1 Effective notification and activation procedures for the facility emergency response organizations are in place and used.

e.3.2 Notifications of the emergency are made to the Shift Superintendent/On Scene Commander and the site-wide authority.

e.3.3 ERO personnel promptly notify building personnel as required.

f. Verify the incident commander performs apprupriate actions upon notification of an emergency as required for the conditions.

g. Verification of implementation of protective actions.

g.1 Verify that the protective action recommendations for the facility have been implemented.

g.2 Verify that all affected personnel have been accounted for.

h. Verify the availability and readiness of the following emergency support teams (as appropriate to the scope of the scenario):

h.1 Medical facilities

h.2 Fire fighting and emergency medical organizations 


\section{h.3 Dose assessment}

\section{h.4 Sampling and Monitoring Field Teams}

h.4.1 Prompt initiation of on-site monitoring and sampling of the release to confirm the composition and magnitude of the release.

h.4.2 Additional on-site sampling and monitoring to redefine or confirm the emergency condition and update the emergency information.

i. The drill control organization shall be provided for the following:

i.1 Controllers that are knowledgeable of responsibilities and the scenario

i.2 Adequate communications resources for controllers

i.3 Improper participant performance is recognized and corrected by control organizations

j. Post-drill critiques should be conducted to provide initial impressions of the drill. The critiques shall be conducted at the facility with all available ERO participants in attendance:

j.1 Strengths, deficiencies, weaknesses, and improvement items identified during the critique(s) and are entered into a commitment tracking system.

j.2 A procedure is in place for tracking corrective actions entered into the commitment tracking system.

j.3 A drill report is prepared and submitted within 20 days as required.

k. General

k.1 Procedures for mitigation activities including facility and process equipment shutdown procedures are in place and effective.

k.2 Logs are kept and all important data, calculations, notifications, and decisions are recorded chronologically.

k.3 Personnel performing key functions at the facility are those who would normally be involved in such activities and are knowledgeable in their duties and responsibilities. 


\section{WERF OPERATIONAL READINESS REVIEW ORR CHECKLIST}

Reviewer

Date

\section{Checklist Designator B.1.1}

\section{Requirements Identification}

1. Element - Health and Safety

2. Sub-element - Fire Protection

3. Basic References:

DOE Order 5480.7, "Fire Protection"

NFPA 13, "Design and Installation of Sprinkler Systems"

NFPA 101, "Code for Safety to Life from Fire in Buildings and Structures"

EG\&G Idaho Procedure 6.2

EG\&G Idaho Procedure 2.6 Par. 2.10, "Preparation of Interface Agreements"

4. Description of Requirement - WERF has implemented a fire protection program and an emergency plan that ensure the protection of personnel and property against loss. The program includes hardware, procedures, design features, training, and staffing in compliance with appropriate regulations. Fire hazard has been adequately evaluated, particularly for the incinerator and plasma arc cutting operations. Reliance on administrative controls is minimized. Regular inspections are conducted.

\section{Review Criteria}

a. Review previous audit findings pertaining to this sub-element to ensure that they have been identified, tracked, and/or resolved satisfactorily.

b. Ensure that WERF conforms to the "Improved Risk Objectives" by providing fire and life safety features designed to reduce property, personnel, and programmatic impacts to acceptable levels.

c. Inspect documentation to ensure that a fire hazard analysis has been performed:

c.1. Determine status of identified deficiencies and corrective actions;

c.2. Ensure that past losses have been analyzed to identify

\section{- $\quad$ Causes}

- Corrective actions 
- Similar situations.

d. Inspect three portable fire extinguishers to ensure that inspections are performed monthly.

e. Inspect records of maintenance and inspections on all fixed fire protection systems to ensure that required inspections are performed.

f. Inspect a copy of the emergency plan and associated records to ensure that they are reviewed by knowledgeable personnel.

g. Interview two supervisors to determine their level of knowledge concerning the content and requirements of the Emergency Plan.

h. Observe at least one simulated abnormal event conducted by WERF Personnel and involving either the incinerator or the plasma arc cutting equipment. Specifically, the simulated event shall be a fire which is not immediately controllable. Evaluate the facility response, availability and use of emergency equipment, and adequacy of procedures.

i. Verify that the maintenance of fire protection equipment is properly scheduled and documented. 


\section{WERF OPERATIONAL READINESS REVIEW ORR CHECKLIST}

Reviewer

Date

\section{Checklist Designator B.1.2}

1. Element - Health and Safety

2. Sub-element - Industrial Safety and Industrial Hygiene

3. Basic References:

DOE Order 5483.1A, "Occupational Safety and Health Program for DOE Contractor Employees at GOCO Facilities"

EG\&G General Policy and Responsibilities 1.d.2

EG\&G Company Procedures Manual, Chapters 2.6 and 2.2

1.2.2 DOE and ID Interim Management Directive 5001, "Safety, Health, and

Environmental Protection"

1.2.3 EDRAM and IDM Chapters 0506, "Occupational Safety and Health Program for EDRA GOCO Contractor Employees"

DOE-ID Order 5480.4, "Environmental Protection, Safety, and Health Protection

Standards"

DOE-ID Order 5480.10, "Contractor Industrial Hygiene Program"

DOE Order 1324.2, "Records Disposition"

WERF Safety Analysis Report, Section 10.

4. Description of Requirement - A program to maintain and improve industrial safety is active. Information is readily available to employees on the hazards of the workplace. The workplace is free from avoidable hazards and complies with appropriate standards. Hazards that cannot be eliminated are clearly marked. Personnel understand safe work practices and employ them in all circumstances. Personal protective equipment is available and used properly. Professional support and equipment are available as required to support the safety program. Regular inspections of facilities and work practices are conducted.

\section{Review Criteria}

a. Review previous audit findings pertaining to this sub-element to ensure that they have been identified, tracked, and/or resolved satisfactorily.

b. Inspect safety instruction signs and locations in the facility where there is a need for general instructions and suggestions relative to safety measures.

c. Assess the safety staff and organization, including the qualifications of the safety engineer. Ensure that management reinforces employee training on the nature of potential hazards in work areas. 
d. Assess work practices to ensure that before repair or maintenance of any equipment or component, the equipment or component is first de-energized and/or isolated, if at all possible.

e. Ensure that notices of employee rights are posted and that responsive action follows inspections.

f. Ensure that the DOE-ID safety and accident prevention program has been implemented.

g. Inspect documents to ensure that a Hazard Communication Plan specific to the WERF Facility has been implemented.

h. Determine by interviews of first-line managers that employees are required to perform assignments in a safe manner.

i. Assess by interviews, review of documentation, and a walkdown of the facility work areas that:

i.1. Where feasible, engineering control measures, process changes, or materials substitutions are used to prevent or minimize exposure to hazards;

i.2. Where appropriate, administrative controls and personal protective equipment supplement engineering controls;

i.3. Personal protective equipment is available and properly used for the types of hazard present.

j. Inspect records and documents to ensure that:

j.1. The results of the monitoring program for toxic materials or harmful physical agents are made available to WERF Personnel;

j.2. An inventory of occupational health hazards is maintained;

j.3. The industrial hygiene staff's evaluation of potential health hazards is documented in written reports;

j.4. The data resulting from occupational environmental monitoring is easily retrievable;

j.5. Records are maintained in accordance with DOE Order 1324.2.

k. Assess through review of program documents that the industrial hygiene staff is qualified and adequate in number and is given sufficient time and authority to design and implement the industrial hygiene program.

1. Assess electrical safety program to be in accordance with 29 CFR 1910. 


\section{WERF OPERATIONAL READINESS REVIEW ORR CHECKLIST}

Reviewer

Date

\section{Checklist Designator B.1.3}

\section{Requirements Identification}

1. Element - Health and Safety

2. Sub-element - Radiation Protection

\section{Basic References:}

DOE Order 5480.11, "Radiation Protection for Occupational Workers"

EG\&G Idaho Procedures Manual, Section 10

EG\&G Idaho Radiological Controls Manual, Chapter 1, Section 3.5

Code of Federal Regulations, Title 49 Section 100-149

WERF Safety Analysis Report, Section 9

4. Description of Requirement - A radiation protection program conforming to applicable regulations and employing the as low as reasonably achievable (ALARA) principle has been implemented. Contaminated areas are minimized and regular surveys are conducted. Dosimetry devices are used properly. Proper work practices are employed in radiation areas. Anti-contamination equipment is used properly, and radioactive waste is minimized by work practices. All staff have a basic understanding of radiation protection. The program meets the criteria specified in the WERF SAR.

\section{Review Criteria}

a. Review previous audit findings pertaining to this sub-element to ensure that they have been identified, tracked, and/or resolved satisfactorily.

b. Review logs of radiological control technicians to verify that the logs are complete, properly executed, and reviewed.

c. Review smear and well-counter logs to verify that the records are complete, properly executed, and that all required information is documented.

d. Examine radioactive material storage areas to ensure that the areas are properly established, maintained, and surveyed. Special attention shall be given to the storage pad area.

e. Inspect radioactive barriers and postings to verify that the areas are properly posted and verified, maintained, and properly equipped where required. 
f. Review documents pertaining to radiation and contamination surveys to verify that:

f.1 All areas requiring a daily, weekly, monthly, or other routine survey are included;

f.2 The results of the routine surveys are properly documented:

f.3 Survey maps are complete, clear, and accurate and correlate to work log entries (if applicable);

f.4 Work procedures have required documented surveys, as required;

f.5 Instrument service checks are documented in the service check logbook.

g. Observe a radiological control technician in performance of a routine or other radiation or contamination survey. Assess the technique and proper documentation of the survey.

h. Review documentation pertaining to radioactive source storage and inventory to ensure that sources are properly managed and controlled.

i. Review at least two work procedures completed within the past three months in which ALARA reviews were required to ensure that:

i.1 The procedure clearly specifies the ALARA concerns for this work;

i.2 ALARA controls are clearly stated;

i.3 The procedure covers all of the areas addressed in the ALARA review form (11.b, from chapter 11 of the EG\&G Idaho Radiological Controls Manual);

i.4 Man-hours and exposures for the work are estimated;

i.5 Exposure summaries are available for personnel who perform the work;

i.6 The work procedure is reviewed to determine methods of exposure reduction or problem elimination.

j. Examine several Radiation Work Permits(RWPs) and Safe Work Permits (SWPs) to ensure that they are complete and properly executed.

k. Review an active job and ensure that the requirements stated on the RWP/SWP reflect the conditions or practices in use at the work area.

1. Assess job coverage by selecting several completed jobs requiring radiological controls and review them for proper documen: : ion, setup, and radiological techniques.

m. Check several areas that have bec:. established for personnel frisking to ensure that they are properiy set up, equipped, anủ maaintáined. 
n. Assess storage, issuing, and use of anti-contamination clothing to ensure that:

n.1 The issue areas are clean and have adequate supplies;

n.2 Sufficient storage areas are established near working areas;

n.3 The laundry sorting area exhibits good housekeeping and proper radiological controls.

o. Review program documentation for temporary dosimetry and exposure recordkeeping to ensure that the program is properly documented, utilized, and administered.

p. Examine portable radiological control instruments to verify that:

p.1 All radiological control instruments in use are recorded in the Master Log book;

p.2 All instruments in use are in current calibration and source check;

p.3 The daily use source check source is correctly marked;

p.4 The current inventory of instruments is adequate.

q. Assess remote area monitor (RAM) and constant air monitor (CAM) operations to ensure that:

q.1 The routine sheet for complete and timely documentation of all required instrument checks is completed;

q.2 The air filter data sheets are complete and current;

q.3 Charts on the CAMs have proper initials, date, and other appropriate information that documents when filters were changed or source checks are completed;

q.4 The alarm settings are at normal set points or are posted to reflect tests in progress and justification for raised alarm values.

r. Review records to ensure that all WERF Site-Specific Radiological Control Training is documented. 


\section{WERF OPERATIONAL READINESS REVIEW ORR CHECKLIST}

Reviewer

Date

Checklist Designator B.1.4

\section{Requirements Identification}

1. Element - Health and Safety

2. Sub-element - Records and Performance Indicators

3. Basic References:

DOE Order 5483.1A, "Operational Safety and Health Procedures"

29 CFR 1910, OSHA Safety and Health Standards

EG\&G Idaho Safety Manual

4. Description of Requirement - Records are kept as required, including injury and accident logs, facility survey results, radiation exposure records, lock and tag logs, and other records maintained by WERF. Performance indicators are maintained on important items as a means to measure and improve health and safety performance.

\section{Review Criteria}

a. Review previous audit findings pertaining to this sub-element to ensure that they have been identified, tracked, and/or resolved satisfactorily.

b. Determine that records pertaining to health and safety required to be maintained by WERF are properly maintained, including:

b.1. Injury and Accident Reports (OSHA Form 200) and supporting documents;

b.2. Facility survey and radiation exposure logs;

b.3. Facility Industrial Hygiene surveys and records (hearing conservation records, medical monitoring records, toxic chemical surveys, etc.);

\section{b.4. Facility lock and tag logs.}

c. Inspect records of performance indicators submitted to the EG\&G Idaho department manager to ensure that performance pertaining to health and safety issues is identified, updated, and tracked. 


\section{WERF OPERATIONAL READINESS REVIEW ORR CHECKLIST}

Reviewer

Date

\section{Checklist Designator B.1.5}

\section{Requirements Identification}

1. Element - Health and Safety

2. Sub-element - Interfaces, authority, and responsibility

3. Basic References:

DOE Order 5480.5, "Safety of Nuclear Facilities"

EG\&G Idaho Procedures Manual

4. Description of Requirement - Interfaces that support health and safety organizations are clear and understood. Staffing and scheduling is adequate. Authority and responsibility of support staff is clear. WERF has a list of all interface agreements in force; the agreements are sufficient in number and scope to support WERF Operations.

\section{Review Criteria}

a. Review previous audit findings pertaining to this sub-element to ensure that they have been identified, tracked, and/or resolved satisfactorily.

b. Review a list of interface agreements in force provided by WERF. Assess the completeness and applicability of the interface agreements list, and note any areas not covered by an agreement that should be.

c. Review at least two interface agreement documents to ensure that:

c.1. The agreement is signed by a person with approval authority for each organization involved;

c.2. The agreement is between organizations and not individuals;

c.3. The purpose of the agreement is clearly and concisely stated, and defines the responsibilities of each organization under the agreement.

d. Review a list of the available support staff and the percentage of their time committed to WERF to ensure that the staffing and scheduling of support staff is adequate. 
e. Interview two support staff to determine that the roles and authority of support staff personnel are clearly understood;

f. Interview two operations personnel to determine that the roles, authority, and availability of support staff are understood. 


\section{WERF OPERATIONAL READINESS REVIEW ORR CHECKLIST}

\section{Reviewer}

Date

\section{Checklist Designator B.2.1}

\section{Requirements Identification}

1. Element - Environmental Protection

2. Sub-element - Resource Conservation and Recovery Act (RCRA)

3. Reference

40 CFR 61.93, 609 and 622

40 CFR 261

40 CFR 262, Subparts B, C, and D

40 CFR 263, Subpart B

40 CFR 265, Subparts B, C, D, E, F, I, J, O, and BB

EG\&G Idaho Procedures 8.1, 8.2, 8.3, 8.17, 8.18, and 8.20

EG\&G Emergency Preparedness Manual (EPM) 2.0

WERF Part A Permit

WERF Part B Permit Application

4. Description of Requirement - WERF meets the RCRA requirements for hazardous waste generators and for treatment, storage, and disposal facilities; it also meets transportation and training requirements. WERF has in place procedures to ensure timely and accurate reporting of environmental parameters to appropriate agencies.

\section{Review Criteria}

a. Review previous audit findings pertaining to this sub-element to ensure that they have been identified, tracked, and/or resolved satisfactorily.

b. Review WERF RCRA Part A and Part B Permit application for content, proper execution, and proper format.

c. Review a list of all environmental permits currently in force or applied for, provided by WERF. Assess the list of permits for completeness and applicability.

d. Review a listing of reports and reporting criteria for environmental permits and regulations as provided by WERF. Assess the list for completeness and applicability.

e. Review the procedures at WERF for providing the reports listed in section d. above. Ensure that procedures are in place to provide for all required reporting in an accurate and timely manner. 
f. Interview two persons isponsible for the reporting listed in section d. above. Assess their level of knowledge concerning the procedures for reporting, and the permit requirements for the reports for which WERF is responsible.

g. Review the Contingency Plan to ensure that:

g.1. The assignment list of emergency coordinators is current and accurate;

g.2. The notification list is current and accurate.

h. Conduct a thorough walkthrough inspection of the RCRA waste storage and processing areas to ensure that:

h.1. Stated Part A storage capacity has not been exceeded;

h.2. Incompatible wastes are separated by a dike, berm, or a similar structure;

h.3. Wastes are contained in a secondary containment that is free from cracks, damage, or deterioration that could lead to a release of hazardous waste to the environment;

h.4. Containers are properly marked with a Hazardous Waste label containing all required information:

- Generator's name and address

- Generator's EPA identification number

- Waste description

- All applicable waste codes

- $\quad$ Required Federal "Hazardous Waste" warning.

h.5. Containers are secured except when adding or removing waste from the container;

h.6. No wastes containing waste codes other than those included on the Part A are stored on site;

h.7. All containers containing a Land Banned waste are dated, and have not exceeded one year unless covered under a national variance or a site-specific exclusion;

h.8. All emergency supplies änd equipment required by the Contingency Plan is in place and functional;

h.9. Satellite accumulation areas do not have more than 55 gallons of hazardous waste; 
h.10. Accumulation areas are adequately segregated and marked, and all drums in such areas are marked with the words "Hazardous Waste," and the accumulation start date.

i. Inspect the facility RCRA training records to ensure that:

i.1. All personnel engaged in waste handling activities are trained in accordance with OSHA 1900.120, "Hazardous Waste Operations;"

i.2. All personnel engaged in activities involving the management of hazardous wastes are trained in appropriate site specific topics pertaining to RCRA in accordance with 40 CFR 265.

i.3 Respiratory equipment fit testing has been documented.

i.4 Training of personnel in the use of personal protective equipment has been documented.

j. Inspect facility records to ensure that:

j.1. All testing of waste materials is performed and documented as per the Waste Analysis Plan in the Part A application and part 265 of 40 CFR;

j.2. All incinerator stack and ash testing is performed and documented as per the Part A appiication and part 265 of $40 \mathrm{CFR}$;

j.3. No feed rate, temperature, particle size, or material form restrictions stated in the Part A application and part 265 of 40 CFR have been violated;

j.4. RCRA facilities inspections are performed, per Part A application and part 265 of $40 \mathrm{CFR}$, and deficiencies are noted.

k. Inspect the Operating Record for the RCRA facilities to ensure that the following records are kept:

k.1. All received manifests and Land Ban forms;

k.2. All outbound manifests and Land Ban forms;

k.3. All biennial reports;

k.4. All unmanifested waste reports;

k.5. Documentation of all events when the Contingency Plan has been enacted;

k.6. Documentation of all spills or releases of hazardous wastes at the facility; 
k.7. All Notices of Deficiency, Notices of Violation, and Consent Orders issued by the EPA or State of Idaho to the facility;

k.8. Documentation of waste analysis and acceptance;

k.9. Documentation of agreements with local agencies, or documentation of refusal to enter into agreements to provide emergency services to the facility.

1. Interview staff to establish:

1.1 Understanding of RCRA requirements;

1.2 Level of concern for RCRA issues. 


\section{WERF OPERATIONAL READINESS REVIEW ORR CHECKLIST}

Reviewer

Date

Checklist Designator B.2.2

Requirements Identification

1. Element - Environmental Protection

2. Sub-element - Air Pollution Control

3. Basic References:

IDAPA 16.01.1000, Idaho Dept. of Health \& Welfare

40 CFR 52

40 CFR 61

EG\&G Idaho Procedure 8.4

4. Description of Requirement - WERF has obtained the State of Idaho air pollution control permits for a stationary source; the facility also complies with the National Emissions Standards for Hazardous Air Pollutants (NESHAP) requirements. The proper training programs are in place to ensure continued compliance with statutes related to air quality.

\section{Review Criteria}

a. Review previous audit findings pertaining to this sub-element to ensure that they have been identified, tracked, and/or resolved satisfactorily.

b. Review training records and interview staff to ensure that air and NESHAP training has been received by the cognizant staff.

c. Review the WERF Permit to Construct Application to ensure accuracy.

d. Review procedures/plans for performance testing upon start-up to ensure that:

d.1. All applicable sampling can be performed by the facility, or that outside assistance will be provided;

d.2. A receiving laboratory is identified and shipping procedures for the laboratory are specified;

d.3. The requested data from the sampling is as required by the air permit;

d.4. That emission testing will be performed within 60 days of full production, but no later than 180 days after startup. 
e. Observe sampling personnel simulate use of sampling equipment and procedures to ensure that they are familiar with the task.

f. Review the procedures and operation of new isokinetic stack monitoring equipment modifications to ensure that:

f.1. Equipment operates as designed;

f.2. Procedures for the operation of the equipment are in place;

f.3. Records are appropriate, and are properly maintained;

f.4. Procedures for reporting data accumulated are in place, and that they address required reporting. 


\section{WERF OPERATIONAL READINESS REVIEW ORR CHECKLIST}

Reviewer

Date

Checklist Designator B.2.3

\section{Requirements Identification}

1. Element - Environmental Compliance

2. Sub-element - Superfund Amendment and Reauthorization Act

3. Basic References:

40 CFR 370

40 CFR 355

40 CFR 372

EG\&G Idaho Procedure 8.6

4. Description of Requirement - The requirements associated with the Superfund Amendment and Reauthorization Act (SARA) are met at the WERF Facility. All procedures and reporting requirements for toxic chemical releases and recordkeeping relating to hazardous chemicals located in the facility are in place.

\section{Review Criteria}

a. Review previous audit findings pertaining to this sub-element to ensure that they have been identified, tracked, and/or resolved satisfactorily.

b. Review toxic chemical reports generated and submitted to the Environmental Technical Support Unit (ETS).

c. Review all Substance Release Report Forms (ID 5480.11) generated by WERF over the past three years.

d. Interview the assigned personnel to assess their understanding of reporting requirements and threshold values under SARA Title III. 


\section{WERF OPERATIONAL READINESS REVIEW ORR CHECKLIST}

Reviewer

Date

\section{Checklist Designator B.2.4}

\section{Requirements Identification}

1. Element - Environmental Protection

2. Sub-element - National Environmental Policy Act

3. Basic References:

42 USC 4321-4347 - NEPA

40 CFR 1500 - 1508 CEQ Regulations

DOE Order 5400.1, "General Environmental Protection Policy"

DOE Order 5400.4, "Comprehensive Environmental Response, Compensation, and Liability Act Requirements"

DOE Order 5440.1C, "National Environmental Policy Act Compliance Program"

DOE-ID Supplemental Dir 5440.1

EG\&G Idaho Procedure 8.5

4. Description of Requirement - The requirements associated with the National Environmental Policy Act (NEPA) have been met for WERF.

\section{Review Criteria}

a. Review previous audit findings pertaining to this sub-element to ensure that they have been identified, tracked, and/or resolved satisfactorily.

b. Review training records and interview staff to ensure that NEPA training requirements have been met.

c. Review all NEPA documentation associated with the WERF Project; check for appropriate signatures and ensure that the necessary DOE NEPA approvals have been received. 


\section{WERF OPERATIONAL READINESS REVIEW ORR CHECKLIST}

Reviewer

Date

\section{Checklist Designator B.2.5}

\section{Requiremerts Identification}

1. Element - Environmental Protection

2. Sub-element - Water Pollution Prevention

3. Basic References:

40 CFR 122

DOE Order 5400.1, "General Environmental Protection Policy" IDAPA 16.01

4. Description of Requirement - The WERF Facility has the procedures in place to ensure compliance with the requirements associated with the Clean Water Act.

\section{Review Criteria}

a. Review previous audit findings pertaining to this sub-element to ensure that they have been identified, tracked, and/or resolved satisfactorily.

b. Review shallow injection well inventory to ensure that no hazardous waste or radioactive waste is being injected.

c. Review WERF storm water run off monitoring and reporting records to ensure:

c.1. Samples are being analyzed and reported as per the facility storm water runoff permit;

c.2. Samples are taken during storm events as specified in the Storm Water runoff permit.

d. Interview assigned sampling personnel to assess their understanding of the sampling requirements for storm water samples.

e. Perform a walkdown inspection of the site perimeter to ensure there are no point discharges to surface waters. 


\section{WERF OPERATIONAL READINESS REVIEW ORR CHECKLIST}

\section{Reviewer}

Date

\section{Checklist Designator B.2.6}

\section{Requirements Identification}

1. Element - Environmental Protection

2. Sub-Element - Regulatory Requirements Document

3. Basic References: WERF Regulatory Requirements Document

4. Description of Requirement - WERF has implemented the Regulatory Requirements Document.

\section{Review Criteria -}

a. Review the Regulatory Requirements Document (RRD) for WERF to ensure that it is current, and is approved by proper authority.

b. Review the implementation of the RRD provided by WERF. Inspect as many documents as necessary to assess the status of implementation.

c. Ensure that a mechanism is in place to review and update the RRD upon changes in relevant environmental statues and regulations.

d. Ensure that a mechanism is in place to change operating procedures and other documents when there is a change to the RRD.

e. Ensure that a mechanism is in place to provide for training of operations personnel on all changes or modifications to the RRD. 


\section{WERF OPERATIONAL READINESS REVIEW ORR CHECKLIST}

\section{Reviewer}

Date

\section{Checklist Designator B.3.1}

\section{Requirements Identification}

1. Element - Safety Analysis Report/Technical Safety Requirements

2. Sub-element - SAR Approval

3. Basic References:

DOE Order 5480.22, "Technical Safety Requirements"

DOE Order 5480.23, "Nuclear Safety Analysis Reports"

4. Description of Requirement - WERF has an SAR approved in accordance with DOE Order 5480.23. WERF has a mechanism by which the SAR is reviewed annually; updates are submitted to the Program Secretarial Officer (PSO). All copies of the SAR are current.

\section{Review Criteria}

a. Review previous audit findings pertaining to this sub-element to ensure that they have been identified, tracked, and/or resolved satisfactorily.

b. Determine by inspection of documents that:

b.1. WERF has an SAR approved by the PSO;

b.2. WERF has in place a document control system to ensure that all users of the SAR have current copies.

b.3. Inspect as many SAR copies as are available to determine that they are current copies.

c. Determine through inspection of WERF procedures that a mechanism for the annual review of the SAR, and submission of updates to the PSO, is in place. 


\section{WERF OPERATIONAL READINESS REVIEW ORR CHECKLIST}

Reviewer

Date

Checklist Designator B.3.2

\section{Requirements Identification}

1. Element - Safety Analysis Report/Technical Safety Requirements

2. Sub-element - TSR Approval

3. Basic References:

DOE Order 5480.21, "Unreviewed Safety Questions"

DOE Order 5480.22, "Technical Safety Requirements"

DOE Order 5480.23, "Nuclear Safety Analysis Reports"

4. Description of Requirement - WERF has an approved TSR that fully implements the requirements of the SAR. Procedures, facility design features, equipment, and staff are prepared to meet every aspect of these documents. The implementing features of the SAR/TSR can be traced from the SAR/TSR to the implementing procedure or facility feature. Limiting conditions of operation that require action in advance of a TSR limit are clearly established and implemented. A mechanism is in place to provide for changing the TSR upon changes in source documents. Training is documented for all TSR changes.

\section{5. $\quad$ Review Criteria}

a. Review previous audit findings pertaining to this sub-element to ensure that they have been identified, tracked, and/or resolved satisfactorily.

b. Ensure that WERF has:

b.1. Prepared a TSR for the facility;

b.2. Submitted the TSR to the PSO for approval;

b.3. Operates the facility in accordance with the TSR as approved by the PSO and including any modifications required by the PSO.

c. Inspect several key operating procedures to ensure that:

c.1. Requirements of the TSR are incorporated into the operating procedures;

c.2. Limiting conditions of operation are clearly and accurately defined in the operating procedures; 
c.3. A mechanism is in place to ensure that all changes or modifications to the SAR/TSR are incorporated into the operating procedure in an expeditious manner.

c.4. A mechanism is in place to ensure that all operations personnel are trained on any changes or modifications to the SAR/TSR and operating procedures.

d. Review the TSR to ensure that:

d.1. The TSR is written in a clear and concise manner, in language that is directed at and clearly understandable by those in the facility operating organization.

d.2. The TSR is kept current at all times so that it reflects the facility as it exists, and is analyzed in SARs.

d.3. That it is to be reviewed at least once a year along with the facility SAR.

d.4. Only the TSR currently approved by the PSO is used for operation of the facility.

e. Review procedures in place to deal with unreviewed safety questions (USQs) to ensure compliance with DOE Order 5420.21.

e.1 Verify that no USQs are currently outstanding. 


\section{WERF OPERATIONAL READINESS REVIEW ORR CHECKLIST}

Reviewer

Date

Checklist Designator B.4.1

\section{Requirements Identification}

1. Element - Operations and Maintenance Performance

2. Sub-element - Conduct of Operations

3. Basic References:

DOE Order 5480.19, "Conduct of Operations."

DOE Order 5484.1A, "ES\&H Protection Information Report Requirements."

EG\&G Conduct of Operations Manual

WERF Conduct of Operations Matrix

4. Description of Requirement - Conduct of Operations has been implemented in accordance with the EG\&G Idaho Conduct of Operations Manual and as described in the SAR for the six processes and operations at WERF. Conduct of Operations is consistent with the philosophy of DOE Order 5480.19.

5. Review Criteria - To ensure compliance with Conduct of Operations guidelines, the following areas, associated with all six WERF Processes and Operations, require investigation:

a. Review previous audit findings pertaining to this sub-element to ensure that they have been identified, tracked, and/or resolved satisfactorily.

b. Operations organization and administration.

b.1. Ensure that WERF has implemented written standards for operating activities by inspecting a minimum of one operating or abnormal operational procedure for each of the six WERF Processes and Operations.

b.2. Interview several operating and supervisory personnel to assess that written standards are being effectively communicated to personnel through training, supervisory monitoring, and guidance of work involving plant operations.

b.3. Inspect program documentation to ensure that:

b.3.1 The program includes inspections, audits, reviews and self-assessments to identify deficiencies; 
b.3.2. Deficiencies are documented, tracked, and trended;

b.3.3. Corrective action is documented;

b.3.4. Workers and supervisors are held accountable for performance;

b.3.5. Formalized management and supervisory training is incorporated into training programs;

b.3.6. Facility guidance exists which describes safety preplanning requirements for all operational activities.

b.4. All expected upset and off-normal conditions defined in the SAR or other approved WERF Documents have been identified and are tested or simulated by procedural validation/walkthrough.

c. Shift routines and operating practices.

c.1. Observe personnel during actual or simulated operations, including at least one simulated abnormal event, to ensure that shift operating personnel conduct their activities professionally and in accordance with good practices. More than one process or operation should be included.

c.2. Observe that the on-duty cognizant manager maintains authority and responsibility for all operations conducted on his shift.

c.3. Inspect round sheets or logs to ensure that required inspections are documented.

c.4. Observe or interview several operating personnel to assess their knowledge of and proper use of safety equipment and procedures.

c.5. Check that only properly trained and authorized personnel operate plant equipment.

c.6. Inspect the shift operating area, or base, and determine that the area is free of distracting written material or devices.

d. Control area activities.

d.1. Observe activities in the "at the controls" area during actual or simulated operation, including at least one simulated abnormal event, to determine that:

d.1.1. Control area is clearly identified, and access is limited to personnel on official business;

d.1.2. Essential activities only are conducted in the control area; 
d.1.3. All activities are conducted in a professional manner;

d.1.4. Operators in control area are frequently monitoring their indications, and are attentive at all times to indicators and alarms;

d.1.5. Administrative duties assigned to control area personnel are minimized:

d.1.6. Only authorized personnel operate equipment in the control area;

d.1.7. Access to the control area is granted by designated individuals.

e. Communications.

e.1. Ensure that procedures and policies are in effect to ensure reliable, accurate communication of information within the facility.

e.2. Determine through review of documentation and interviews of operating personnel that methods are employed to promptly alert personnel of emergencies, and these methods are periodically tested.

e.3. Observe that the facility public address system is administratively controlled to ensure effectiveness.

e.4. Determine through monitoring of facility communications during actual or simulated operations, including at least one simulated abnormal event, that:

e.4.1. Only approved abbreviations and acronyms are used;

e.4.2. Oral communications are clear and concise, with sender and receiver clearly identified;

e.4.3. Instructions involving operation of equipment are repeated back to the sender to ensure instructions are understood.

f. Control of on-shift training.

f.1. Observe on-the-job training conducted by WERF Personnel to determine that:

f.1.1. On-shift training is conducted in accordance with a training program that identifies specific accomplishments to be performed, and knowledge requirements are identified;

f.1.2. Requirements are understood by trainee and instructor;

f.1.3. Training is conducted by a qualified operator; 
f.1.4. The instructor observes and effectively controls the trainee operations to preclude trainee errors that could adversely impact the facility;

f.1.5. Instructor verifies all entries recorded in round or log sheets by the trainee.

g. Investigation of abnormal events. (DOE 5484.1A)

g.1. Review documentation of past abnormal events and present procedures to determine that:

g.1.1. Events which occur at WERF that adversely affect operations, personnel safety, or DOE requirements are properly investigated;

g.1.2. Investigations are the responsibility of the operations supervisor or cognizant manager and are conducted by personnel who are knowledgeable and trained;

g.1.3. Structured review of abnormal events occurs, including event reconstruction, event analysis and evaluation, root cause determination, and corrective action determination;

g.1.4. Investigative reports are issued and approved by the facility manager, and lessons learned from the event incorporated;

g.1.5. Training on events is conducted.

g.2. Review documentation to ensure that periodic reports on events, causes, and trends are submitted to appropriate supervisory personnel.

h. Control of equipment status.

h.1. Interview the on-shift operating supervisor to determine that he/she is cognizant of the status of equipment in the plant, including:

- $\quad$ Equipment status

- System alignments

- Equipment locking and tagging

- Equipment deficiency identification and documentation

- $\quad$ Authorization and status of work

- $\quad$ Equipment testing and return to service

- $\quad$ Alarm status. 
h.2. Review procedures to determine that administrative control for installation of temporary modifications of plant equipment exists.

h.3. Ensure by inspection of documents and interviews that operating personnel have and use the latest drawings and specifications for plant equipment, and are aware of any changes in the references.

h.4. Review documents and logs to ensure there is documentation of compliance with requirements of operational limits.

i. Independent verification.

i.1. Ensure that WERF has an independent verification program in place and functioning for safety significant systems, and that other systems are included, where prudent.

i.2. Review the program to determine that it includes elements to ensure independent verification of components when

i.2.1. Removing equipment from service.

i.2.2. Restoring systems from extended shutdown periods

i.2.3. Performing periodic checks of critical equipment.

i.3. Review the program to ensure that it addresses verification techniques and training of operators on independent verification.

j. Logkeeping.

j.1. Inspect several independent operating logs to ensure that the information entered provides an accurate history of facility operations.

j.2. Determine that the logs inspected in j.1. contain documentation of

- $\quad$ Actions taken

- Activities completed

- Transfer of information among operators

- Data necessary for event reconstruction.

j.3. Check by inspection that log entries are legible, concise, and are periodically reviewed by supervisory personnel.

j.4. Determine if logs are preserved for the life of the facility, and are retrievable. 
k. Operations turnover.

k.1. Attend two separate supervisory shift turnovers to ensure that personnel:

k.1.1. Utilize a turnover checklist;

k.1.2. Review pertinent documents;

k.1.3. Perform appropriate walkdowns;

k.1.4. Perform a discussion and formal exchange of responsibility.

k.2. Attend two separate operating personnel shift turnovers to ensure that personnel:

k.2.1. Review pertinent documents;

k.2.2. Perform appropriate walkdowns;

k.2.3. Perform a discussion and formal exchange of responsibility.

k.3. Determine that the same procedure is used in watch turnovers during a shift by observation of operations.

k.4. Attend a crew briefing conducted by the operating supervisor as required, either before turnover, or after.

1. Operations aspects of unique processes.

1.1. Perform formal or informal interviews of several operating personnel of different levels to assess:

1.1.1. WERF Operating Personnel's understanding of all processes at the facility;

1.1.2. Operating personnel's ability to recognize out of specification or adverse conditions on the equipment they operate;

1.1.3. capability of operating personnel for providing appropriate, timely corrective action.

1.2. Determine, through interviews and review of documentation, that there is active communication between process sections and operators.

m. Required reading.

m.1. Inspect the required reading file to ensure that appropriate reading assignments are made. 
m.2. Check that a required date for completion of the required reading is assigned, and completion of the assignment by operation personnel is documented.

m.3. Ensure the file is periodically reviewed by supervisory personnel to ensure compliance.

n. Timely orders to operators.

n.1. Ensure that a means for the communication of short-term information and administrative instructions to operating personnel is implemented.

n.2. Ensure that orders are segregated into daily and long-term orders.

n.3. Check that outdated or no longer applicable orders are promptly removed or cancelled.

o. Operator aid posting.

o.1. Ensure that posted operator aids are approved for posting by inspecting several posted aids.

o.2. Observe operators using posted operator aids to ensure that the aids are not used in lieu of approved procedures.

o.3. Ensure that aids inspected in q.1. are documented in a list of posted operator aids.

0.4. Assess that operator aids are reviewed periodically to ensure they continue to be correct and necessary.

p. Equipment and piping labeling.

p.1. Inspect several components and piping for proper labelling.

p.2. Interview several operating personnel of different levels to ensure that the labeling program is clearly understood by operating personnel.

p.3. Assess that lost or damaged labels are identified and replaced on an ongoing basis. 


\section{WERF OPERATIONAL READINESS REVIEW ORR CHECKLIST}

Reviewer

Date

\section{Checklist Designator B.4.2}

\section{Requirements Identification}

1. Element - Operations and Maintenance Performance

2. Sub-element - Conduct of Maintenance

3. Basic References:

DOE Order 4330.4A, "Maintenance Management Program"

WERF Maintenance Management Program Implementation Plan

4. Description of Requirement - Maintenance activities comply fully with DOE Order 4330.4A, Maintenance Management Program, as defined by the WERF Maintenance Implementation Plan.

5. Review Criteria : To ensure that the maintenance program for all facilities, systems, and components at WERF contains the required elements, the following areas need to be investigated:

a. Review previous audit findings pertaining to this sub-element to ensure that they have been identified, tracked, and/or resolved satisfactorily.

b. Assess the development of an integrated approach to maintenance so that working relationships are developed among all organizational units that support the maintenance function (e.g., operations, health physics, stores, quality control, engineering, procurement, and modifications).

c. Assess the effectiveness the maintenance program long-range planning.

d. Ensure that the preventative maintenance staff in the post-start up organization is adequate and has sufficient personnel and time for training and administrative activities, including:

d.1. A written or practical test to demonstrate a minimum level of competence;

d.2. A training and qualification program should be developed for maintenance supervisors, planners, and craftspersons;

d.3. All maintenance management and supervisory positions should be held by EG\&G Idaho personnel. 
e. Assess the use of maintenance goals as a management tool for involving cognizant facility groups in improving maintenance performance and for measuring maintenance effectiveness.

f. Assess the use of a performance feedback program, such as performance appraisals, to evaluate facility maintenance personnel.

g. Determine the progress of implementing a maintenance training and qualification program consistent with DOE Order $4330.4 \mathrm{~A}$ to develop and maintain the knowledge and skills needed by personnel to effectively perform maintenance activities, including:

g.1 Ensuring that on-the-job training (OJT) will be a formal part of the maintenance training program;

g.2 Review of employees' training accomplishments prior to qualifying them for a given task;

g.3 Training of a select group or team in root-cause analysis in addition to their technical training;

g.4 Ensuring that the maintenance manager is directly involved in approving and periodically reviewing the maintenance training program;

g.5 Establishing a formalized training program that addresses and provides the necessary training to develop and maintain management and supervisory skills.

h. Ensure that maintenance facilities, equipment, and tools fficiently support facility maintenance and maintenance training, including:

h.1 A detailed master list of equipment, components, and structures in the maintenance program;

h.2. Establish methods to provide for storage, issuance, and maintenance of an adequate and readily available supply of tools and equipment, and for the development of special tools and equipment needed in the maintenance program.

i. Inspect maintenance program documents and perform formal or informal interviews with maintenance personnel to determine that:

i.1. The maintenance manager approves the preventive maintenance program, including new or revised preventive maintanance actions and their frequencies;

i.2. Preventive maintenance actions are scheduled at appropriate intervals;

i.3. Written procedures are developed for all work that could resuit in a significant process transient, degraded facility reliability, or a personnel or equipment hazard; 
i.4. Format and technical accuracy of a new or revised procedure is verified;

i.5. Procedures are validated with a final review to ensure their usability and correctness;

i.6. The approval is consistent with facility technical specifications or their equivalent and administrative procedures;

i.7. Procedures are located to be readily available and clearly identified to ensure the user can determine the purpose, applicability, physical completeness, and proper approval;

i.8. Administration of the procedure program is clearly defined;

i.9. All work requests or work packages are reviewed by the planner;

i.10. The work control system provides the means for identifying and recording the status of all valid work requests;

i.11. Establishment of meaningful priorities that determine how soon to start on a work request;

i.12. The planning group (or maintenance supervisors) maintain the status of all open work requests and preventive maintenance items that are overdue or coming due;

i.13. Maintenance activities are controlled so that maintenance practices are effective in maintaining a safe and reliable facility operation;

i.14. That the facility has an administrative procedure describing the work control system;

i.15. That maintenance performed on facility systems is controlled by the facility work request or another approved work control document;

i.16. Maintenance supervisors routinely monitor work in progress to verify that maintenance activities are conducted in accordance with DOE and facility policies and procedures:

i.16.1. A post job review should be held with the craftsperson involved;

i.16.2. Feedback should be provided to planning, scheduling, and maintenance personnel to highlight areas that were exemplary and areas that needed improvement.

j. Inspect at least two work documents to ensure that post-maintenance testing is performed to verify that components will fulfill their design function when returned to service after maintenance. 
k. Review policies for the procurement of parts, material, and services.

1. Ensure that all phases of receiving, inspecting, handling, storing, and retrieving and issuing equipment, parts, and materials for maintenance are governed by effectively implemented policies and procedures. Ensure that procedures are in place for suspect parts, and that the procedures are effective.

m. Ensure that the program for control and calibration of measuring and test equipment (M\&TE) is consistent with the quality assurance requirements of DOE Order 4330.4A.

n. Inspect two pieces of M\&TE to ensure a unique identification number is permanently marked on or attached to the M\&TE (the identification number may consist of the manufacturer's serial number).

o. Ensure that a master list of all controlled M\&TEs is being maintained. If separate organizations control their own M\&TE, each organization should maintain or have access to a list of its own equipment.

p. Ensure that management conducts periodic inspections of equipment and facilities to assure an excellent facility condition:

p.1. Ensure that personnel involved in inspection activities are informed as to the techniques required to perform facility condition inspections;

p.2. Ensure that administrative procedures that describe the inspection program define expected standards, provide for documentation of deficiencies, provide for a means to follow up on deficiency corrective actions, assign responsibilities for program implementation, and establish a means to measure program effectiveness;

p.3. Rotate inspectors periodically through the various inspection areas;

p.4. Prepare a list of all deficiencies not included in the work control system or some other corrective action system with responsibility for correction or disposition of each deficiency;

p.5. Ensure that the results of maintenance performance indicators, goals and objectives, and other related information are developed, trended, and reported to provide feedback.

q. Ensure that the maintenance history of all equipment is documented. The maintenance history program defines the type of data that should be collected and recorded.

r. Ensure that procedural control over modifications exists, so that they are accomplished in accordance with the requirements and limitations of applicable procedures, codes, standards, specifications, licenses, and predetermined safety restrictions identical to or commensurate with those of the item being modified. 
s. Ensure that a mechanism exists where temporary repairs to the facility that allow equipment to remain in or be returned to service receive a safety review in accordance with the facility temporary modification program.

t. Review the program to prevent equipment and building damage due to cold weather.

u. Verify the implementation of graded approach to maintenance requirements as specified in DOE Order 4330.4A and the EG\&G Idaho Maintenance Management Program. 


\section{WERF OPERATIONAL READINESS REVIEW ORR CHECKLIST}

Reviewer

Date

\section{Checklist Designator B.4.3}

\section{Requirements Identification}

1. Element - Operations and Maintenance Performance

2. Sub-Element - Procedure Changes and Training

3. Basic References:

DOE Order 5480.22, "Technical Safety Requirements"

DOE Order 5480.23, "Nuclear Safety Analysis Reports"

4. Description of Requirement - Procedures for development of existing WERF routine, abnormal, and casualty procedures include technical review by systems engineering experts and validation of the procedures by actual facility walkdown.

\section{Review Criteria}

a. Review previous audit findings pertaining to this sub-element to ensure that they have been identified, tracked, and/or resolved satisfactorily.

b. Review the WERF Administrative Procedures to ensure that a mechanism is in place to:

b.1. Provide for the identification of procedural problems, and the need for procedure review and/or revision;

b.2. Provide for a thorough review of proposed changes by appropriate qualified technical and administrative personnel;

b.3. Provide for a clear and understandable path for authorization of changes to operating procedures;

b.4. Provide for a method of controlling the entry of changes, and of notification and training on the entered changes to operating personnel in an expeditious manner.

c. Inspect several operating procedures from different storage and operating locations to ensure that only current, authorized copies of the procedures are available for use by operating personnel.

d. Verify procedures for development of existing normal, abnormal, and casualty operation procedures include technical and operational verification. 
d.1 Review WERF Procedures for development of operational procedures to ensure that the required elements were included.

d.2 Select a representative sample from each procedure category for each of the six processes or facilities and verify that the elements of the procedure development process were met.

d.3 In coordination with CRA B.4.1, observe execution or walkthrough of selected procedures to verify that the development process was successful (i.e., the selected procedures can be conducted in the plant).

d.4 Review elements of the test program as a method of verifying operability of WERF Procedures. 


\section{WERF OPERATIONAL READINESS REVIEW ORR CHECKLIST}

Reviewer

Date

\section{Checklist Designator B.4.4}

Requirements Identification

1. Element - Operations and Maintenance Performance

2. Sub-element - Waste Acceptance Criteria

3. Basic References:

DOE Order 5820.2A, "Radioactive Waste Management"

DOE/ID-10112, Rev. 4

40 CFR 262, 263, and 265, "Environmental Protection," applicable sections

49 CFR, "Transportation"

4. Description of Requirement - Waste accepted for treatment or storage at WERF meets written requirements of a formal WAC. Implementing procedures, facilities and equipment, and personnel are available to ensure that all receipts are documented as meeting the WAC or to take corrective action when they do not. The WAC, and supporting documentation, is audited annually, and appropriate corrective action for discrepancies is taken.

\section{Review Criteria}

a. Review previous audit findings pertaining to this sub-element to ensure that they have been identified, tracked, and/or resolved satisfactorily.

b. Administrative Documents - Review WERF Documents to ensure that:

b.1. Each waste generator has an approved Waste Certification Program Plan on file with WROC and RWMC Technical Programs, as applicable.

b.2. Review several WACs to ensure low-level waste and mixed low-level waste shipped to WERF has been properly characterized by the generator to ensure proper handling and treatment;

b.3. Review documentation of several waste packages to ensure that the following documentation has been prepared and submitted by the waste enerator for each package sent to WERF.

\section{b.3.1. Form ID F 5840.3A, "U.S. DOE Hazardous Material Shipping Record."}


b.3.2. Form ID F 5820.2, "Stored, Disposed, or Processed Solid Radioactive Waste Form;"

\section{b.3.3. Waste Characterization Reports (WCRs), approved by RWMC and WERF;}

\section{b.3.4. Certification Statements, as appropriate;}

b.3.5. Nuclear Accountability documents, as applicable.

\section{c. WERF Waste Acceptance Criteria.}

c.1. Review WERF Procedures pertaining to waste acceptance, and several acceptance documents, to ensure that the acceptance criteria are applied to LLW and MLLW shipped to WERF:

c.1.1. Items prohibited from receipt for treatment as LLW at WERF are identified and precluded from acceptance;

c.1.2. Complete segregation of prohibited waste materials is required;

c.1.3. Low-Level Wastes do not contain hazardous materials;

c.1.4. Generators identify radionuclides and associated activity;

c.1.5. Radiological limits do not exceed those specified;

c.1.6. Low-Level radioactive liquids with flash points greater than 140 degrees fahrenheit are shipped in fixed head $17 \mathrm{C}$ drums with threaded closures;

c.1.7. Bulk wood waste materials are shipped in proper containers, and are not mixed with metallic waste;

c.1.8. Low-Level processable radioactive solid wastes are categorized into one of the following categories:

- Incinerable wastes

- $\quad$ Compact wastes

- $\quad$ Processable, low-density, noncompactible metallic wastes for recycling or volume reduction and disposal. 

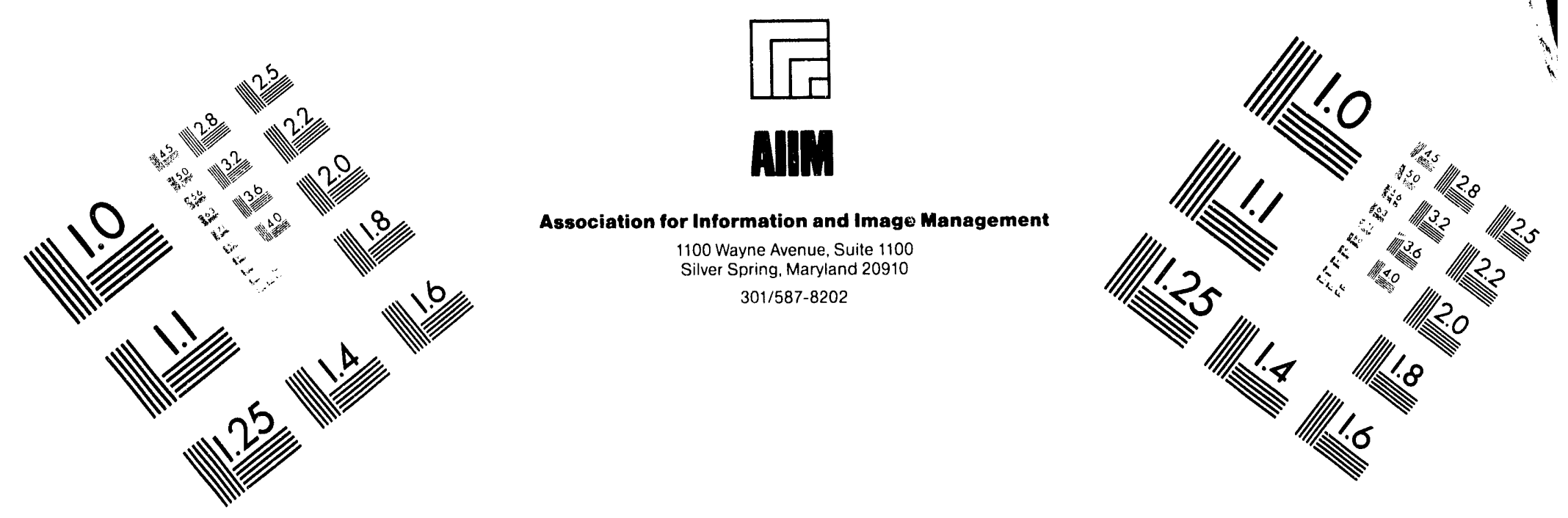

\section{Centimeter}

$\begin{array}{llllllllllllllll}1 & 2 & 3 & 4 & 5 & 6 & 7 & 8 & 9 & 10 & 11 & 12 & 13 & 14 & 15 & 15 m\end{array}$ ||$_{2}$ Inches
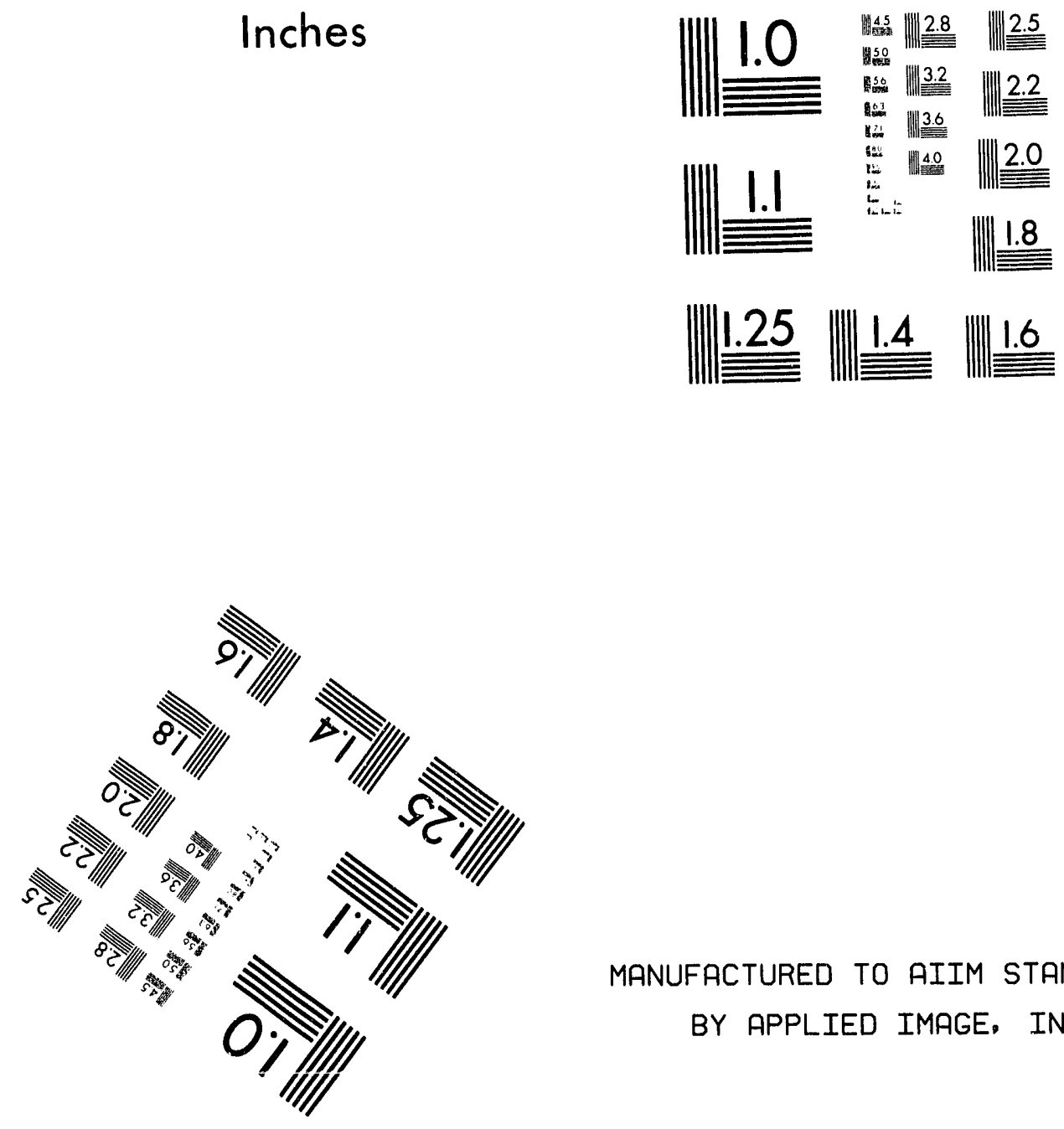

MANUFACTURED TO AIIM STANDARDS

BY APPLIED IMAGE, INC.

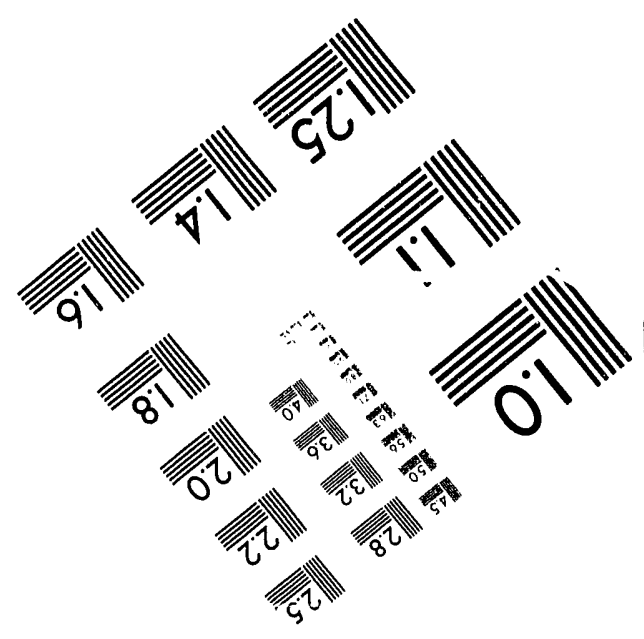



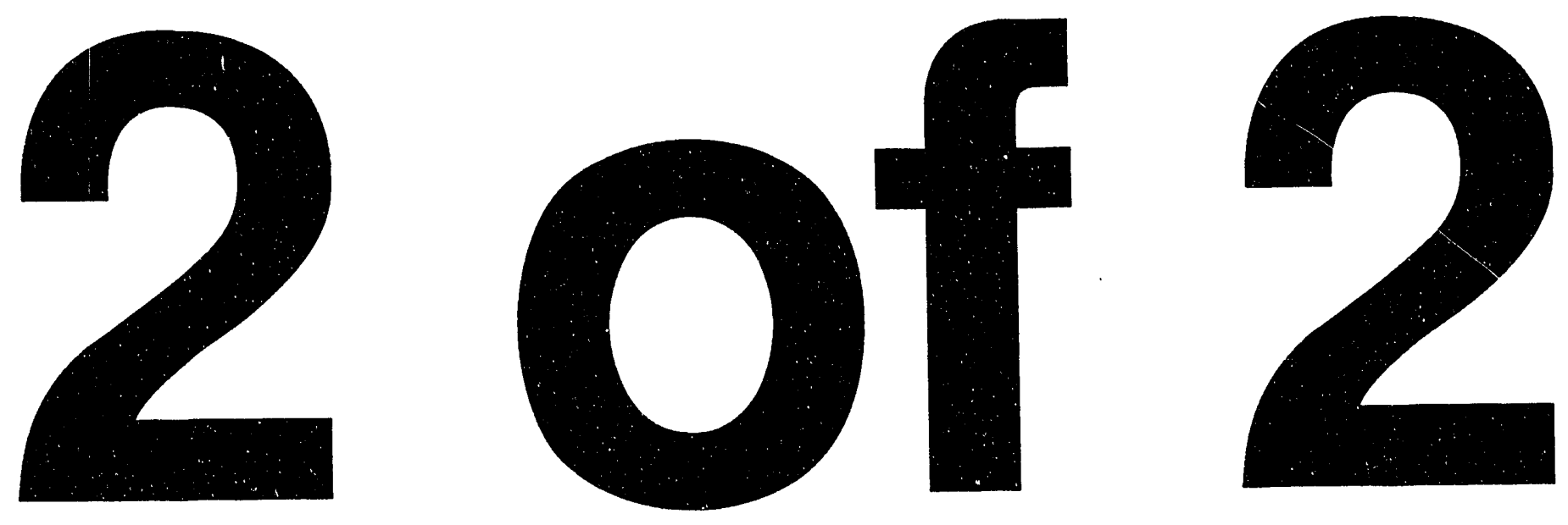
c.2. Inspect several containers that have been shipped to WERF to ensure that:

c.2.1. The following required labeling and markings are intact and readable:

- $\quad$ DOT shipping labels

- Waste package gross weight

- Shipper's complete name and address

- Shipper's unique container identification number

- $\quad$ Major nuclide (fissionable materials only)

- Maximum radiation level on contact, and at three feet in air

- Asbestos labels, as required.

- Hazardous Waste Labels, as required.

c.2.2. Containers are in good condition, free from rips, punctures, or any type of breach. Containers shall not be excessively wetted or weathered.

c.2.3. Radioactive liquids are in DOT $17 \mathrm{C}$ fixed head drums, with threaded closures. Drums are in good condition, with no excessive dents or creases.

d. Inspect documentation pertaining to Audits of generators by WERF to determine that:

d.1. Each waste generator's waste operation is audited at least annually;

d.2. The audit plan is audited against the generator's Waste Certification Plan;

d.3. The Waste Certification Plan is audited against the INEL Low-Level and Mixed Low-Level Waste Acceptance Criteria;

d.4. Audit findings have been transmitted to the waste generator for corrective action;

d.5. Generators have submitted corrective action plans to WERF for concurrence. 


\section{WERF OPERATIONAL READINESS REVIEW ORR CHECKLIST}

Reviewer

Date

\section{Checklist Designator B.4.5}

\section{Requirements Identification}

1. Element - Operations and Maintenance Performance

2. Sub-element - Packaging and Transportation Requirements

3. Basic References:

10 CFR 71, "Packaging of Radioactive Material for Transport and Ttansportation of Radioactive Material Under Certain Conditions"

49 CFR, section 171-179, "Hazardous Materials Regulations"

40 CFR 262, 263, 264, 265; "Standards of Operation for Generators (Transporters, Storage Facilities, Interim Status Facilities) of Hazardous Waste," Environmental Protection Agency DOE Order 1540.2, "Hazardous Material Packaging for Transportation, Administrative Procedures" WERF Safety Analysis Report, Section 7

4. Description of Requirement - Shipping, receiving, and pad storage facilities, procedures, operations, training, and personnel ensure compliance with all applicable waste and hazardous materials packaging and transportation requirements.

\section{Review Criteria}

a. Review previous audit findings pertaining to this sub-element to ensure that they have been identified, tracked, and/or resolved satisfactorily.

b. Review WERF Procedures for the receipt of waste materials to ensure that:

b.1. The procedures provide for the monitoring and evaluation of the condition of received shipments;

b.2. The procedures provide for evaluation of compliance of the shipment with appropriate regulations;

b.3. The procedures provide for the proper handling of off-spec or leaking containers in received shipments;

b.4. The procedures provide for appropriate notifications for outbound shipments. 
c. Review written packaging requirements and records for materials shipped to and from WERF to ensure that:

c.1. The requirements meet or exceed DOT requirements for the material types as defined in 49 CFR.

c.2. Packaging used for transport of radioactive materials meet the requirements of DOE order 1540.2 and 5480.3 .

c.3. There is on file the latest copy of DOE Certificate of Compliance, or other appropriate documentation, for all DOE-approved packaging used by WERF.

c.4. For all "Special Form encapsulations" shipped by or received by WERF, there exists a Special Form Certification, including a complete safety analysis, on file for at least one year after the last shipment is made.

d. Inspect the pad storage areas to ensure that:

d.1. Spacing of materials is appropriate;

d.2. Container marking is appropriate;

d.3. Status of the container (awaiting receipt, received, awaiting shipment, etc.) is consistent with the container placement, and whether the placement of the container is appropriate for the status.

e. Review WERF loading/Unloading procedures and interview at least two operations personnel to assess:

e.1. Personnel understanding of the procedures for loading and unloading waste material containers;

e.2. Knowledge of procedures for loading mixed materials (incompatibles) on same transport vehicle;

e.3. Knowledge of "Reportable Quantities;"

e.4. Knowledge of when and how to report a release exceeding the reportable quantity;

e.5. How to review and complete, where appropriate. the shipping paperwork, and who is authorized to sign;

e.6. Knowledge of the types of containers authorized for the shipment of waste materials to WERF, and which containers are appropriate for specific types of waste (Radioactive liquids, bulk wood, etc.); 
e.7. Knowledge of the routine checks to be performed on each package to be loaded with radioactive materials prior to such loading, and how to accomplish those checks.

f. Review the manifests for mixed waste received and shipped at WERF to ensure that:

f.1. Manifest records are maintained at the facility for the life of the facility;

f.2. All mixed waste shipment manifests are accompanied by Land Disposal Restriction Notifications (Land Ban forms).

g. Inspect at least ten manifest documents to ensure the manifests and Land Ban forms are properly executed, and that any discrepancies are properly documented and resolved.

h. Inspect training records of operation personnel assigned to transportation, materials shipment, and waste handling duties to ensure that they are trained in:

- Radiological or toxic material hazards

- $\quad$ Proper packaging

- Radiological Controls

- $\quad$ Shipping regulations

- Accidents, notifications, and emergency actions

- Transport considerations

- OSHA training for Hazardous Waste Operations (20-hour course)

- $\quad$ Preparation of shipping paperwork as required by DOT regulations (paperwork preparers only).

i. Given hypothetical outbound shipment data, have two operations and two supervisor personnel complete shipment manifests and landban paperwork as the shipper.

j. Given hypothetical receiving shipment data and accompanying manifest and Land Ban documents, have two operations and two supervisor personnel review the paperwork as the receiving facility, and show to the interviewer the proper procedure for identification and resolution of the discrepancies.

k. Inspect records of wastes shipped from WERF to ensure that they have:

k.1. Return receipts for radioactive shipments;

k.2. A completed Quality Assurance Checklist for radioactive shipments; 
k.3. Information has been entered into the RWMIS data base for radioactive shipments;

k.4. Information has been entered into the INWMIS data base for non-radioactive hazardous material shipments;

k.5. Drivers complete a Vehicle Inspection Checklist.

1. Inspect HP logs to determine that:

1.1. Radioactive shipments are surveyed within 8 hours of their release;

1.2. Direct radiatun levels are within DOT or DOE equivalent limits;

1.3. Radioactive contamination levels are within DOT or DOE equivalent limits;

1.4. Radiological control surveys of incoming shipments of radioactive waste materials are performed and documented.

m. Determine that WERF has in place a quality assurance, inspection, and maintenance program or procedure for the packaging used or under the jurisdiction of WERF that includes:

m.1. An auditable system for recording findings and corrective action;

m.2. A procedure for performing work on packagings;

m.3. A method for identifying unusable packagings;

m.4. A method for releasing packaging for unrestricted use.

n. Verify that the management of waste generated at WERF is conducted as required by the WERF SAR, Section 7. 


\section{WERF OPERATIONAL READINESS REVIEW ORR CHECKLIST}

Reviewer

Date

\section{Checklist Designator B.4.6}

\section{Requirements Identification}

1. Element - Operations and Maintenance Performance

2. Sub-Element - Notifications

3. Basic References - DOE Order 5480.19, "Conduct of Operations" DOE Order 5000.3A, "Occurrence Reporting and Processing of Operations Information" EG\&G Idaho Safety Manual

4. Description of Requirement - WERF has in place procedures to ensure the timely and accurate notification of appropriate authorities and tracking, recording, and investigation of reportable events. WERF incorporates any lessons learned from reportable events into its operations training program.

\section{Review Criteria}

a. Review previous audit findings pertaining to this sub-element to ensure that they have been identified, tracked, and/or resolved satisfactorily.

b. Ensure that procedures are in place to provide for timely notification of DOE and other agencies, when required, of reportable events.

c. Determine through review of the procedure and inspection of documentation that:

c.1. Notification is the assigned responsibility of the operations supervisor;

c.2. Names and phone numbers of contacts and pager codes are readily available;

c.3. All notifications formally recorded.

d. Interview shift supervisors to determine they recognize events requiring notification.

e. Review several recent Occurrence Reports to ensure that:

e.1. The reports were submitted in a timely manner;

e.2. The reports were properly executed; 
e.3. The reported cause, corrective actions, and root cause are recorded and are logical;

e.4. The lessons learned are appropriate, and are properly utilized. 


\section{WERF OPERATIONAL READINESS REVIEW ORR CHECKLIST}

Reviewer Date

\section{Checklist Designator B.4.7}

\section{Requirements Identification}

1. Element - Operations and Maintenance Performance

2. Sub-Element - Lockout and Tagout

3. $\quad$ Basic References - DOE Order 5480.19, "Conduct of Operations."

EG\&G Conduct of Operations Manual

EG\&G Company Procedure 4.4

Waste Management Department Procedure 16.13

4. Description of Requirement - WERF has fully implemented a lockout and tagout program meeting the requirements of DOE Order 5480.19, Conduct of Operations, and the Occupational Safety and Health Administration's lockout and tagout requirements.

\section{Review Criteria}

a. Review previous audit findings pertaining to this sub-element to ensure that they have been identified, tracked, and/or resolved satisfactorily.

b. Inspect/review documents and procedures to ensure that:

b.1. A lockout/tagout program is established, meeting the requirements, consisting of procedures to control potentially hazardous energy and materials and personnel training;

b.2. The program provides for the isolation of hazardous energy or materials sources during maintenance or servicing, or where unexpected energizing, startup, or release of stored energy or toxic material could cause injury;

b.3 Procedures clearly state the scope, purpose, authorization, rules, and techniques of the program;

b.4. Procedures include:

b.1.1. Specific statement of intent of use;

b.1.2. Specific procedural steps for isolating, blocking, and securing machines or equipment for hazardous energy or materials; 
b.1.3. Specific procedural steps for the placement, removal, and transfer of the lockout/tagout devices;

b.1.4. Specific requircments to test machines and to determine the effectiveness of lockout/tagout, and other control measures.

c. Inspect program documentation and records to determine that lockout/tagout placement. activation and removal is recorded.

d. Verify that this record is maintained by the shift supervisor, and is

d.1. Reviewed to ensure accuracy and completeness

d.2. Reviewed periodically by operations and maintenance personnel.

e. Review documentation to ensure periodic inspections are conducted and documented to ensure procedures are being followed, and any observed deviations or inadequacies are corrected.

f. Inspect documents pertaining to information and control tags not covered under Lockout and Tagout requirements, to verify formal procedure for their use exists, and follows the requirements of Waste Management Department Procedure 16.13.

g. Inspect training documents to ensure training of personnel and retraining required is conducted.

h. Conduct interviews of supervisory and operations personnel, or observe an actual or simulated lockout/tagout evolution to determine that:

h.1. The program and its elements are understood by all personnel;

h.2. Only authorized personnel conduct lockout/tagout activities;

h.3. Notification is given to affected pers nel by supervision before application or removal of lockout/tagout devices;

h.4. Procedures are utilized to ensure continuity of lockout/tagout protection between shifts. 


\section{WERF OPERATIONAL READINESS REVIEW ORR CHECKLIST}

Reviewer

Date

\section{Checklist Designator C.1.1}

\section{Requirements Identification}

1. Element - Orders, Statutes and Regulations

2. Sub-element - NEPA Documentation and Federal and State Permits

3. Basic References:

40 CFR 264

40 CFR 270

10 CFR 1021

IDAPA 16.01 .1000

40 CFR 60

WERF Regulatory Requirements Document (RRD)

4. Description of Requirement - Facilities, systems, and hardware comply with the requirements defined in the NEPA documentation, Federal Permits (RCRA Part A/B), and State of Idaho Permits (Air Pollution Permit/PDS Permit/NESHAPS).

\section{Review Criteria}

The facility design, documentation and as-built condition should fully reflect the descriptions and assumption in the NEPA documentation and Federal and State permits.

a. Conduct a review of the hazardous waste storage facility to verify compliance with 40 CFR 264.175, Containment. Currently Building PER 633 is uncer Interim Status; a Part B Permit has been submitted.

a.1. Verify that a containment system has been provided.

a.2. Verify that the floor is free of cracks or gaps and is sufficiently impervious to contain leaks and spills.

a.3. Verify that the floor is sloped or the containment system is designed to drain and remove liquids resulting from leaks unless containers are elevated.

a.4. Verify adequacy of the containment system (10\% of total or $100 \%$ of largest which ever is greater.)

a.5. Verify a system is available to empty the sump. 
b. Conduct a review of the application for a State of Idaho Permit to Construct (PTC) an Air Pollution Source/NESHAPS Assessment.

b.1. Verify that the PTC application descriptions match the physical installation in the following areas:

- Incineration

- Solidification

- $\quad$ Compaction and sizing

- Storage

- Diesel generator

- $\quad$ Source stack parameters

- $\quad$ Filtration systems

- Monitoring systems.

b.2. Verify that the NESHAPS Assessment description is consistent with the physical installation and in accordance with 40 CFR 61 and ANSI 13.1 in the following areas:

- Stack modification to enhance the flow profile

- Multiport sampling probe design and location

- $\quad$ Sampling system design.

c. Verify compliance with the RCRA Part B application.

c.1. Review physical installations of the following systems to verify consistency with the Permit application:

- Steam quench system

- Combustion air system

- $\quad$ Auxiliary burner system

- $\quad$ Liquid waste feed system

- $\quad$ Liquid waste control system 
- Incinerator air pollution control system.

c.2. Review operation of the incinerator control and safety systems against the description in the Permit Application.

d. Verify compliance with the NEPA documentation.

d.1. Review physical plant and systems to verify consistency with the Section 2.3, WERF Faciliticj and Incineration Process, of the Environmental Assessment.

d.2. Compare critical parameters for the following processes to the technical requirements:

- Waste incineration

- $\quad$ Compaction and sizing.

e. Review previous audit findings and commitment tracking system items pertaining to this sub-element to ensure that they have been identified, track, and/or satisfactorily resolved. 


\section{WERF OPERATIONAL READINESS REVIEW ORR CHECKLIST}

Reviewer

Date

Checklist Designator C.1.2

\section{Requirements Identification}

1. Element - Orders, Statutes and Regulations

2. Sub-element - Compliance with Primary Orders

3. Basic References:

DOE Order 6430.1A, "General Design Criteria"

DOE Order 5480.5, "Safety of Nuclear Facilities"

DOE-ID Order 5480.5

WERF Safety Analysis Report, Section 6

4. Description of Requirement - Compliance with DOE Orders 6430.1A and 5480.5, as described in the SAR, can be demonstrated in the facility and related hardware, as appropriate. This includes the documentation and design bases for the facility, particularly recent modifications and upgrades. Graded compliance with DOE Order 6430.1A. General Design Criteria, is specifically demonstrated.

\section{Review Criteria}

The facility design documentation and as-built condition should fully reflect the requirements of DOE Orders 6430.1A and 5480.5, and DOE-ID Order 5480.5. Review WERF compliance with DOE Order 6430.1A compliance assessment report by LATA, dated May 27, 1992. Conduct the following reviews in conjunction with the LATA report findings:

a. Verify that safety significant systems meet the requirements of DOE Order 6430.1A, as modified and approved by Section 6 of the WERF SAR, for the following systems

- Fire protection

- Breathing air

- $\quad$ Stack monitors

- Standby electrical power

- $\quad$ HEPA filtration systems 
- Comrnunication systems

- incinerator safety systems

- Ventilaticn systems

b. Verify compliance with requirements for a solid and liquid radioactive waste facility per DOE Order 6430.1A, as appropriate, at the WWSB and the Incinerator Building

c. $\quad$ rify that the incinerator design and installatica meets the requirements of DOE Order 6430.1A Section 1589-4, Combustion Process Installations.

d. Health and safety criteria are considered in the design of the facility. Radiation protection for personnel and the public comply with published national consensus codes and standards. Consider the following areas:

d.1. Assess radiation monitoring, alarm, and warning systems (6430.1a, 1300-6.5.1 and 6.5.7);

d.2. Assess radiation air monitoring systems (6430.1a, 1300-6.5.2.);

d.3. Verify that confinements are used to isolate radioactive operations (6430.1a-1324-6.1 and 1324-6.3);

d.4. Assess the design of confinement ventilation systems (6430.1a-1550-99.0.1, 1324-5.1 and 1550-99.0.2);

d.5. Verify that HEPA filters shall be located and shielded to maintain the occupational doses ALARA for operations and maintenance (6430.1a-1550.99.0.2).

e. Ensure that there are no serious and obvious violations of human factors principles in the design and construction of the facility.

f. Initial testing verifies that the facility/systems can be operated as specified in the design requirements documents. Review the System Operational Test results of modified safety significant systems and selected other major systems to ensure that the design criteria and operational performance parameters are validated.

g. Facilities, systems, and components are in compliance with DOE Order 5480.5 and DOE-ID Order 5480.5 .

g.1. Verify compliance with Sections f and i of DOE Order 5480.5.

g.2. Verify compliance with Section F(4) of DOE-ID Order 5480.5. 


\section{WERF OPERATIONAL READINESS REVIEW ORR CHECKLIST}

Reviewer

Date

Checklist Designator C.2.1

\section{Requirements Identification}

1. Element - Safety Analysis Report and Technical Safety Requirements

2. Sub-element - Safety Analysis Report (SAR)

3. Basic References:

DOE Order 5480.5, "Safety of Nuclear Facilities"

DOE Order 5480.23, "Nuclear Safety Analysis"

EG\&G Idaho Safety Manual Sections 2 and 25

4. Description of Requirement - The facility is as described in the SAR for those aspects critical to the analysis and to hazard mitigation. General descriptive sections of the SAR are accurate for the purposes intended.

\section{Review Criteria}

The facility design, documentation, and as-built condition should fully reflect the description, assumptions, and analysis contained in the SAR. To verify that the facility conforms to the SAR, perform the following:

a. Design of principal structures, components, systems, engineered safety features and processes are reviewed for the following: compliance with codes and standards for design and construction. Perform spot checks of major standards particularly DOE Orders 6430.1a and 5480.7. Review project identified codes and standards noncompliance issues and the project basis for acceptance (in conjunction with CRA C.1.2.).

b. Descriptions provided in the SAR for facility/systems designs are assessed as accurate with hazards and safety features identified. Review design data and walk down Safety Significant Systems and selected major facility/systems for comparison to SAR description to ensure features credited in the safety analysis are contained in the installed system. For example:

b.1. Design data or analysis supports HEPA filter operation at $500 \mathrm{~F}$ and $10 \mathrm{psi}$ differential pressure (PER 609) and $250 \mathrm{~F}$ and $10 \mathrm{psi}$ differential pressure (PER 622).

b.2. Design and analyses of stack monitoring systems supports isokinetic sampling and provides sufficient withdrawal points to meet ANSI N13.1. 
b.3. Loss of primary power activates the automatic transfer switch to transfer power to the standby diesel generator.

b.4. Alarm systems exist to alert personnel at a manned control room/panel/area, or an automatic function is provided to mitigate operating problems for: HEPA filter temperature and flow, fire protection discharge flows, breathing air system low pressure and carbon monoxide, stack isokinetic flow and high differential pressure across sample filter, incinerator system control parameters, steam injection control, ventilation system low flow, high radiation and contamination.

b.5 Safe shutdown under all emergency conditions as defined by the SAR or other approved WERF Documents have been demonstrated; 


\section{WERF OPERATIONAL READINESS REVIEW ORR CHECKLIST}

Reviewer

Date

\section{Checklist Designator C.2.2}

\section{Requirements Identification}

1. Element - Safety Analysis Report and Technical Safety Requirements

2. Sub-element - Technical Safety Requirements (TSR)

3. Basic References:

DOE Order 5480.22, "Technical Safety Requirements"

DOE Order 5480.23, "Nuclear Safety Analysis"

EG\&G Idaho Safety Manual Sections 2 and 25

4. Description of Requirement - Facility features required by the TSR are complete, operable, and fully tested. They are documented by accurate drawings readily available in the facility. Design bases for features or hardware required for TSR implementation are traceable to the source document.

\section{Review Criteria}

The facility design, documentation and as-built condition are capable of maintaining Safety Limits (SL), Limiting Control Settings (LCS), Limiting Conditions of Operations (LCO), and Surveillance Requirements (SR).

a. Review the TSRs and assess that those facility features important to maintaining limits or surveillance have been properly designed, installed and tested. 


\section{WERF OPERATIONAL READINESS REVIEW ORR CHECKLIST}

Reviewer

Date

Checklist Designator C.3.1

\section{Requirements Identification}

1. Element - Facilities

2. Sub-element - Corrective Actions and Upgrades

3. Basic Reference:

DOE Order 5700.6C, "Quality Assurance"

EG\&G Idaho Quality Manual

4. Description of Requirement - All corrective actions and upgrades described in the WERF Restart Project Management Plan are complete and formally accepted by facility management. Satisfaction of design basis is demonstrated and verified through testing, inspection, or some other independent means. Outstanding items are formally managed in the commitment tracking system.

\section{Review Criteria}

Controlled processes must be established and implemented to ensure facility modifications are based on appropriate need and on defined and technically sound requirements. The processes used to verify that the modifications meet the requirements should be defined, approved, and effectively implemented. Records demonstrating compliance with requirements, and acceptance by an established management hierarchy, need to be retrievable from an approved records management system.

The following investigations will be conducted:

a. Review WERF Controlled Procedures to verify clear definition of processes and responsibilities covering the following:

a.1. Responsibiiities and processes for identifying the need for specific modifications are defined in the approved procedures;

a.2. The method(s) and responsibilities for identifying, documenting and approving requirements applicable to modifications are clearly defined;

a.3. The process for authorizing the design and construction of selected modifications is defined. 
b. Review selected restart modification design files to verify the procedures identified above are implemented.

b.1. Review the processes used to identify the modifications needed for the restart, and verify that they were subjected to the required reviews and approvals.

b.2. Verify that the purposes of the modifications are clearly identified.

b... Verify that the requirements for the modification are consistent with the SAR, and that they include performance as well as design requirements. Verify that the interfaces with the other systems and hardware are defined, and were approved by the designated authorities.

c. Review applicable WERF Procerlures and design files to verify design disclosures (sketches, drawings, specifications, and other documentation) are prepared in accordance with approved procedures.

c.1. Verify that the requirements and processes for preparing design disclosure documentation are defined. Confirm that sketches, drawings, specifications, supporting analyses anc lesign studies are addressed.

c.2. Revieu representative sample of design disclosure documentation to confirm that it provides evidence that the procedures are being implemented in performance of the design process. This includes a review of all types of design disclosure documentation used at WERF.

d. Review WERF Procedures and design files to verify that a design verification process is implemented to ensure modifications meet all prescribed requirements.

d.1. Review procedures to confirm that the method(s) used for design verification are defined in the modification requirements documentation or as part of the documented design process.

d.2. Review design files or design review files to verify that reviews are conducted in accordance with approved WERF Procedures or documents. The following characteristics will be evaluated:

d.2.1. Reviewer qualifications and responsibilities are clearly defined; Appropriate disciplines are involved in the review, including Operations and safety personnel;

d.2.2. Reviews are conducted in a depth that is defined and consistent with stated review objectives;

d.2.3. Review results are documented; 
d.2.4. Issues raised in the reviews are documented, responsibilities for resolution assigned, action completed, and final disposition recorded; Final disposition is acknowledged by the design review chair/team, and any lack of concurrence with adequacy of resolution is appropriately addressed.

d.3. If alterrate calculations are used in the design verification process, approved procedures/processes should be used to ensure adequacy. Review design files to confirm the implementation of a defined and controlled process:

d.3.1. Qualifications of the alternate analyst are identified and verified;

d.3.2. The scope of the alternate calculation is defined in project records;

d.3.3. The alternate calculation is performed and approved in accordance with approved procedures;

d.3.4 A comparison of the original and alternate calculations is made with a clear statement of the results and of the adequacy of the analysis.

d.4. When design verification includes the use of qualification testing, an approved test program/test plan must be implemented to demonstrate that the modification meets applicable performance requirements. Review design files in which design verification through testing was applied to verify adequate test plan control and application.

d.4.1. A test plan is documented that includes a statement of the performance requirements that the modified system is to meet.

d.4.2 The plan is approved in accordance with authorities defined in approved WERF Documentation.

d.4.3 The test is performed in accordance with the plan, with any deviations recorded and approved at the designated level of authority.

d.4.4 Test results are reviewed by qualified personnel and accepted as evidence that the tested system is in compliance with the defined requirements.

d.4.5 System response outside the specified range is assessed to ensure the unexpected performance will not adversely affect that system or interfacing systems.

e. Review the procedures applicable to preparing instructions for the installation of facility modifications. Review facility records of modification installation to verify adequate instructions and compliance with those instructions. 
e.1. Review procedures to verify that they define the authorizations required for modifications to the facility. All approval requirements and approval authorities should be defined.

e.2. Verify that requirements applicable to the format and content of the installation package are defined and followed. Representative instruction packages are consistent with procedures, and provide sufficient direction for unambiguous interpretation by installation crafts and verification by inspection personnel.

e.3. Review representative facility records to confirm that installation proceeds only after required approvals are documented.

e.4. Review field change records in installation packages to verify deviations from the original plan are approved in accordance with WERF Procedures.

e.5. Review work packages to verify hold points for quality or other inspections/witnessing are identified in the work instructions and are implemented as evidenced by appropriate sign-off.

e.6. Review WERF Records to ensure all installation and construction activities are complete and documented through closed work packages.

e.6.1. All modifications and construction activities supporting the restart are identified and have corresponding installation work packages.

e.6.2. All work packages are complete and accepted by the facility unless specifically exempted by appropriate authorities.

e.6.3. Planned construction or modification work that is not complete prior to restart has been evaluated for potential impact on facility operation and safety. Justification for proceeding with restart has been documented and approved by appropriate management authorities.

e.6.4. Deficiencies from installation and construction activities are identified tracked through final resolution.

f. Acceptance Testing must be performed to ensure the equipment and systems were installed properly, and to ensure acceptable basic operability of components.

f.1. Review installation an: test documentation to verify that test plans are prepared in accordance with WERF Procedures. Verify that the following are included:

f.1.1. Test objectives are clearly defined.

f.2.2. Prerequisites are identified for instrument calibration, personnel briefings and training, and status of supporting systems. 
f.3.3. Hold and witness points in the test procedure where inspections are to be performed by specifically qualified personnel.

f.4.4. Step-by-step test instructions are provided with provision made for sign-off by specified performers or inspectors on key steps.

f.4.5. Acceptance criteria for all performance parameters being measured are defined.

f.4.6. Final acceptance authorities (Title III Inspection, WERF Operations, WERF Engineering, EG\&G Quality, etc.) are identified.

f.2. Review WERF Test Records to verify completion in accordance with the approved instructions. Verify that any deviations from the plan were evaluated and approved in accordance with applicable WERF Procedures.

f.3. Review WERF Facility Records to verify acceptance test results are retrievable for future reference.

g. Facility acceptance of modifications must be performed and documented in accordance with approved criteria and procedures. Facility records will be reviewed to confirm that defined processes are in place and are used.

g.1. Verify that the prerequisites for facility acceptance of modifications are clearly defined in approved procedures.

g.2. Verify that the implementation of those procedures is documented in facility records.

g.3. Confirm that conditional acceptance, if it is allowed, is accomplished in accordance with approved procedures to ensure closure of open items within a defined time or chronological sequence.

h. Facility deficiencies are formally identified, tracked, and closed.

h.1. Review the commitment tracking system to determine that all items are properly tracked and managed and that none invalidates the conclusions of this sub-element.

h.2 Review test and inspection files to identify open action items and verify proper tracking and management within CTS. 


\section{WERF OPERATIONAL READINESS REVIEW ORR CHECKLIST}

Reviewer

Date

\section{Checklist Designator C.3.2}

\section{Requirements Identification}

1. Element - Facilities

2. Sub-element - General Readiness

3. Basic Reference:

DOE Order 4330.4A, "Maintenance Management Program"

DOE Order 5700.6C, "Quality Assurance"

EG\&G Idaho Quality Manual

4. Description of Requirement - The facility, supporting all six processes and operations, is in a general state of readiness. Housekeeping is excellent. Preventive maintenance is up-to-date, and corrective maintenance has been completed as required. Any outstanding maintenance items that affect safety have been specifically justified for deferral. Except in special cases, no temporary construction or equipment is in use or located within the facility. Where such items are used, justification is documented.

\section{Review Criteria:}

Facility physical condition and readiness to support restart will be assessed through a walkdown of the facility, and fo!low-up through a review of selected facility records. The walkdown will emphasize housekeeping, and should confirm that construction activities are complete. The follow-up review of selected facility records will be performed to confirm that preventive and corrective maintenance activities for selected systems and components are documented and current with respect to defined preventive maintenance and corrective maintenance programs.

The following items will be included in the assessment:

a. General Housekeeping will be assessed through a walkdown of all facilities.

a.1. A detailed list will be used during a walkdown of all major buildings to assess housekeeping. The following items will be included: free aisles, access to safety equipment, access to process monitoring equipment, absence of construction materials, clear floors with acceptable low risk of trip hazards, minimal accumulations of trash/unused material, labeling of emergency equipment and exits, adequacy of lighting, and presence of guard rails. Other items may be added with the development of the detailed checklist. 
a.2. If any construction is still in progress, the documentation providing the justification for proreeding into restart prior to completion of the construction will be reviewed for consistency with WERF Controlling Documents and Procedures. If completion of construction is a prerequisite for restart, the risk analysis prepared to justify its specific completion date in the restart sequence will be reviewed for completeness and consistency with observations in the facility walkdown.

b. Implementation of the Preventive Maintenance (PM) Program will be assessed through the facility walkdown and a review of maintenance files.

b.1. Select several pieces of equipment during the walkdown for further verification of implementation of the PM program. Equipment will be selected from a variety of systems, but will emphasize systems with potential safety or mission related significance.

b.2. Review vendor data related to the selected equipment items to determine recommended PMs. If the items selected are not purchased items, design files will be reviewed for definition of required/recommended PM.

b.3. Review the PM plan to verify the equipment PMs are included in the PM program.

b.4. Review PM records to confirm that maintenance was performed by personnel with the appropriate qualifications, in accordance with the approved procedure, and on the schedule defined in the PM program.

c. The implementation of the WERF Corrective Maintenance Program will be assessed through the facility walkdown and a subsequent review of maintenance records.

c.1. Any deficiencies noted during the walkdown that require corrective maintenance will be investigated to verify they are included on the list of outstanding maintenance items.

c.2. A representative sample (5\%) of the corrective maintenance items closed during restart preparations will be revicwed for the following:

c.2.1. Instructions provided to the technician performing the repair were clearly documented.

c.2.2. Approvals required by the WERF Procedures were followed in approving the instructions.

c.2.3. Inspection/verifications/tests were specified and performed to confirm the adequacy of the corrective action. 
c.2.4. Facility documentation (drawings, procedures, specifications) affected by the corrective maintenance were revised in accordance with WERF Procedures.

c.2.5. Final closeout of the corrective maintenance action was approved in accordance with the approved procedures.

d. Review deficiency identification and tracking system/process to validate that deficiencies identified during routine management facility walkdowns are formally tracked, managed, and closed. Deficiencies identified during routine operations should also be managed. 


\section{WERF OPERATIONAL READINESS REVIEW ORR CHECKLIST}

Reviewer

Date

Checklist Designator $C .3 .3$

\section{Requirements Identification}

1. Element - Facilities

2. Sub-element - Integrated Systems Test

3. Basic Reference:

DOE Order 5700.5C, "Quality Assurance"

EG\&G Idaho Quality Manual

4. Description of Requirements - An Integrated Systems Test and associated Component Checklist and Systems Operation Tests have demonstrated the operability of the entire facility, including interfaces between cooperating systems. Reaction of the system to expected upset and off-normal conditions has been tested or simulated. Safe shutdown under emergency conditions has been demozstrated.

5. Review Criteria - An Integrated Systems Test must provide effective testing of the entire facility and interfaces with cooperating systems. All tests used to verify the facility performance during normal, expected upset, off normal, and emergency safe shutćown conditions shall be defined, approved, and effertively implemented. Records demonstrating compliance with requir, ments, and acceptance by an established management hierarchy need to be retrievable from approved records $m$ inagement system.

a. Review the Integrated Systems Test procedure objectives to verify an adequate framework for assessing the acceptability of the facility for operation. The major elements of the objectives of the test should include the foliuwing:

a.1. The Integrated Systems Test is compatible with and based upon existing safety analysis reports and hazards analysic;

a.2. The Integrated Systems Test provides a comprehensive testing of the entire facility, including interfaces between cooperating systems;

b. Review the Integrated Systems Test procedure to verify that the test provides a framework for evaluating the following aspects of the facility:

b.1. Operability of support equipment;

b.2. Performañce of Opcrations personne!; 
b.3. Credibility and logical sequencing of events;

b.4. Effectiveness of communications and controls;

b.5. Responses of systems and instruments;

b.6. Interfaces between cooperating systems.

c. Review the Integrated Systems Test procedures to verify that the following elements are covered:

c.1. Contents of supporting Operational procedures and methods are adequate;

c.2. Authorities and responsibilities of individuals are clearly defined;

c.3. Events and expected responses are clearly defined;

c.4. Notifications and responses for off-normal events are defined;

c.5. Technical capability exists for assessment of any off-normal events and consequence mitigation;

c.6. Verification that personnel performing the tests have received proper training

d. Review the Integrated Systems Test procedures to verify that there is a requirement to establish/verify readiness to initiate testing.

d.1. All procedures or supporting documentation required to be completed prior to performing the Integrated Systems Test have been identified and are adequately addressed in the Integrated Systems Test.

d.2. All prerequisite or controlling process required to be completed prior to starting the Integrated Systems Test have been defined and are adequately addressed in the Integrated Systems Test.

e. Ensure that the Integrated Systems Test objectives and scenario are reviewed and approved in accordance with WERF Procedures prior to performing the test.

f. Verify that facility acceptance of the test is performed and documented in accordance with approved criteria and procedures. Records will be reviewed to confirm that:

f.1. The requirements for facility acceptance of the tests are defined in approved procedures;

f.2. The test results are reviewed and approved. Any recovery or corrective action events are evaluated to ensure these actions will not invalidate preceding tests or requirements; 
f.3. The implementation of those procedures is documented in facility records:

f.4. Conditional acceptance, if allowed, is accomplished in accordance with approved procedures to ensure closure of open items within a defined time or chronological sequence. 


\section{WERF OPERATIONAL READINESS REVIEW ORR CHECKLIST}

Reviewer

Date

Checklist Designator C.4.1

\section{Requirements Identification}

1. Element - Configuration Control

2. Sub-element - Technical Baseline

3. Basic References:

DOE Order 5700.6C, "Quality Assurance"

DOE Order 6430.1A, "General Design Criteria"

WERF Configuration Management Plan (CMP-131)

EG\&G Idaho Quality Manual

4. Description of Requirement - Approved processes are defined and implemented to ensure that facility modification activities maintain a controlled technical baseline.

5. Review Criteria - WERF Document Control maintains information on all systems, equipment, and components that are critical to the WERF Operation and are under configuration management control.

a. Review WERF Configuration Management Documentation to verify that criteria have been established for identifying those facility items to be maintained under configuration control.

a.1. Verify that WERF Document Control maintains the WERF Comprehensive Equipment List.

a.2. Review the Graded Approach criteria used to determine which systems, equipment, and components are included under configuration management control against the Comprehensive Equipment List.

a.3. Verify that the Comprehensive Equipment list has been approved by the WERF Facility Manager.

b. Through a review of records and field verification during a facility walkdown, confirm that the "Identification and Labeling of Operational Systems and Components" being utilized at WERF is in accordance with WERF Procedures and consistent with EG\&G Idaho Company Procedure 2.13, and that the hardware and the associated documentation correlations are complete and correct. 
c. Verify that each system at WERF has a system engineer assigned as the design authority.

d. Review WERF Documentation to verify the establishment of procedures that ensure changes are processed through the formal WERF Control System and are approved before implementation.

d.1. Review facility records to verify that the Facility Change Form (FCF) process is utilized for applicable modifications performed at the WERF Facility.

d.2. Review change control procedures and facility records to verify that changes to released and controlled procedures and documents at WERF utilize a Document Revision Request (DRR) and are processed through the WERF Change Control System.

d.3. Review representative DRRs to verify that they have an Unreviewed Safety Question (USQ) evaluation performed per Waste Management Department Procedure 2.13. 


\section{WERF OPERATIONAL READINESS REVIEW ORR CHECKLIST}

Reviewer

Date

\section{Checklist Designator C.4.2}

\section{Requirements Identification}

\section{Element - Configuration Control}

2. Sub-element - Key Drawings

3. Basic References:

EG\&G Idaho Company Procedure 2.7, "Use of Drawings"

PD-WERF-3.7 WERF Drawing Control

4. Description of Requirement - Key drawings are those drawings identified by WERF Management as critical to normal and emergency operation of the facility. They are maintained up-to-date and readily available to operators and the emergency response organization, and are controlled through approved WERF Procedures.

5. Review Criteria - Key Drawings are identified and maintained at the WERF Facility.

a. Review WERF Controlled Documents and procedures to verify that criteria have been established to define Key Drawings, and that procedures are in place to ensure they are maintained current.

a.1. Verify that the WERF Document Change Control (DCC) stick files are up-to-date.

a.2. Verify through a review of WERF Procedures and a representative sampling of Key Drawings that WERF DCC has performed an initial (restart) audit and has procedures in place to ensure semiannual audits of Key Drawings to include the following:

a.2.1. Drawings are legible and in good condition;

a.2.2. Interim drawings greater than 1 year old are valid;

a.2.3. Current revision of drawings are confirmed either through the Automated Document Control System (ADoCS) database or contacting Configuration and Document Management (C\&DM) document control;

a.2.4. Stick files agree with verified list; 
a.2.5. Documenting the performance of the review in facility records.

b. Verify through a review of selected Key Drawings and modification records that the information from Architect Engineering construction drawings is incorporated on existing WERF Key Drawings at the completion of the construction task, as identified on the applicable FCF.

c. Review facility records (old Key Drawing Lists, and facility DRRs) to verify that DRRs are processed for adding or deleting drawings from the Key Drawing list.

d. Through interviews with engineers having responsibility for selected modifications, and through a review of the design files, verify that Vendor Drawings are reviewed for possible inclusion in the Key Drawing List.

e. Review Key Drawings for verification that only As-Built changes are included on the drawings. Verify that no Advance Drawing Change Notices (ADCNs) are released against any of the Key Drawings. 


\section{WERF OPERATIONAL READINESS REVIEW ORR CHECKLIST}

Reviewer

Date

Checklist Designator C.5.1

\section{Requirements Identification}

1. Element - Quality Assurance

2. Sub-element - Quality Program Plan

3. Basic References:

DOE Order 5700.6C, "Quality Assurance"

DOE-ID Supplemental Directive 5700.6C, "Quality Assurance"

EG\&G Idaho, Inc., Quality Manual

DOE-ID 4700.1, "Project Management System"

4. Description of Requirement - A Quality Program Plan (QPP) that identifies the facility quality assurance and control requirements and implementation procedures applicable to the facility has been established. The QPP has been approved as required by the EG\&G Idaho Quality Manual and is maintained current.

\section{Review Criteria}

The QPP and implementation procedures shall provide for effective quality assurance and control requirements based on the facility programmatic requirements in accordance with the above basic reference documents.

a. Review the QPP to verify that it meets the QPP preparation requirements of the EG\&G Idaho Quality Manual, Section QP-2.

b. Review the QPP to verify that the appropriate quality program elements have been applied to and are consistent with facility program activitics.

c. Review the QPP to verify that the mandatory QPP review and approvals were obtained as required by Section QP-2 of the EG\&G Idaho Quality Manual, and that the QPP was released and controlled by the facility-recognized document control system. 


\section{WERF OPERATIONAL READINESS REVIEW ORR CHECKLIST}

\section{Reviewer}

Date

\section{Checklist Designator C.5.2}

\section{Requirements Identification}

1. Element - Quality Assurance

2. Sub-element - Quality Program Plan Implementation

3. Basic References:

DOE Order 5700.6C, "Quality Assurance"

DOE Supplemental Directive 5700.6C, "Quality Assurance"

DOE-ID 4700.1, "Project Management System"

EG\&G Idaho, Inc., Quality Manual

WERF Safety Analysis Report, Section 18

4. Description of Requirement - The facility has approved procedures in place that implement the requirements for each QPP element; the requirements of the EG\&G Idaho Quality Manual are fully implemented.

\section{Review Criteria}

a. Review the past calendar year's self-assessments conducted by quality and management, other independent assessments, and audits for documented evidence that the facility quality program is fully implemented for each QPP element, and is in compliance with the EG\&G Idaho Quality Manual. If the review discloses areas of uncertainty, the areas shall be assessed to a formal Quality Manual assessment/audit checklist to determine acceptance. 


\section{WERF OPERATIONAL READINESS REVIEW ORR CHECKLIST}

Reviewer

Date

\section{Checklist Designator C.5.3}

\section{Requirements Identification}

1. Element - Quality Assurance

2. Sub-element - Quality Program Plan Indoctrination and Training

3. Basic References:

DOE Order 5700.6C, "Quality Assurance"

DOE Supplemental Directive 5700.6C "Quality Assurance"

EG\&G Idaho Quality Manual

DOE-ID 4700.1, "Project Management System"

4. Description of Requirement - The facility has identified training requirements and personnel (management, operations, technical support, administrative and others) who are to be indoctrinated and trained on primary QPP requirements and QA principles; training records are maintained.

\section{Review Criteria}

a. Review the facility personnel training requirements to verify that specific quality program training has been established and that personnel requiring training have been identified.

b. Review training records to verify that the records document that personnel training has been conducted, that training records are in sufficient detail to the type of training conducted, and that the date of training, personnel trained, and instructor name are shown. Interview at least one individual from facility management operations and technical support to substantiate their knowledge of Quality Program requirements.

c. Review the facility cognizant Quality Engineer Certificate of Qualification to ensure qualifications are current in accordance with element QP-2 of the EG\&G Idaho Quality Manual. 


\section{Appendix C}

Referenced Regulations, DOE Orders, and EG\&G Idaho Implementing Documents 


\section{Appendix C}

\section{Referenced Regulations, DOE Orders and EG\&G Idaho Implementing Documents}

\begin{tabular}{|c|c|c|c|}
\hline $\begin{array}{c}\text { DOE Order } \\
\text { Number }\end{array}$ & DOE Order Title & $\begin{array}{c}\text { EG\&G Idaho } \\
\text { Implementing Document } \\
\end{array}$ & $\begin{array}{c}\text { ORR } \\
\text { Element } \\
\end{array}$ \\
\hline $1324.2 \mathrm{~A}$ & Records Disposition & & B.1 \\
\hline 1540.2 & $\begin{array}{l}\text { Hazardous Material Packaging } \\
\text { for Transport - Administrative } \\
\text { Procedures }\end{array}$ & & B.4 \\
\hline $4330.4 \mathrm{~A}$ & $\begin{array}{l}\text { Maintenance Management } \\
\text { Program }\end{array}$ & $\begin{array}{l}\text { EG\&G Idaho } \\
\text { Maintenance Management } \\
\text { Program Manual }\end{array}$ & B.4, C.3 \\
\hline 4700.1 & Project Management System & $\begin{array}{l}\text { EG\&G Idaho Project } \\
\text { Management Manual }\end{array}$ & A.1: C. 5 \\
\hline $5000.3 \mathrm{~A}$ & $\begin{array}{l}\text { Occurrence Reporting and } \\
\text { Processing of } \\
\text { Operations Information }\end{array}$ & $\begin{array}{l}\text { EG\&G Idaho Safety } \\
\text { Manual }\end{array}$ & B.4 \\
\hline 5400.1 & $\begin{array}{l}\text { General Environmental } \\
\text { Protection Program } \\
\end{array}$ & & B.2 \\
\hline 5400.4 & $\begin{array}{l}\text { Comprehensive } \\
\text { Environmental Response, } \\
\text { Compensation, and } \\
\text { Liability Act Requirements }\end{array}$ & & B.2 \\
\hline $5440.1 C$ & $\begin{array}{l}\text { National Environmental Policy } \\
\text { Compliance Act }\end{array}$ & & B.2 \\
\hline 5480.5 & Safety of Nuclear Facilities & $\begin{array}{l}\text { EG\&G Idaho Safety } \\
\text { Manual; EG\&G Idaho } \\
\text { Radiological Controls } \\
\text { Manual }\end{array}$ & $\begin{array}{l}\text { A. } 1, \text { A. } 2 \\
\text { E. } 1, \text { C. } 1 \\
\text { C. } 2\end{array}$ \\
\hline 5480.4 & $\begin{array}{l}\text { Environmental Protection, } \\
\text { Safety, and Health Protection } \\
\text { Standards }\end{array}$ & & B.1 \\
\hline 5480.7 & Fire Protection & $\begin{array}{l}\text { EG\&G Idaho Safety } \\
\text { Manual }\end{array}$ & B.1 \\
\hline ID-5480.10 & $\begin{array}{l}\text { Contractor Industrial Hygiene } \\
\text { Program }\end{array}$ & $\begin{array}{l}\text { EG\&G Idaho Safety } \\
\text { Manual }\end{array}$ & B.1, A.3 \\
\hline
\end{tabular}




\begin{tabular}{|c|c|c|c|}
\hline $\begin{array}{l}\text { DOE Order } \\
\text { Number }\end{array}$ & DOE Order Title & $\begin{array}{l}\text { EG\&G Idaho } \\
\text { Implementing Document }\end{array}$ & $\begin{array}{c}\text { ORR } \\
\text { Element }\end{array}$ \\
\hline 5480.11 & $\begin{array}{l}\text { Radiation Protection for } \\
\text { Occupational Workers }\end{array}$ & $\begin{array}{l}\text { EG\&G Idaho Radiological } \\
\text { Controls Manual }\end{array}$ & A.3, B.1 \\
\hline 5480.19 & $\begin{array}{l}\text { Conduct of Operations } \\
\text { Requirements for DOE } \\
\text { Facilities }\end{array}$ & $\begin{array}{l}\text { EG\&G Conduct of } \\
\text { Operations Manual }\end{array}$ & $\begin{array}{l}\text { B.4, A.1. } \\
\text { A.2 }\end{array}$ \\
\hline 5480.20 & $\begin{array}{l}\text { Personnel Selection } \\
\text { Qualification and Staffing } \\
\text { Requirements at DOE } \\
\text { Reactor and Non-Reactor } \\
\text { Nuclear Facilities }\end{array}$ & WMO Training Manual & A.2, B. 4 \\
\hline 5480.21 & Unreviewed Safety Questions & & B.3 \\
\hline 5480.22 & $\begin{array}{l}\text { Technical Safety } \\
\text { Requirements }\end{array}$ & & $\begin{array}{l}\text { B.3, C.2, } \\
\text { B.4 }\end{array}$ \\
\hline 5480.23 & $\begin{array}{l}\text { Nuclear Safety Analysis } \\
\text { Reports }\end{array}$ & & $\begin{array}{l}\text { B.3, C.2, } \\
\text { B.4 }\end{array}$ \\
\hline $5483.1 \mathrm{~A}$ & $\begin{array}{l}\text { Occupational Safety and } \\
\text { Health Program for DOE } \\
\text { Contractor Employees at } \\
\text { GOCO Facilities }\end{array}$ & $\begin{array}{l}\text { EG\&G Idaho Safety } \\
\text { Manual }\end{array}$ & B.1 \\
\hline $5484.1 \mathrm{~A}$ & $\begin{array}{l}\text { Environmental Protection, } \\
\text { Safety, and Health Protection } \\
\text { Information Report } \\
\text { Requirements }\end{array}$ & & B. 4 \\
\hline $5500.2 \mathrm{~B}$ & $\begin{array}{l}\text { Emergency Categories, } \\
\text { Classes, and Notification and } \\
\text { Reporting Requirements }\end{array}$ & & A.3 \\
\hline $5500.3 \mathrm{~A}$ & $\begin{array}{l}\text { Planning and Preparedness for } \\
\text { Operational Emergencies }\end{array}$ & $\begin{array}{l}\text { EG\&G Idaho Emergency } \\
\text { Preparedness Manual }\end{array}$ & A. 3 \\
\hline 5500.4 & $\begin{array}{l}\text { Public Affairs Policy and } \\
\text { Planning Requirements for } \\
\text { Emergencies }\end{array}$ & & A. 3 \\
\hline 5500.10 & $\begin{array}{l}\text { Emergency Readiness } \\
\text { Assurance Program }\end{array}$ & & A. 3 \\
\hline $5700.6 \mathrm{C}$ & Quality Assurance & $\begin{array}{l}\text { EG\&G Idaho Quality } \\
\text { Manual }\end{array}$ & $\begin{array}{l}\text { C.3, C.4, } \\
\text { C. } 5\end{array}$ \\
\hline
\end{tabular}




\begin{tabular}{||l|l|l|l||}
\hline $\begin{array}{c}\text { DOE Order } \\
\text { Number }\end{array}$ & \multicolumn{1}{|c|}{ DOE Order Title } & \multicolumn{1}{|c|}{$\begin{array}{c}\text { EG\&G Idaho } \\
\text { Implementing Document }\end{array}$} & \multicolumn{1}{|c|}{$\begin{array}{c}\text { ORR } \\
\text { Element }\end{array}$} \\
\hline $5820.2 \mathrm{~A}$ & $\begin{array}{l}\text { Radioactive Waste } \\
\text { Management }\end{array}$ & & B.4 \\
\hline $6430.1 \mathrm{~A}$ & General Design Criteria & & C.1, C.4 \\
\hline ID-5700.6D, & Quality Assurance & $\begin{array}{l}\text { EG\&G Idaho Quality } \\
\text { Manual }\end{array}$ & $\begin{array}{l}\text { C.3, C.4, } \\
\text { C.5 }\end{array}$ \\
\hline
\end{tabular}

\section{EG\&G POLICIES AND PROCEDURES}

EG\&G Idaho, Inc., 1992, Waste Experimental Reduction Facility Program Management Plan, EGG-WMO-10165, June 1992.

EG\&G Idaho, Inc., Company Procedures Manual, current issue.

EG\&G General Policy and Responsibilities 1.d.2.

EG\&G Idaho Company Procedure Chapters 2.2, "Readiness Review."

EG\&G Idaho Company Procedure Chapter 2.6, "Preparation of Interface Agreements."

EG\&G Idaho Company Procedure 2.7, "Use of Drawings."

EG\&G Idaho Company Procedure 4.4, "Lock and Tag Procedure."

EG\&G Idaho Company Procedure 6.2, "Fire Hazard Analysis."

EG\&G Idaho Company Procedures 8.1, 8.2, 8.3, 8.17, 8.18, and 8.20, "Environmental Protection Procedures."

EG\&G Idaho Company Procedure 8.4, "Air Permit Application Procedure."

EG\&G Idaho Company Procedure 8.5. "Preparation and Approval of NEPA Documentation."

EG\&G Idaho Company Procedure 8.6, "SARA Reporting."

EG\&G Idaho Company Procedures, Section 10, "Radiological/Health Physics Procedures."

EG\&G Idaho Quality Manual.

EG\&G Idaho Conduct of Operations Manual. 
EG\&G Idaho Safety Manual Sections 2 and 25.

EG\&G Idaho Safeguards and Security Manual.

EG\&G Idaho DOE Order Compliance Plan.

EG\&G Idaho Emergency Preparedness Manual.

EG\&G Idaho Radiological Controls Manual, Chapter 1, Section 3.5.

EG\&G Idaho Emergency Preparedness Manual 2.0.

Waste Management Department Procedures 16.13

1.2.3 ERDAM and IDM Chapters 0506, "Occupational Safety and Ilealth Program for ERDA GOCO Contractor Employees."

WERF Regulatory Requirements Document.

WERF Configuration Management Plan (CMP-131).

PD-WERF-3 7, WERF Drawing Contro:.

WERF Safety Analysis Report.

WERF Hazard Classification.

WERF Conduct of Operations Matrix.

\section{FEDERAL CODES AND REGULATIONS}

10 CFR - Energ: - Part 71.

10 CFR - Energy - Part 1021.

29 CFR - Labor - Part 1910.

40 CFR - Enviroumental Protection - Part 52.

40 CFR - Environmental Protection - Part 60.

40 CFR - Environmen:al Protection - Part 61.

40 CFR - Environmental Protection - Parts 61.93, 609 and 622.

49 CFR - Transportation - Sections 100-149. 
49 CFR - Transportation - Sections 171-179, "Hazardous Materials Regulations."

40 CFR - Environmental Protection - Part 122.

40 CFR - Environmental Protection - Part 261.

40 CFR - Environmental Protection - Parts 262. 263, 264; "Standards of Operation for Generators (Transporters, Storage Facilities) of Hazardous Waste."

40 CFR - Environmental Protection - Part 262, Subparts B, C, and D.

40 CFR - Environmental Protection - Part 264.

40 CFR - Environmental Protection - Part 265, Subparts B, C, D, E, F, I, J, O, and BB.

40 CFR - Environmental Protection - Part 270.

40 CFR - Environmental Protection - Part 355.

40 CFR - Environmental Protection - Part 370.

40 CF. ? - Environmental Protection - Pari 372.

40 CFR - Environmental Protection - Parts 1500 through 1508 CEQ Regulations.

IDAPA 16.01.1000, Idaho Dept. of Health \& Welfare.

IDAPA 16.01, Idaho Dept. of Health \& Welfare.

42 USC 4321-4347 - NEPA. 


\section{Appendix D}

\section{Operational Readiness Review Team Resumes}

D-1 


\title{
Appendix D \\ Operational Readiness Review Team Resumes
}

\author{
DELWIN JAY ALLRED
}

\section{QUALIFICATIONS}

Mr. Allred, a Certified Safety Professional, has been with EG\&G Idaho for six years. He has served as a technical leader for a work group that included industrial hygiene, safety, and environmental professionals.

\section{EDUCATION}

BS Occupational Safety, Brigham Young University MS Safety Management, University of Idaho

JUAN ALVAREZ

\section{QUALIFICATIONS}

Mr. Alvarez served in the U.S. Navy for seven years. His final assignment was as Operations Officer and Shift Engineer at the Naval Nuclear Power Training Unit at the INEL. He is currently an Engineering Specialist with EG\&G Idaho. His responsibilities include performing appraisals of operations and radiation safety and coordinating DOE Order compliance for EG\&G Idaho Senior Management. He developed EG\&G Idaho's Conduct of Operations procedures.

\section{EDUCATION}

BS Education and Mathematics, University of Miami 


\section{MICHA:SL M. GARLAND}

\section{QUALIFICATIONS}

Mr. Garland has experience as Regulatory Compliance Officer charged with ensuring day-to-day operational compliance with Federal, State. and local environmental statutes at a hazardous waste TSD facility and waste fuels blending operation in Memphis. Tennessee. He Also served as primary Emergency Coordinator and Laboratory Manager and was instrumental in development and modification of the facility's RCRA Part B permit. Air Pollution Control permit, stormwater discharge permits, Sewer Discharge Agreement, and Federal HSWA Permit. Served as Safety and Health Officer.

\section{EDUCATION}

US Navy, Nuclear Power School. Qua, issurance Numerous short courses in U.S. environmental protection laws and regulations

\section{WILLIAM L HICKS}

\section{QUALIFICATIONS}

Mr. Hicks has more than 25 years experience in nuclear programs with the U.S. Navy Nuclear Submarine Force, and recently with EG\&G Idaho in support of DOE's Defense Programs Office of Inspection. His experience includes three years as Nuclear Submarine Squadron Commander, two years as Deputy Squadron Commander, two years as Senior Member of the Fleet Nuclear Propulsion Examining Board, four years as Commanding Officer of a Nuclear Submarine, and various other assignments within the Nuclear Submarine Force.

As Senior Member of the Nuclear Power Examining Board, Mr. Hicks conducted numerous Post Overhaul Reactor Startup Examinations which have a purpose and formality identical to the Operational Readiness Review (ORR). He also conducted examinations of DOE reactor prototype sites and Nuclear repair bases. As Submarine Squadron Commander and Deputy Squadron Commander, he managed and evaluated the preparation of numerous activities for operational readiness examinations. He also conducted post overhaul operational readiness certifications in preparation for initial at sea operations.

His current responsibility within the Defense Programs Office of Inspection includes active participation in Technical Safety Appraisals and monitoring of selected Progress Assessments that focus on the criteria central and critical to the ORR. He has also participated in the preparation for three different ORRs conducted by DOE.

\section{EDUCATION}

BS Engineering, Pennsylvania State University

Naval Nuclear Power Training Program, including qualification for command 


\section{QUALIFICATIONS}

Mr. Hill has managed a number of nuclear systems projects during his 25 -year career. He has also conducted numerous safety appraisals of moderate- and high-risk programs. He is currently the manager of EG\&G Idaho's Technical Support Unit in the New Production Reactor Systems Engineering Group.

\section{EDUCATION}

BS Mechanical Engineering, Massachusetts Institute of Technology MS Mechanical Engineering, University of Pittsburgh

\section{HENRY MATTHEW JONES}

\section{QUALIFICATIONS}

Mr. Jones served for seven years in reactor operator and instructor positions in the U.S. Navy; and for 16 years as a trainer and manager for DOE contractors. Accomplishments include his current task of reorganizing EG\&G Idaho's company-wide training program; managing the Richland, Washington Office of General Physics Corporation; and managing the Operations Training Group for another INEL contractor. He was a member of the ORR Team at DOE's Rocky Flats Plant.

\section{EDUCATION}

FFTF Third Academic Training Class, Richland, Washington

U.S. Navy Nuclear Power Training Unit, Idaho Falls and Mare Island, California

\section{ANTHONY A (FRED) KOVACH}

\section{QUALIFICATIONS}

Mr. Kovach has experience in various aspects of corporate training, including training program evaluation and performance-based training. He also has experience in implementation of DOE's Conduct of Operations Order, in maintenance of mechanical systems, and in reactor operations, maintenance, and training. He was a member of the ORR Team at DOE's Rocky Flats Plant.

\section{EDUCATION}

BS Corporate Training, Idaho State University

U.S. Navy Nuclear Power Program Training 


\section{GARY A. LEUZINGER}

\section{QUALIFILATIONS}

Mr. Leuzinger has 15 years experience in a wide variety of engineering and management responsibilities at the INEL and nine years experience in the steel fabrication and aircraft industries. Currently he is the Technical Leader responsible for developing the EG\&G Idaho Maintenance Management Program Manual.

\section{EDUCATION}

BS Business Engineering, Idaho State University

\section{JOHN D. MULLIN}

\section{QUALIFICATIONS}

Mr. Mullin has experience in maintenance of nuclear and industrial facilities; a primary responsibility in his current position is evaluating the existing maintenance program at the Test Reactor Area against the requirements of DOE Order 4330.4A. He is also experienced and certified as a Lead Auditor and has performed numerous audits of INEL facilities against the DOE Orders, EG\&G Idaho requirements, and the standards of industry and professional societies.

\section{EDUCATION}

BS Mechanical Technology, University of Idaho (degree expected in 1994)

Numerous short courses in nuclear plant maintenance and hazardous waste transportation

\section{WILBUR L NEES}

\section{QUALIFICATIONS}

Mr. Nees has 23 years experience in health physics. working at various DOE sites and in commercial nuclear power. A Certified Health Physicist, he managed the Coeration Health Physics Section at N Reactor, Hanford, Washington and was director of ES\&H for UNC Geotech at Grand Junction, Colorado. He has participated in severai ORRs at the Rocky Flats Plant and was part of the pre-Tiger Team appraisal of the INEL.

\section{EDUCATION}

BS Physics, Portland State University

MS Physics, Portland State University

Certified American Board of Health Physics 


\section{HAROLD D. OAK}

\section{QUALIFICATIONS}

Mr. Oak has more than 26 years experience providing support to and assessment of Department of Energy and Nuclear Regulatory Commission safety applications, including SAR, TSR, USQ, and QA programs and procedures. He is a Qualified Lead Quality Auditor, and he participated in DOE's Operational Readiness Evaluation of the New Waste Calcining Facility at the Idaho Chemical Processing Plant in December 1992.

\section{EDUCATION}

BS Physical Science, Washington State University

MS Nuclear Engineering, Washington State University

\section{W. L POWELL}

\section{QUALIFICATIONS}

Mr. Powell has more than 28 years experience, with the U.S. Navy's Nuclear Propulsion Program, support to the U.S. Nuclear Power Industry, and recently with EG\&G Idaho as manager of non-reactor nuclear facilities in the Power Reactor Programs Department. His experience included two submarine command tours, which included managing the training and preparation of the crew for readiness to operate various systems and function. Readiness of each phase of this preparation was validated through formal examinations by external inspection teams. As commanding officer of a Trident Refit Facility, he managed the initial training and readiness of a major controlled industrial facility to conduct radiological repair, contaminated waste management, and support functions.

\section{EDUCATION}

MS Computer Systems, U.S. Naval Postgraduate School BS Engineering. U.S. Naval Academy 


\section{TED L RASMUSSEN}

\section{QUALIFICATIONS}

Mr. Rasmussen has successfully managed a number of nuclear programs during his 30 years in the industry. These programs include engineering services, environmental restoration, major construction projects, reactor safety research, and reactor startup and operations projects. He is currently the manager of EG\&G Idaho's Transportation and Renewable Energy Unit.

\section{EDUCATION}

BS, Mechanical Engineering, Oregon State University

\section{DAVID E. WILKINS}

\section{QUALIFICATIONS}

Mr. Wilkins has managed a number of organizations responsible for construction planning and management at the Idaho National Engineering Laboratory. He is currently manager of EG\&G Idaho's Stored Waste Project Engineering Unit.

\section{EDUCATION}

BS Mechanical Engineering, Drexel University, Philadelphia, Pennsylvania MS Nuclear Engineering, Pennsylvania State University 

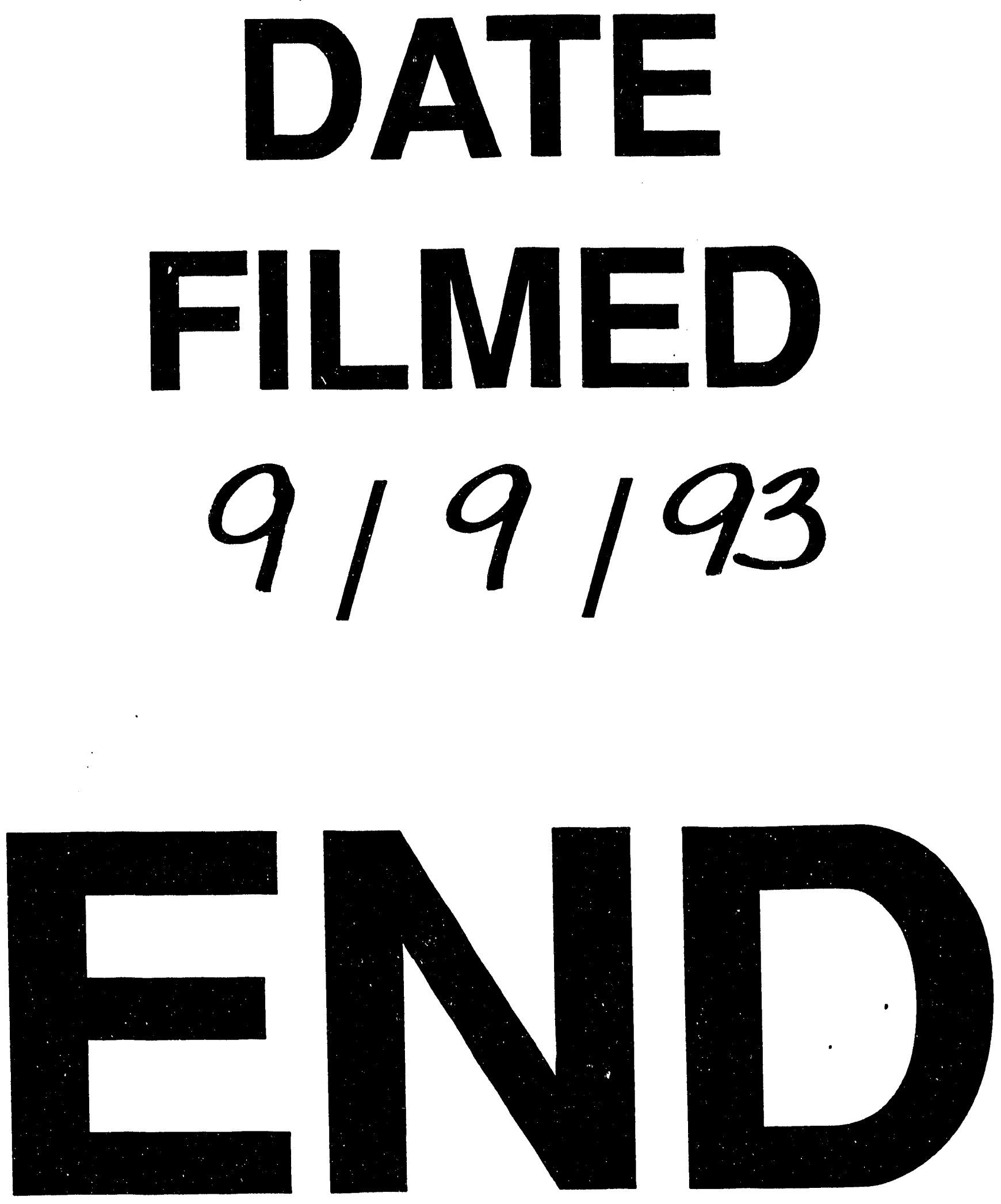
